\title{
EHEALTH FOR PEOPLE WITH DEMENTIA IN HOME-BASED AND RESIDENTIAL CARE
}
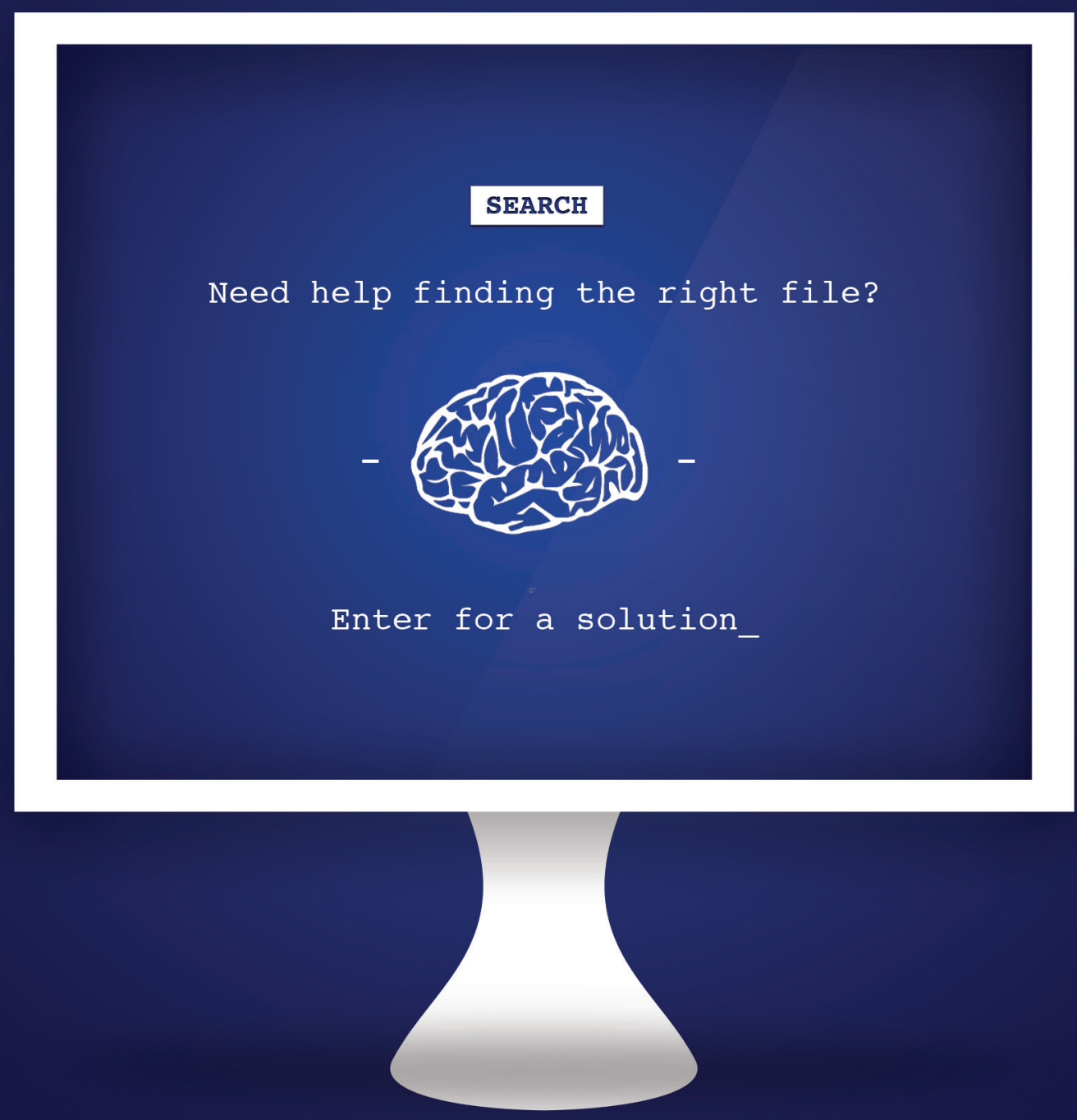

NIENKE N I JHOF 


\section{EHEALTH FOR PEOPLE WITH DEMENTIA IN}

\section{HOME-BASED AND RESIDENTIAL CARE}


Dissertation, University of Twente, 2013

(C) Nienke Nijhof

ISBN: 978-90-365-3455-0

DOI: $10.3990 / 1.9789036534550$

With the support of Alzheimer Nederland (Amersfoort), dr. G.J. van Hoytema Stichting (Enschede), Focus Cura BV (Driebergen), Futurelab en Novartis Pharma BV (Arnhem).

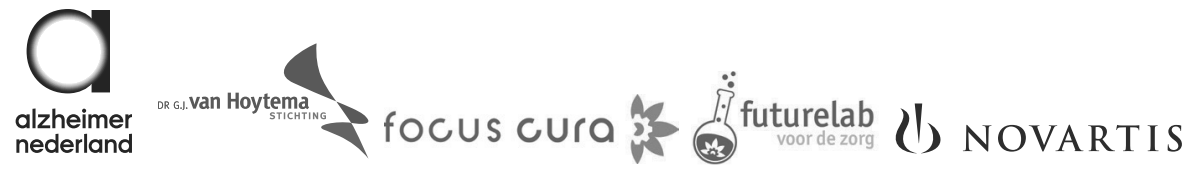

Cover design by Milan Compeer

Book design by Gildeprint Drukkerijen

Printed by Gildeprint Drukkerijen, Enschede, the Netherlands

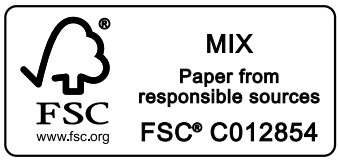

The studies presented in this thesis were financially supported by IBR Research Institute for Social Sciences and Technology and care organization Bruggerbosch. 


\title{
EHEALTH FOR PEOPLE WITH DEMENTIA IN HOME-BASED AND RESIDENTIAL CARE
}

\author{
PROEFSCHRIFT \\ ter verkrijging van \\ de graad van doctor aan de Universiteit Twente, \\ op gezag van de rector magnificus, \\ prof. dr. H. Brinksma, \\ volgens besluit van het College voor Promoties \\ in het openbaar te verdedigen \\ op vrijdag 26 april 2013 om 14.45 uur
}

door

Nienke Nijhof

geboren op 13 mei 1983

te Leiderdorp 
Dit proefschrift is goedgekeurd door de promotor, prof. dr. E.R. Seydel en door de assistent-promotor, dr. J.E.W.C. van Gemert-Pijnen 


\section{Samenstelling promotiecommissie}

Promotor: $\quad$ Prof. dr. E.R. Seydel, Universiteit Twente

Assistent-promotor: dr. J.E.W.C. van Gemert-Pijnen, Universiteit Twente

Leden: $\quad$ Prof. dr. A. Sixsmith, Simon Fraser University, Vancouver, Canada

Prof. dr. R.M. Dröes, VU Medisch Centrum, Amsterdam

Prof. dr. M.C.P.M. Hertogh, VU Medisch Centrum, Amsterdam

Prof. dr. M.G.M. Olde-Rikkert, Radboud Universiteit Nijmegen

dr. ir. J. van Hoof, Fontys Hogescholen, Eindhoven

Prof. dr. ir. H.J. Hermens, Universiteit Twente

Prof. dr. ir. T. de Vries, Universiteit Twente 



\section{Contents}

$\begin{array}{llr}\text { Chapter 1. } & \text { Introduction } & 9\end{array}$

Chapter 2. Literature review: 29

Dementia and technology. A study of technology interventions

in healthcare for people with dementia and their caregivers.

Chapter 3. Monitoring technology at home:

An evaluation of preventive sensor technology for dementia care.

Chapter 4. Monitoring technology residential care:

How assistive technology can support dementia care:

a study about the effects of the IST Vivago watch on patients'

sleeping behavior and the care delivery process in a nursing home.

Chapter 5. Social contact technology at home:

A personal assistant to stay at home safe at reduced cost.

Chapter 6. Social contact technology residential care:

The use of a technology-based leisure activity to support social behavior of people with dementia.

Chapter 7. Conclusions and discussion

Chapter 8. Practical guidelines 
Chapter 1

Introduction 
Chapter 1

$\mathrm{R} 1$

$\mathrm{R} 2$

$\mathrm{R} 3$

R4

$\mathrm{R} 5$

\begin{tabular}{l}
$\mathrm{R} 6$ \\
$\mathrm{R} 7$ \\
\hline
\end{tabular}

$\mathrm{R} 8$

$\mathrm{R} 9$

$\mathrm{R} 10$

R11

$\mathrm{R} 12$

$\mathrm{R} 13$

R14

$\mathrm{R} 15$

R16

R17

$\underline{\mathrm{R} 18}$

R19

220

R21

R22

$\mathrm{R} 23$

R24

R25

R26

$\mathrm{R} 27$

$\mathrm{R} 2 \varepsilon$

R2S

$\mathrm{R3}$

R31

R32

$\mathrm{R} 33$

R34 
Dementia is an umbrella term for different types of diseases whereby a person

suffers from a serious loss of cognitive ability beyond what might be expected from the normal aging process. Dementia affects a person's memory, thinking, behaviour and ability to cope with everyday activities. Alzheimer's disease is the most common form of dementia, other types are frontotemporal dementia, vascular dementia and dementia with Lewy bodies. There are over 50 different types of dementia in total $(1,2)$.

This thesis is about the use of eHealth for people with dementia (no restriction of type). In this thesis we focus on the implementation of different eHealth applications, including their uptake in terms of usage and usability, and the impact of these applications on people with dementia and their caregivers (including relatives who are caregivers). We also focused on the changes in the healthcare delivery process which could occur through the use of eHealth technologies. eHealth might generate cost savings in caring for people with dementia by giving them the extra support they need to continue living in their own homes for a longer period of time instead of having to go into residential care. This dissertation provides a starting point for creating a business model for the use of eHealth applications in a home-based setting for people with dementia.

\section{Dementia worldwide}

Worldwide, an estimated 35.6 million people had dementia in 2010; this is $0.5 \%$

of the world's total population. By 2050 an increase into 115.4 million is expected.

We all have a $20 \%$ chance of getting dementia during our lifetime. For women this percentage is $30 \%$ because they have a tendency to grow older. The older people become, the greater their chances of getting dementia. The percentage of people over the age of 90 with dementia is $40 \%$ (1). People with dementia are more forgetful than usual for their age and have different symptoms than normal older people. 
Chapter 1

activities, but for people with dementia this becomes more and more of a challenge (3).

In $2010,58 \%$ of all people with dementia lived in low and middle-income countries. This figure is expected to rise to $71 \%$ in 2050. In 2010 the total worldwide estimated costs of dementia were 604 billion dollars. Informal care (unpaid care provided by family members and others) and the direct cost of social care (care in the community and residential homes) contributes a similar proportion of these overall costs (42\%), in contrast to direct medical care costs, which only account for $16 \%$ of the total cost. Based solely on the growing number of people with dementia, by 2030 these costs will have increased by $85 \%$ (1).

\section{Dementia in the Netherlands}

According to the Dutch Alzheimer Society, there are currently 250,000 people with dementia living in the Netherlands today. By 2050 this figure will most likely rise to 500,000 people because of the aging population. Even people under 65 years old will start to have dementia: nowadays this number is around 12,000 (2). Conversely, the International Society for Alzheimer Research states that the number of people living with dementia in the Netherlands is currently 180,000 (4); a significantly lower number than the Dutch Alzheimer Society. Yet, according to research findings provided by general practitioners in the Netherlands, the number of people living with dementia is more likely to be 81,000 , while ERGO research from the Erasmus Medical Centre in Rotterdam gives a much higher figure of 203,000 people (5). All in all, these different figures show the lack of clarity and agreement about the actual number of people with dementia in the Netherlands, which is mostly caused by under diagnosis and estimation (6).

The cost of caring for people with dementia in 2005 was 3.2 billion euro, which is $4.7 \%$ of the total cost of the Dutch healthcare system. Dementia ranks just under having a mental disability as the most expensive disease in the Netherlands (7). 
Overall, the number of professional caregivers should be $25 \%$ of the total number of

people working in 2025 in order to take care of the elderly and patients in need of

long-term care (8). This is not realistic in the Netherlands because of the expected

decrease in the number of people working from $68 \%$ now to $56 \%$ in 2030 (9). Alongside the professional caregivers, a lot of care is provided by informal caregivers (usually family members). However, the majority of these informal caregivers experience having to take care of their relative as a burden. In total, $64 \%$ of caregivers from within the family experience taking care of their sick relative as a mild burden, with a further $18 \%$ experiencing it as a heavy burden, which is $82 \%$ in total (10).

\section{Daily life for people with dementia and their caregivers}

This chronic disease has an enormous impact on society. People with dementia have several behavioural and mental problems according to Burns, Jacoby and Levy (1990) (11-14). These include delusions, hallucinations, major depression, mania, agitation/aggression, wandering and apathy. In addition to these mental problems, the symptoms of dementia can also cause problems for the patients themselves as well as their caregivers; especially symptoms such as memory loss and changes in mood or behaviour (4).

People with dementia also have their basic needs. Van der Roest et al. (2009) interviewed 236 people with dementia who still lived in the community and 322 informal caregivers about their needs using the Camberwell Assessment of Need for the Elderly (CANE). This is a semi-structured interview that investigates met and unmet care needs and care use in 24 areas; including social, medical, and (2009) fall within the categories of memory, information, company, psychological distress and daytime activities. The results could be used to improve community care 
Caregivers think about the Instrumental Activities of Daily Living (IADL), Activities of Daily Living (ADL) and safety issues in relation to their needs $(17,18)$. Other studies related to the concerns of family caregivers specifically showed that their main anxieties were in areas such as safety in the home, a lack of quality time for themselves, the absence of meaningful activities for people with dementia, and difficulties experienced with time orientation $(19,20)$. These differences between the needs experienced by the caregivers themselves and those of the people with dementia highlights the need to find a way to combine the needs of the caregiver and the person with dementia to assist both of them in their daily life and work. It is important to assist a person with dementia in their day-to-day life so that they can live at home for as long as possible, but at the same time it is equally important to reduce the burden on the caregiver as well in order to make it possible for the person with dementia to live at home for as long as possible.

Research into the field of needs of people with dementia that is directly related to technology is rare. Wherton and Monk explored the problems of dementia in the home and indentified day-to-day activities in everyday life where technology could be supportive. The main support was needed in the following areas: dressing, taking medication, maintaining personal hygiene, preparing food and socializing (21).

The support required for those living with dementia brings about specific challenges to the older person and those who care for them (22). Currently, community care (informal and formal care for people with dementia in their own homes) does not satisfy the more specific needs of people suffering from dementia and their caregivers, which can result in increased distress, a loss of skills amongst older people, and the caregiver having a breakdown (23).

Nowadays, older people, including those with dementia, prefer to stay in their own homes for as long as possible (24). The literature on aging-in-place suggests that the home environment is a locus of meaning for the older person. Not only is the home environment a place where they can retain a sense of independence and well-being, it is also more cost-effective if a person is living at home for a longer period of time due to the high costs of a nursing home (24). 
The reasons given by caregivers for institutionalizing people with dementia were most

frequently incontinence, followed by withdrawal (acceptation of institution by the

family caregiver). The main problem was the dependence of the dementia patient on

the caregiver, with behavioural disorders taking second place in the list of problems which led to institutionalization. Home-based care for people with dementia should focus on preventing any loss of autonomy for the patient with dementia by focusing on the above-mentioned needs and should also give caregivers periods of relief to lessen the burden on their shoulders (25).

$\underline{\mathrm{R} 4}$

R5

R6

R7

R8

R9

R10

R1

$\mathrm{R} 12$

R1

R1

R1

R1

R1

$\underline{\mathrm{R} 1 \varepsilon}$

$\underline{\mathrm{R} 1 \mathrm{~S}}$

R2C

R2

$\mathrm{R} 2$

$\mathrm{R} 2$

$\mathrm{R} 2$

There is widespread recognition that innovative approaches are required to meet the demands that will be placed upon formal and informal care systems in the future (27) and to promote the independence and well-being of an aging population. The emergence of eHealth is one such innovative approach. In this thesis we will talk about eHealth. eHealth itself covers a broad spectrum of technologies. Eysenbach defined eHealth in 2001 as follows: "eHealth is an emerging field in the intersection of medical informatics, public health and business, referring to health services and information delivered or enhanced through the Internet and related technologies. In a broader sense, the term characterizes not only a technical development, but also

Focusing on the Netherlands, the Dutch Alzheimer Society mentions the use of quality care for people with dementia). They mention the possibility of people living 
a state-of-mind, a way of thinking, an attitude, and a commitment for networked, global thinking, to improve health care locally, regionally, and worldwide by using information and communication technology"(28). However, eHealth is much more than simply a tool; it is a holistic way to support healthcare via technology. The interdependencies between system, content, context, and stakeholders should therefore always be taken into account (29). Consequently, in the case of healthcare for people with dementia, an investigation will be carried out into how best to support the patients in their day-to-day environment, taking into account their needs and the way in which the healthcare delivery process (home-based care/residential care) has been structured.

\section{Low impact and low sustainability for eHealth}

Generally, there is a lack of scientific evidence about the impact of eHealth in healthcare (30-32). But more importantly many eHealth technologies are not doing well in realizing sustainable innovations in healthcare practices $(32,33)$. Sustainability means the way in which the eHealth application is sustained or embedded into an organization's day-to-day routine (34). This low sustainability for eHealth in general has a lot to do with poor implementation $(33,34)$.

Mair et al. (2007) described the key barriers that can prevent eHealth from being implemented successfully. These included: inadequate information management, inadequate inter-agency cooperation, intrusive technology/rigidity of system, cost, and a lack of testing systems (35). There is a narrow focus on the implementation of eHealth, with little attention paid to the impact of new eHealth technologies on the workload, inter-professional relationships and the communication between caregivers and patients (36). For the successful development and implementation of eHealth technologies it is important to know about the day-to-day lives and needs of the people involved: how do they live their lives on a day-to-day level and manage their health and well-being? At the same time, it is also important to look at the people around them such as relatives and professional caregivers and their capacity to work with technology. Nowadays not all of the people involved (stakeholders) make 
a contribution towards the development and implementation of eHealth. Adequate

management of the eHealth implementation process within the healthcare setting is

There are very little conclusive data available about the impact of eHealth on people with dementia in particular, and the sustainability of eHealth technologies in healthcare practice is generally low.

Although evidence about the impact of eHealth technologies is still scarce, some evidence does exist. Research indicates that technology may provide a useful tool for supporting people with dementia within the home environment, thereby reducing the burden of care on the caregivers, while encouraging patient education and self management $(39,40)$. Research has also demonstrated that the use of technology within the home environment is more effective at supporting people with dementia and their caregivers by promoting independent living, earlier identification of problems, and improved self-monitoring $(39,41-45)$. Within a residential care setting too, eHealth can have a positive effect by providing support to the professional caregivers, boosting efficiency, ensuring a higher quality of life for the residents, reducing the number of incidents of falling down by residents and giving them more opportunities to move around freely (46-49).

The market for technology in the area of caring for people with dementia is technological developments to dementia care (50). 


\section{Aim and scope of the thesis}

Van Gemert et al. (2011) suggests a holistic view on the use of eHealth, which consists of a combined focus on the human characteristics and socio-economic, cultural and technology factors altogether (29). In the CeHRes roadmap a holistic approach for research into, and the development of, eHealth is described from the very first steps in the design process to the final stages of assessing the effect and uptake of eHealth. This holistic approach is needed to ensure that eHealth is actually used by the intended target group and that its outcome is effective. In this thesis we focus on the implementation, uptake related to actual usage and usability. eHealth impact should be measured to assess whether the intended and unintended objectives of the eHealth technology are realized.

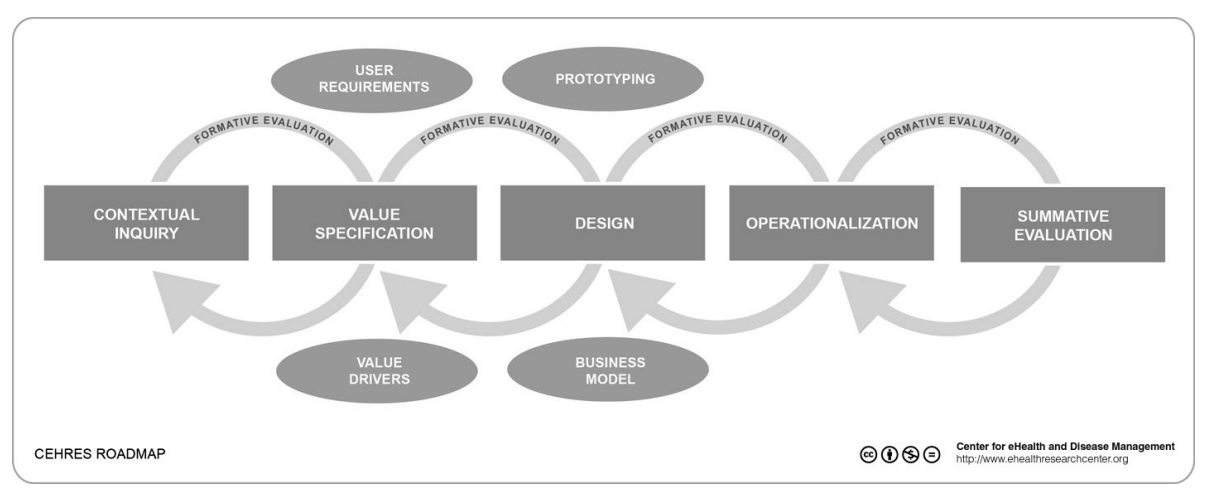

Figure 1 CeHRes Roadmap

In this research we focused on the operationalization aspect, specifically the execution of the implementation plan and the summative evaluation which can be divided into uptake and impact. The operationalization phase involves the launch of the eHealth technology in day-to-day practice and the execution of the implementation plan. In the summative evaluation we examine in greater detail the extent to which the implementation plan was realized successfully. The reason for focussing on the summative evaluation is the fact that the eHealth technologies, which were used in the different studies, were already developed and commercially available. The 
main topics in this study's summative evaluation are related to the uptake: usage

behaviour and usability of the eHealth technology used and its impact: healthcare

With this thesis we want to present the implications for the development and implementation of eHealth applications for people with dementia in home-based and residential care, focusing on monitoring and social contact technology. These implications are meant for eHealth implementers.

$\underline{\mathrm{R} 4}$

R5

R6

$\underline{\mathrm{R} 7}$

$\underline{\mathrm{R} 8}$

$\underline{\mathrm{R} 9}$

$\underline{R 10}$

R1

R1

R13

$\underline{\mathrm{R} 14}$

R1

R1

R1

technology, and technology to support social contact (41).

Another differentiation in technology is the three generations of technology for supporting older people. The first generation is the community alarm system which provides the elderly person with the option to contact a call centre or caregiver whenever they are in need of assistance; the second generation uses sensors to detect potential emergency situations such as a fall or environmental hazard and summon help without action on the part of the user. The third and last generation, also known as ambient assisted living, involves the application of devices that can be integrated within everyday living contexts to provide a wide range of services, help and support to senior citizens, who may require assistance in order to continue living independently (for example, sensors such as ADLife) (51).

In this thesis we made a combination of these differentiations with signalling (generates an alarm when a dangerous situation occurs), monitoring (registers behaviour patterns of people) and social contact (related to social behaviour) technology. The lack of use in healthcare practice and the absence of scientific 
research was greater in the field of monitoring and social contact technology than with signalling technology. The use of signalling technology, like sensor technologies that send out alarm signals, was used more than the other two technologies and so more research has already been done in this field. In this thesis the focus is on the technologies used for monitoring and stimulating social contact, also because of the positive impact and outcomes for these two categories of technologies on the patients' quality of life and behaviour.

Secondly, we carried out a summative evaluation for four technology projects in dementia care ranging from commercially available products to research into the impact of the use of eHealth for people with dementia. These studies are used to provide insights into whether the eHealth technologies are sustainable. The overall purpose is to provide insights into the use of eHealth for people with dementia, acquire a better understanding of the uptake and impact, but most importantly, highlight the implications and practical guidelines. These guidelines are intended to help with developing and implementing sustainable eHealth technology in both home-based and residential care for people with dementia.

Two of these projects were carried out in a residential care home using monitoring and social contact technology. Two of the projects were carried out within the patients' own homes; also one project with monitoring technology and one with social contact technology. For the operationalization phase we focused on the execution of the implementation plan and during the summative evaluation the focus was on the uptake and impact of these technologies. Because a person with dementia lives for most of the time in their own home and later in residential care, both of these settings are important for the person with dementia. Therefore, in this thesis we examine both of these environments. We organized the chapters in this thesis according to the type of technology used. Therefore, the first chapters will focus on eHealth technologies used to monitor patients with dementia while the subsequent chapters will be about eHealth technology used to enhance social contact. 
The overall research questions are:

1. What kind of eHealth applications are used for people with dementia?

Operationalization: implementation (empirical studies)

2. Which activities have been undertaken in order to implement eHealth in dementia care?

Summative evaluation: uptake: usage and usability (empirical studies)

3. What level of uptake has eHealth had in caring for people with dementia in relation to usage and usability?

Summative evaluation: impact: well-being, healthcare delivery and cost savings (empirical studies)

4. What impact has eHealth had on the well-being of both the person with dementia and the caregiver, overall healthcare delivery, and cost savings?

Implications (empirical studies)

5. Which implications can be described for the development and implementation of eHealth technology in home-based and residential care?

The terms used in these research questions can be operationalized in the following ways. The research questions for usage in this research are related to actual usage, while for usability they are about the user-friendliness of the technology. For the research questions about impact, the healthcare delivery is related to healthcare interventions (for example, a change in medication) and support for the caregiver (for example, having contact with the patient through video instead of personal house visits). Well-being is related to something that is ultimately good for a person (52). The cost savings in this study are related to someone living at home who 
To address these questions we used a mixed-method design.

For the first research question we used a literature review.

For the second research question related to the implementation phase we applied a qualitative design and interviews and focus group sessions were carried out with members of the family and professional caregivers.

For the third research question, which relates to the uptake of the eHealth application, we used qualitative data (such as interviews with the family and professional caregivers and observations from people with dementia) and quantitative data (such as log files and monitoring data).

For the fourth research question we collected qualitative data such as interviews and focus group sessions with family members and professional caregivers again. Quantitative data were collected as well, such as observations from people with dementia with bootstrapping techniques, monitoring data and cost data.

In all of our four (4) studies with different technologies, research questions are answered and the results from these four (4) studies are combined in the conclusion and discussion section of this thesis. From the results of these four empirical studies we give practical guidelines for the further development and implementation of eHealth in caring for people with dementia.

\section{Introduction}

\section{Chapter 2: Literature review}

Dementia and technology. A study of technology interventions in healthcare for people with dementia and their caregivers.

Chapter 2 consists of a literature review carried out in 2009 into how different kinds of technology can support healthcare for people with dementia. This provides an answer to the research question about eHealth applications that have already been used. The literature review included 18 international and 8 national studies. Three categories of technology can be distinguished: (1) help with the symptoms of dementia (signalling technology), (2) social contact and company for the patient, and (3) health monitoring and safety. The results of these studies were described using the following categories: behavioural effects, quality of life, job satisfaction, user satisfaction, operational technology, costs and cost savings. 


\section{Empirical studies}

Chapter 3: Monitoring technology in the home

An evaluation of preventive sensor technology for dementia care.

Chapter 3 explores the use of the ADLife preventive sensor technology system. The ADLife preventive technology system is a commercially-available monitoring technology, designed as an early warning system for older people with dementia living at home to detect problems before they require emergency help. The ADLife comprises a gateway with an alarm button and different sensors, which register the pattern of a person's behaviour within their own home. The professional caregiver from the nursing home taking part contacts the person with dementia or the contact person within the family if changes in activity occur which might indicate a dangerous situation. The research questions were related to the implementation and uptake of the ADLife system; usage, usability, and impact of the ADLife system; care interventions, well-being and cost savings. A mixed-method approach was used, involving interviews with professional and family caregivers, researcher observations during project group meetings, analysis of nurses' diaries, and a cost analysis.

\section{Chapter 4: Monitoring technology residential care}

How assistive technology can support dementia care: a study about the effects of the IST Vivago watch on clients' sleeping behaviour and the care delivery process in

Chapter 4 presents the use of the IST Vivago Watch in a residential care home for by measuring their movement, skin temperature and skin conductivity. The watch was used for people with dementia who exhibited a disturbed sleep/wake rhythm. The main purpose of this study was to gain insights into the uptake and impact of the watch on the sleep/wake rhythm and on the healthcare delivery process of patients with dementia. The research questions focus on the implementation, uptake, its usage, and usability. The impact was measured by the interventions that have been carried out based on using the watch and the effects of these interventions on the sleeping patterns of the patients. These questions were answered using a mixed- 
about usage and care interventions related to the monitoring data, observations, and in-depth interviews with caregivers about the implementation and usage of the watch.

\section{Chapter 5: Social contact technology at home}

A personal assistant for dementia to stay at home safe at reduced cost

Chapter 5 describes the use of a touch screen, PAL4, for people with dementia. PAL4 (personal assistant for life) is a touch screen which shows people with dementia an agenda for their day, a diary, a life album and a so-called PAL4 button. In this PAL4 button more information can be found such as memory games to play, information about their disease, information about the neighbourhood in which they currently live. PAL4 is used as a supportive and social contact technology. One of the features of PAL4 is also making video contact with the family caregiver or the professional caregiver. The research questions were related to the implementation and uptake of the PAL4 system; its usage, usability and impact, healthcare delivery, well-being and cost savings. A mixed-method design was used using log files, interviews with caregivers from within the family, a focus group made up of professional caregivers, observations from the project group meetings, and a cost analysis.

\section{Chapter 6: Social contact technology residential care}

The use of a technology-based leisure activity to support the social behaviour of people with dementia

Chapter 6 explains the use of the technology-supported, social leisure activity known as the Chitchatters. The Chitchatters intend to stimulate social interaction and behaviour among people with dementia. The activity includes four interactive objects: a television, radio, telephone and treasure chest, each of which triggers memories in its own specific way. In this study the focus is on the impact of the Chitchatters on the social behaviour of people with dementia and its supportive role in the work of activity therapists. In addition, this study focuses on the uptake related to the key factors for usability of the Chitchatters in residential care and for day-care purposes. A mixed-method research design was applied, with observations using the Oshkosh Social Behaviour Coding scale, whereby the statistical method known as 
bootstrapping was used because of the small sample size ( $n=10$ participants, multiple rounds of observations), as well as interviews with the activity therapists.

\section{Conclusions and practical guidelines}

Chapter 7: Conclusions and discussion

In chapter 7, a reflection on the major findings and conclusions of the studies reported in this thesis are discussed. The implications for the use of eHealth technologies in dementia care and future research are described.

Chapter 8: Practical guidelines

In this chapter we present practical guidelines for eHealth implementers. These technologies. 


\section{References}

1. Wimo A, Prince M. World Alzheimer Report. London: Alzheimer's Disease International, 2010.

2. Alzheimer Nederland. Informatie Dementie. Bunnik: Alzheimer Nederland; 2012 [cited 2012 January 9]; Available from: http://www.alzheimer-nederland.nl/informatie/watis-dementie/dementie.aspx.

3. American Medical Association. Differentiating Normal Aging and Dementia. American Medical Association; n.d. [cited 2012 August 16]; Available from: http://www.amaassn.org/resources/doc/public-health/aging_vs_dementia.pdf.

4. Alzheimer's disease international. About Alzheimer's Early symptoms. 2008 [cited 2010 June 13]; Available from: http://www.alz.co.uk/alzheimers/symptoms.html.

5. van der Meulen A, Keij-Deerenberg I. Sterfte aan dementie. Den Haag: Centraal Bureau voor Statistiek; n.d. [cited 2012 August 16]; Available from: http://www.cbs.nl/NR/ rdonlyres/57D8293E-8EA9-4B53-B8C1-04DDEDFE1C00/0/2003k2b15p024art.pdf.

6. de Lange J, Poos MJJC, Schoemaker C. Hoe vaak komt dementie voor en hoeveel mensen sterven eraan? Bilthoven: Rijksinstituut voor Volksgezondheid en Milieu; 2010 [cited 2012 August 16]; Available from: http://www.nationaalkompas.nl/gezondheiden-ziekte/ziekten-en-aandoeningen/psychische-stoornissen/dementie/omvang/.

7. Rijksinstituut voor Volksgezondheid en Milieu. Kosten van ziekten. Bilthoven 2005 [updated 26 June, 2008; cited 9 January 2012]; Available from: http://www. kostenvanziekten.nl/kvz2005/kosten-naar-diagnose/psychische-stoornissen/.

8. Centraal Bureau voor de Statistiek. Gezondheid en zorg in cijfers 2009. Den Haag: Centraal Bureau voor de Statistiek; 2009 [updated December 4, 2009; cited 2012 October 1]; Available from: http://www.cbs.nl/nl-NL/menu/themas/gezondheidwelzijn/publicaties/publicaties/archief/2009/2009-c156-pub.htm.

9. Centraal Bureau voor de Statistiek. Afname potentiële beroepsbevolking begint. Den Haag: CBS; 2007 [cited 2012 July 24]; Available from: http://www.cbs.nl/NR/ rdonlyres/4CB9E5E3-357E-4A95-8221-F2F31F4CB12D/0/pb07n008.pdf.

10. Francke A. Mantelzorg voor dementiepatienten onverminderd zwaar. Utrecht: Nivel; 2009 [cited 20129 January]; Available from: http://www.nivel.nl/oc2/page. asp?PagelD=12895.

11. Burns A, Jacoby R, Levy R. Psychiatric phenomena in Alzheimer's disease, I: Disorders of thought content. The British Journal of Psychiatry. 1990;157(1):72-6.

12. Burns A, Jacoby R, Levy R. Psychiatric phenomena in Alzheimer's disease, II: Disorders of perception. The British Journal of Psychiatry. 1990;157(1):76-81.

13. Burns A, Jacoby R, Levy R. Psychiatric phenomena in Alzheimer's disease, III: Disorders of mood. The British Journal of Psychiatry. 1990;157(1):81-6.

14. Burns A, Jacoby R, Levy R. Psychiatric phenomena in Alzheimer's disease, IV: Disorders of behavior. The British Journal of Psychiatry. 1990;157(1):86-94.

15. Reynolds T, Thornicroft G, Abas M, Woods B, Hoe J, Leese M, Orrell M. Camberwell Assessment of Need for the Elderly (CANE): development, validity and reliability. British Journal of Psychiatry. 2000;176(5):444-52.

16. van der Roest HG, Meiland FJ, Comijs HC, Derksen E, Jansen AP, van Hout HP, Jonker C, Dröes RM. What do community-dwelling people with dementia need? A survey of those who are known to care and welfare services. International Psychogeriatrics. 2009;21(21):949-65.

17. Kirsi T, Hervonen A, Jylha M. Always One Step Behind: Husbands' Narratives about Taking Care of their Demented Wives. Health (London). 2004;8(2):159-81. 
18. Pollitt PA, Andersont I, D.W. OC. For better or for worse: The experience of caring for an elderly dementing spouse. Ageing and Society. 1991;11(4):443-69.

19. Bank AL, Arguelles S, Rubert M, Eisdorfer C, Czaja SJ. The value of telephone support groups among ethnically diverse caregivers of persons with dementia. The Gerontologist. 2006;46(1):134-8.

20. Nolan M, Ingram P, Watson R. Working with family carers of people with dementia. Dementia. 2002;1(1):75-93.

21. Wherton J, Monk A. Technological opportunities for supporting people with dementia who are living at home. Journal of Human Computer Studies. 2008;66(8):571-86.

22. Brown J, Hillan J. Dementia. Edinburgh: Churchill Livingstone; 2004.

23. Bamford C, Bruce E. Defining the outcomes of community care: the perspectives of older people with dementia and their carers. Ageing and Society. 2000;20(5):543-70.

24. Tinker A. Housing for elderly people. Reviews in Clinical Gerontology. 1997;7(2):171-6.

25. Thomas $P$, Ingrand $P$, Lalloue $F$, Hazif-Thomas $C$, Billon R, Viéban $F$, Clément JP. Reasons of informal caregivers for institutionalising dementia patients previously living at home: the Pixel study. International Journal of Geriatric Psychiatry. 2004;19(2):127-35.

26. Alzheimer Nederland, Vilans. Zorgstandaard dementie. Bunnik: Alzheimer Nederland; 2012 [cited 2012 July 24]; Available from: http://www.alzheimer-nederland.nl/ media/11405/Zorgstandaard\%20Dementie\%20PDF.pdf.

27. Bharucha AJ, Anand V, Forlizzi J, Dew MA, Reynoalds CF, Stevens S, Wactlar H. Intelligent Assistive Technology Applications to Dementia Care: Current Capabilities, Limitations and Future Challenges. American Journal of Geriatric Psychiatry. 2009;17(2):88-104.

28. Eysenbach G. What is eHealth? Journal of Medical Internet Research. 2001;3(2):e20.

29. Van Gemert-Pijnen JEWC, Nijland N, Ossebaard HC, van Limburg AH, Kelders SM, Eysenbach G, Seydel ER. A holistic framework to improve the uptake and impact of eHealth technologies. Journal of Medical Internet Research. 2011;13(4):e111.

30. WHO. Medical devices: managing the mismatch. Geneva, Switzerland: World Health Organization, 2010.

31. Black AD, Car J, Pagliari C, Anandan C, Cresswell K, Bokun T, McKinstry B, Procter R, Majeed A, Sheikh A. The impact of eHealth on the quality and safety of health care: $a$ systematic overview. PLoS Medicine. 2011;8(1):1-16.

32. Atienza AA, Hesse BW, Gustafson DH, Croyle RT. E-health research and patient-centered care examining theory, methods, and application. American Journal of Preventive Medicine. 2010;38(1):85-8.

33. Nijland N. Grounding eHealth. Towards a holistic framework for sustainable eHealth technologies [Dissertation]. Enschede: University of Twente; 2011.

34. Greenhalgh T, Robert G, Bate P, Kyriakidou O, Macfarlane F, Peacock R. How to Spread Good Ideas. A systematic review of the literature on diffusion, dissemination and sustainability of innovations in health service delivery and organisation. London: National Health Service,2004.

35. Mair FS, May C, Finch T, Murray E, Anderson G, Sullivan F, O'Donnell C, Wallace P, Epstein $\mathrm{O}$. Understanding the implementation and integration of e-health services. Journal of Telemedicine and Telecare. 2007;13 (1):36-7.

36. Mair FS, May C, Murray E, Finch T, Anderson G, O'Donnell C, Wallace P, Sullivan F. Understanding the implementation and integration of e-Health Services. London: National Health Service and Delivery R \& D Organisation,2009.

37. Resnicow K, Strecher V, Couper M, Chua H, Little R, Nair V, Polk TA, Atienza AA. Methodologic and design issues in patient centered eHealth research. American Journal of Preventive Medicine. 2010;38(1):98-102.

38. Cain M, Mittman R. Diffusion of Innovation in Health Care. Oakland: California HealthCare Foundation, 2002. 
39. Cahill S, Begley E, Faulkner JP, Hagen I. "It gives me a sense of independence"Findings from Ireland on the use and usefulness of assistive technology for people with dementia. Technology and Disability. 2007;18(2-3):133-42.

40. Carswell W. A review of the role of assistive technology for people with dementia in the hours of darkness. Technology Health Care. 2009;17(4):281-304.

41. Lauriks S, Reinersmann A, van der Roest HG, Meiland FJ, Davies RJ, Moelaert F, Mulvenna MD, Nugent CD, Dröes RM. Review of ICT based services for identified unmet needs in people with dementia. Aging Research Reviews. 2007;6(3):223-46.

42. Topo P. Technology studies to meet the needs of people with dementia and their caregivers. A literature review. Journal of Applied Gerontology. 2009;28(1):5-37.

43. Duff $P$, Dolphin C. Cost-benefit analysis of assisitive technology to support independence for people with dementia - Part 2: Results from employing the ENABLE cost- benefit model in practice. Technology and Disability. 2007;19(2):79-90.

44. Cahill S, Macijauskiene J, Nygård AM, Faulkner JP, Hagen I. Technology in dementia care. Technology and Disability. 2007;19(2-3):55-60.

45. Nijhof N, van Gemert-Pijnen JEWC, Dohmen D, Seydel ER. Dementie en technologie. Een studie naar toepassingen van techniek in de zorg voor mensen met dementie en hun mantelzorgers. Tijdschrift voor Gerontologie en Geriatrie. 2009;40(3):113-32.

46. Nouws H, Sanders L, Heuvelink J. Domotica voor dementerenden. De eerste ervaringen in het Leo Polakhuis te Amsterdam en het Molenkwartier te Maassluis. Amersfoort, 2006.

47. Lauriks S, Osté JP, Hertogh CMPM, Dröes RM. Effectenonderzoek naar de toepassing van domotica in kleinschalige groepswoningen voor mensen met dementie. Amsterdam: GGD, 2008.

48. Vilans. Kerkrade: Groepswoningen/ verpleeghuis Lückerheide. Utrecht: Vilans; 2008 [cited 2012 July 24]; Available from: www.domoticawonenzorg.nl.

49. Engstrom M, Ljunggren B, Lindqvist R, Carlsson M. Staff perceptions of job satisfaction and life situation before and 6 and 12 months after increased information technology support in dementia care. Journal of Telemedicine and Telecare. 2005;11(6):304-9.

50. Sixsmith A. New technologies to support independent living and quality of life for people with dementia. Alzheimer's Care Quarterly 2006;7(3):194-202.

51. Sixsmith A, Sixsmith J. Ageing in place in the United Kingdom. Ageing International. 2008;32(3):219-35.

52. Crisp R. Well being. Stanford: MetaPhysics Research Lab, Stanford University; 2008 [cited 2012 August 30]; Available from: http://plato.stanford.edu/entries/well-being/. 


\section{Chapter \\ 2}

Literature review

Dementia and technology. A study of technology interventions in healthcare for people with dementia and their caregivers

Based on: Nijhof N, van Gemert-Pijnen JEWC, Dohmen D, Seydel ER.

Dementie en technologie. Een studie naar toepassingen van techniek in de zorg voor mensen met dementie en hun mantelzorgers. Tijdschrift voor Gerontologie en Geriatrie. 2009;40 (3):113-32. doi: 10.1007/BF03079573 


\section{Abstract}

Objective: To explore the possibilities of using technological interventions in dementia care in order to make sound decisions about the added value of using technological applications in healthcare in the future.

Methodology: An inventory was made of all the international and national studies that focus on the implementation and evaluation of technological interventions to help patients with dementia and their caregivers. Three categories of technology were examined in this inventory, namely technology that helps patients and their caregivers to cope with the symptoms of dementia, technology that supports the patients' need for social contact and companionship, and technology that is used to monitor and safeguard the health and safety of patients with dementia.

Results: Eighteen international and eight national studies were included. The first results of using technological interventions to care for patients with dementia look promising. Significant improvements have been seen with regard to the patients' quality of life and the effect that the technology has had on the patients' behaviour (such as fewer reported incidents of falling down). The informal caregivers and people with dementia are satisfied with the usability of the technology. However, the cost of procuring and applying the technology is often too high. So far, no in-depth research has been carried out into the level of satisfaction among professional caregivers with regard to the use of technology.

Conclusion: Although technology can improve a patient's ability to cope independently with some of the effects of dementia, the impact of technology on the daily lives of dementia patients, informal caregivers and professional caregivers has not been studied extensively. Further research will focus on the effect of technology on people suffering from dementia and their caregivers in terms of improvements to their quality of life, an enhanced sense of personal safety and greater degree of job satisfaction, respectively. 
In recent years there have been significant advancements in the use of technology to

support healthcare for patients with dementia. The focus has been on technological

This technology can be divided in three different groups: technology that is used by the patients with dementia, technology that is used by the caregivers, and technology that works automatically $(1,2)$. The technology that works automatically, without any external intervention, is also called "ambient intelligence". Loosely translated, ambient intelligence is a form of invisible, intelligent technology that goes unnoticed by the patients in their home. Intelligent technology uses software that interprets situations by using incoming signals from sensors (3). For example, a sensor on the fridge door that registers whether the fridge has remained closed for too long, thereby implying that the patient may not have eaten for some time. At that moment, the sensor transmits an alarm to a caregiver.

To date, no literary overview has been compiled in the Netherlands about the different technology applications that are being used to help people with dementia, and the effect that these applications are having on them, their informal caregivers and their professional caregivers. This article strives to provide such an overview with a view to advocating the deployment of technology to assist people with dementia.

A literature review involving a quick scan was the method selected to conduct research for this article. This was because, to date, very little empirical research has been carried out into the use of technology to help people with dementia. Consequently, a systematic review is not yet feasible in the Netherlands. There are currently too few completed projects that have gone through the necessary evaluation and publication procedure. By a 'quick scan', we mean a global scan of all the available (empirical) literature. This literature review aims to give some preliminary insights into the type of projects that are currently being carried out in the Netherlands for people 
with dementia, and to provide a snapshot of the effect that technology is having on patients' self-reliance and how healthcare is organized for people with dementia. The following questions are central to this: "What technologies are around at the moment?" "What do these technologies do?" "Which technologies are applied widely in the Netherlands?" "What effects have already been found in people with dementia and informal caregivers?" The Dutch situation is compared with the international situation, where already a lot more experience has been acquired about these types of technology.

One of the few previous review studies is carried out by Lauriks et al. (2007), which focused on the use of Information and Communication Technology (ICT) for people with dementia (4). However, the authors did not focus specifically on the Dutch situation and it was only recently (after the study by Lauriks et al. had already ended) that some other studies were also published in the Netherlands. The review by Lauriks et al. focuses on the technology needs of people with dementia and their family caregivers, which originated from an earlier needs assessment carried out among patients with dementia and their volunteer caregivers, including:

- The need for general and personal information

- The need for help with the symptoms of dementia

- The need for social contact and companionship

- The need for monitoring health and safety.

The main findings were that while websites do indeed provide useful information for caregivers, they offer very little information to the patients who are actually suffering from dementia and the websites that were investigated provided very little personal information (such as noting down one's own doctor's appointments).

The study by Lauriks et al. (2007) cited above shows that ICT tools help to reduce the limitations of people with dementia (such as memory loss and the difficulties they encounter when trying to carry out day-to-day tasks), enhance the patients' confidence and have a generally positive impact on the lives of patients with dementia and their caregivers. This has been demonstrated in patients with mild to moderately severe dementia who are able to handle simple electronic tools. One example of this 
is a handheld computer that registers when a patient needs to take their medication

Information and communication technology (ICT) tools that are used to promote social contact and companionship such as the video phone, simple mobile phones, and forms of communication carried out by patients with dementia. These tools for social contact and companionship seem easy to use. People with dementia also appear to like using them. GPS technology and monitoring systems appear to provide an increasing sense of safety and reduce feelings of fear and anxiety.

The results of the studies described in Lauriks' review are promising. Nevertheless, the review also clearly indicates that more studies are needed in a 'real life' situation (4). In this literature review we will delve deeper into three of the technology requirements listed above, namely:

- The need for help with the symptoms of dementia

- The need for social contact and companionship

- The need to monitor health and safety.

The first category listed by Lauriks et al. (4), "The need to make general and personal

Publications were collected for this literature review between May and August 2008.

All of the publications focused on empirical research into technological interventions were put in place in terms of the quality of the studies; this was partly because research into technology for people living with dementia is still very limited. In this literature review the emphasis is on the behavioural effects of the technology interventions, and research in this area is still rare. Articles that focused on problems 
how the technology functioned in practice and where no evaluation was performed. Scientific publications and reports from 1998 to 2008 were included in this literature review.

The following electronic databases were consulted: Science Direct, Google Scholar, PiCarta and the website of a Centre of Expertise (Vilans) in the Netherlands that specialises in providing care in this area. The keyword combinations that are used, both in Dutch and in English, are 'dementia' in combination with 'technology', 'IT', 'telecare', 'telemedicine', 'telehealth' and 'telemonitoring'. The articles were then examined based on the following indicators: effects on behaviour, quality of life, job satisfaction, user satisfaction, how the technology functioned in practice, and the cost and savings that were made.

\section{Results}

A total of forty (40) studies were identified, out of which twenty-six (26) remained after all the abstracts had been read. In the end, eighteen (18) international and eight (8) national studies that complied with the criteria, see tables 1 and 2, were included. With regard to the international studies, a worldwide search was carried out for projects that focused on one of the three categories of technology. In the case of the national studies, a systematic search was carried out for any projects that focused on evaluating health and safety for dementia patients, because these have been researched in more detail in the Netherlands. The information in the tables has been divided into four categories, namely: "reference, country, year and length of the intervention", "study setting and technology requirements", "study set-up, inclusion criteria and methods" and finally "results". Furthermore, the results are grouped into the effects on behaviour, quality of life, job satisfaction, user satisfaction, how the technology functions in practice, cost and cost savings. 


\section{Results of international studies}

Table 1 International inventory of technological interventions for caregivers of people with

1. With regard to the technological requirements.

A: Requirements for help relating to the symptoms of dementia;

B: Requirements for social contact and company for the person with dementia;

C: Need to monitor the health and safety of the patient with dementia (by requirements we mean the needs of patients with dementia themselves or their caregivers as listed in the study by Lauriks et al. 2007).

R1

2. With regard to the results:

D. Patients with dementia;

Z. Professional caregivers;

M. Informal caregivers (e.g. family members). 


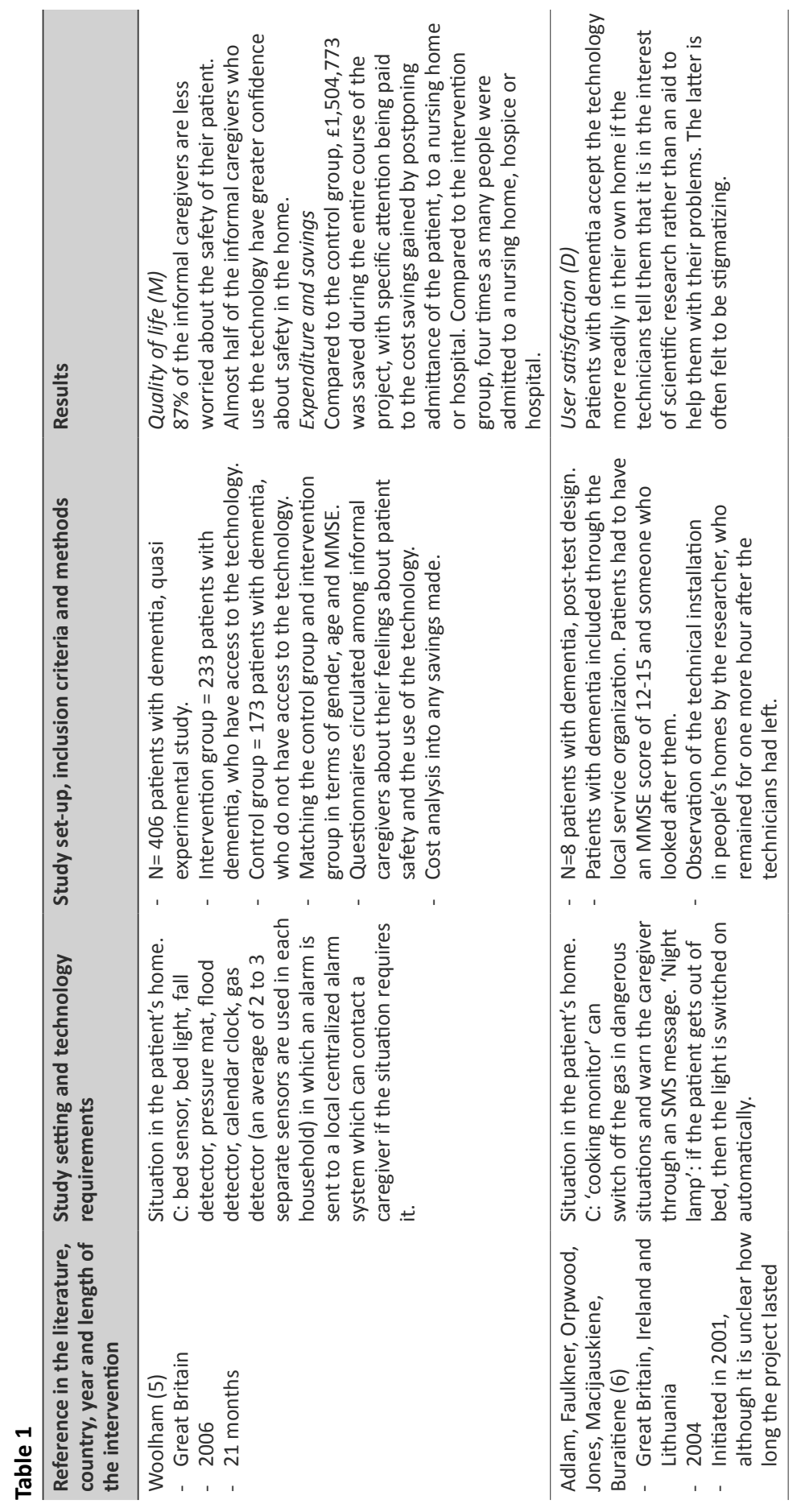




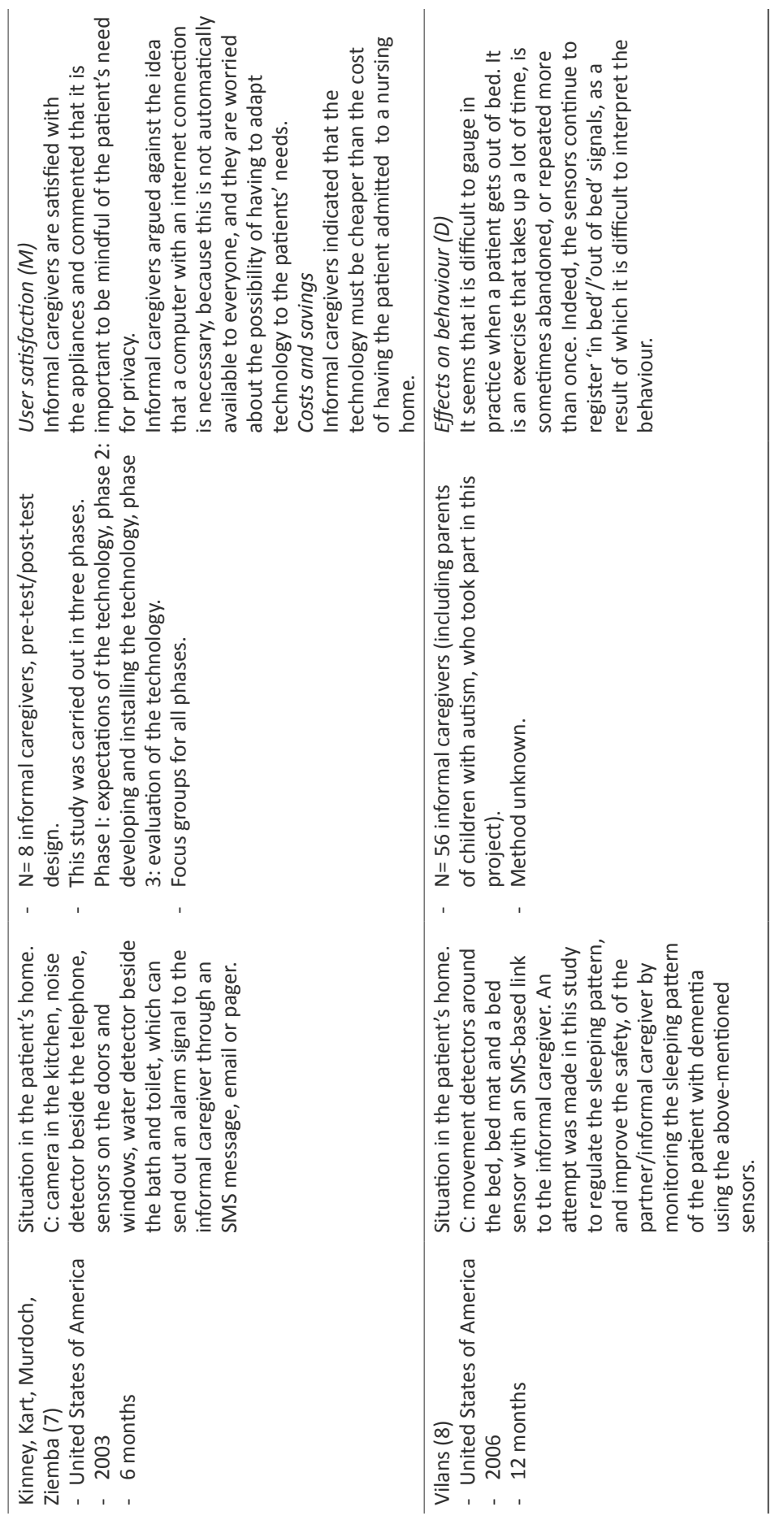

R1

R2

R3

R4

R5

R6

R7

2 R8

R9

R1

R1

R1

R1

R1

R1

R1t

R17

$\underline{\mathrm{R} 18}$

$\underline{\mathrm{R} 1 \mathrm{~S}}$

$\mathrm{R} 2 \mathrm{C}$

$\mathrm{R} 2$

R2

$\mathrm{R} 2$

$\mathrm{R} 2$

$\mathrm{R} 2$

$\mathrm{R} 2$

$\mathrm{R} 2$

$\mathrm{R} 2$

$\mathrm{R} 2 \mathrm{~S}$

$\mathrm{R} 3 \mathrm{C}$

R31

$\mathrm{R} 32$

R33

R34 


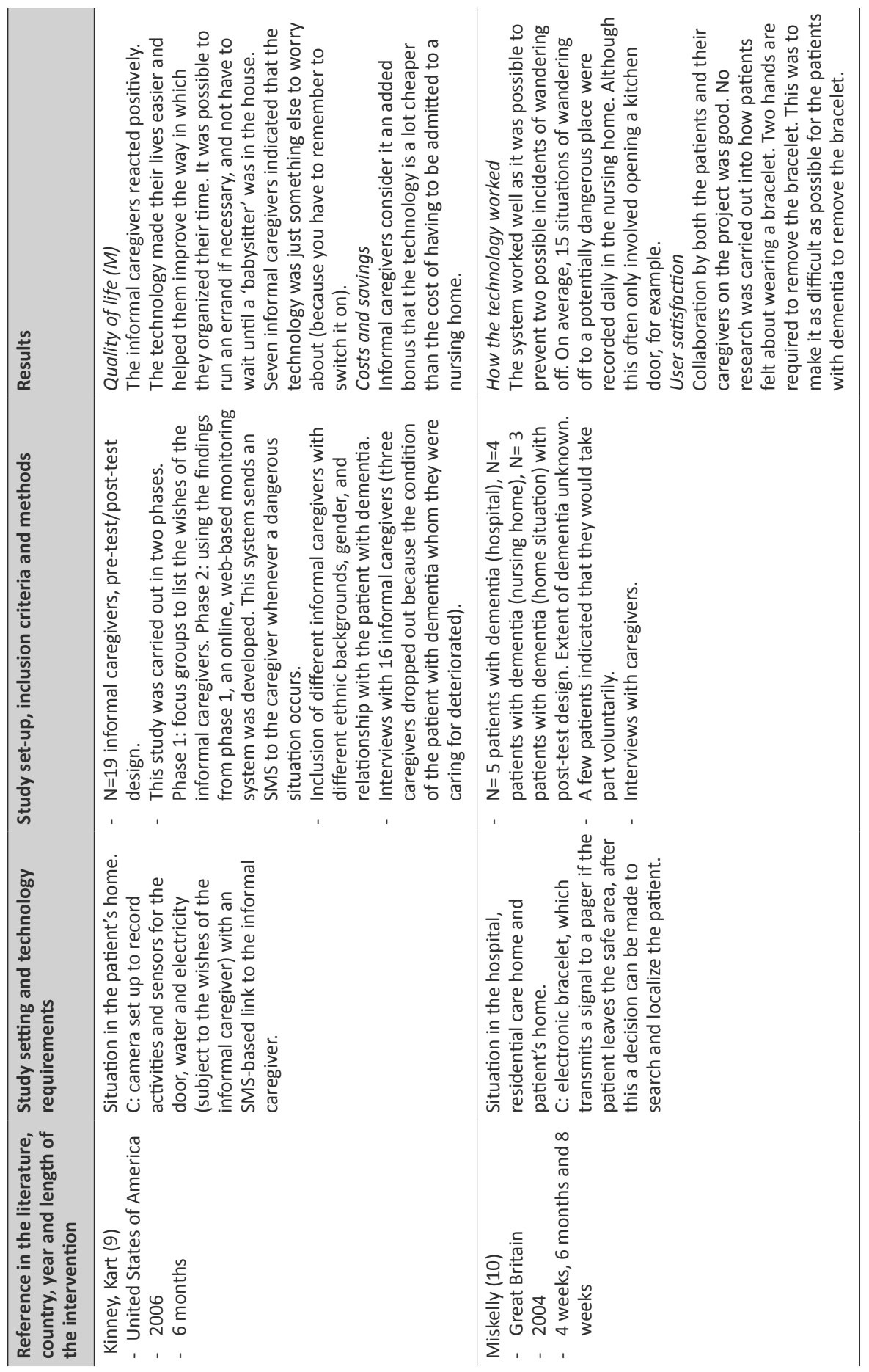




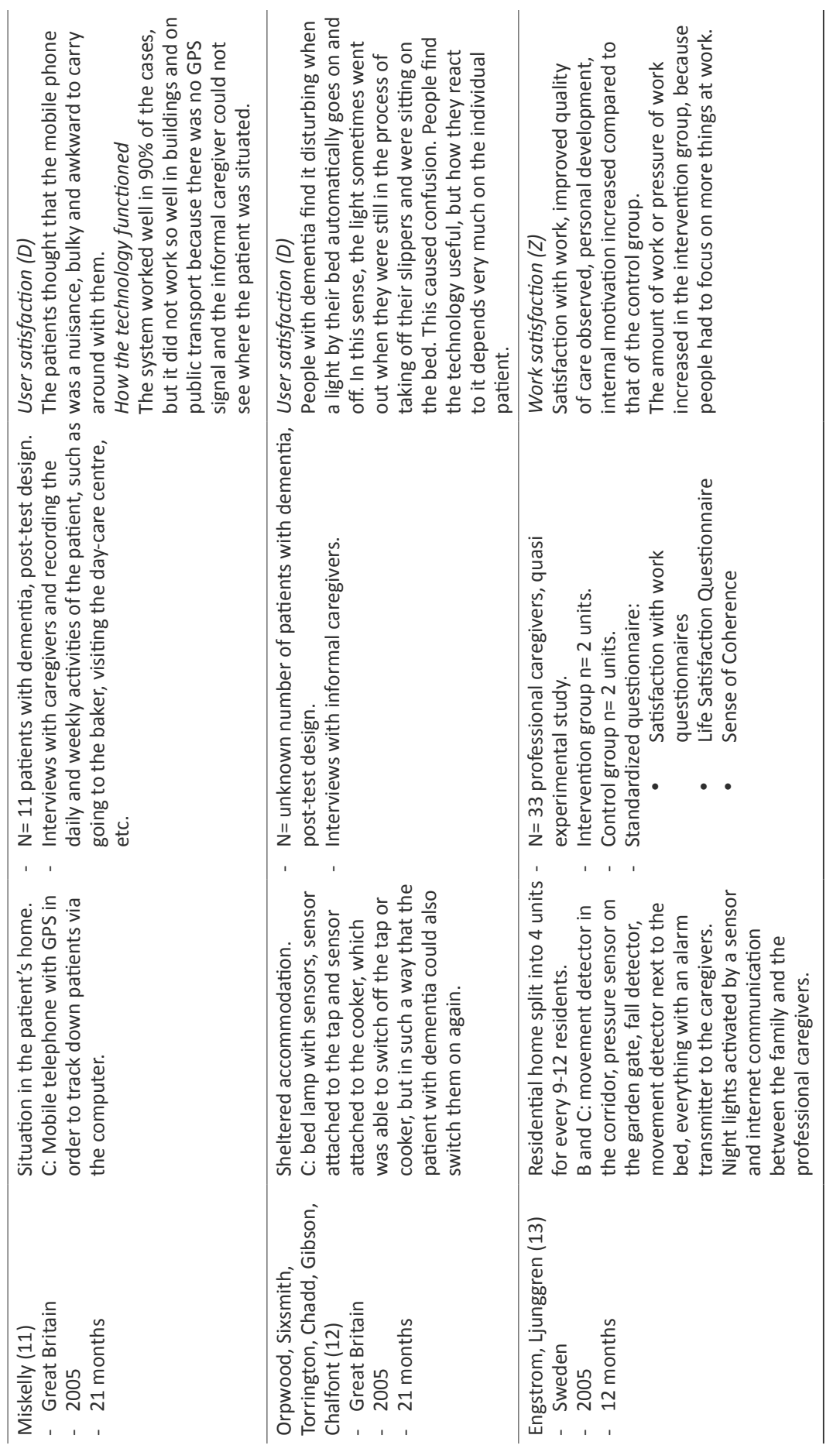

R1

R2

R3

R4

R5

R6

R7

$\mathrm{R} 8$

R9

R1

R1

R1

R1

R14

R1

R16

R1

$\underline{\mathrm{R} 18}$

R1S

$\mathrm{R} 2 \mathrm{C}$

$\mathrm{R} 2$

R2

$\mathrm{R} 2$

R2

$\mathrm{R} 2$

$\mathrm{R} 2$

$\mathrm{R} 2$

$\mathrm{R} 2$

R2S

$\mathrm{R} 3 \mathrm{C}$

R31

$\mathrm{R} 32$

R33

R34 


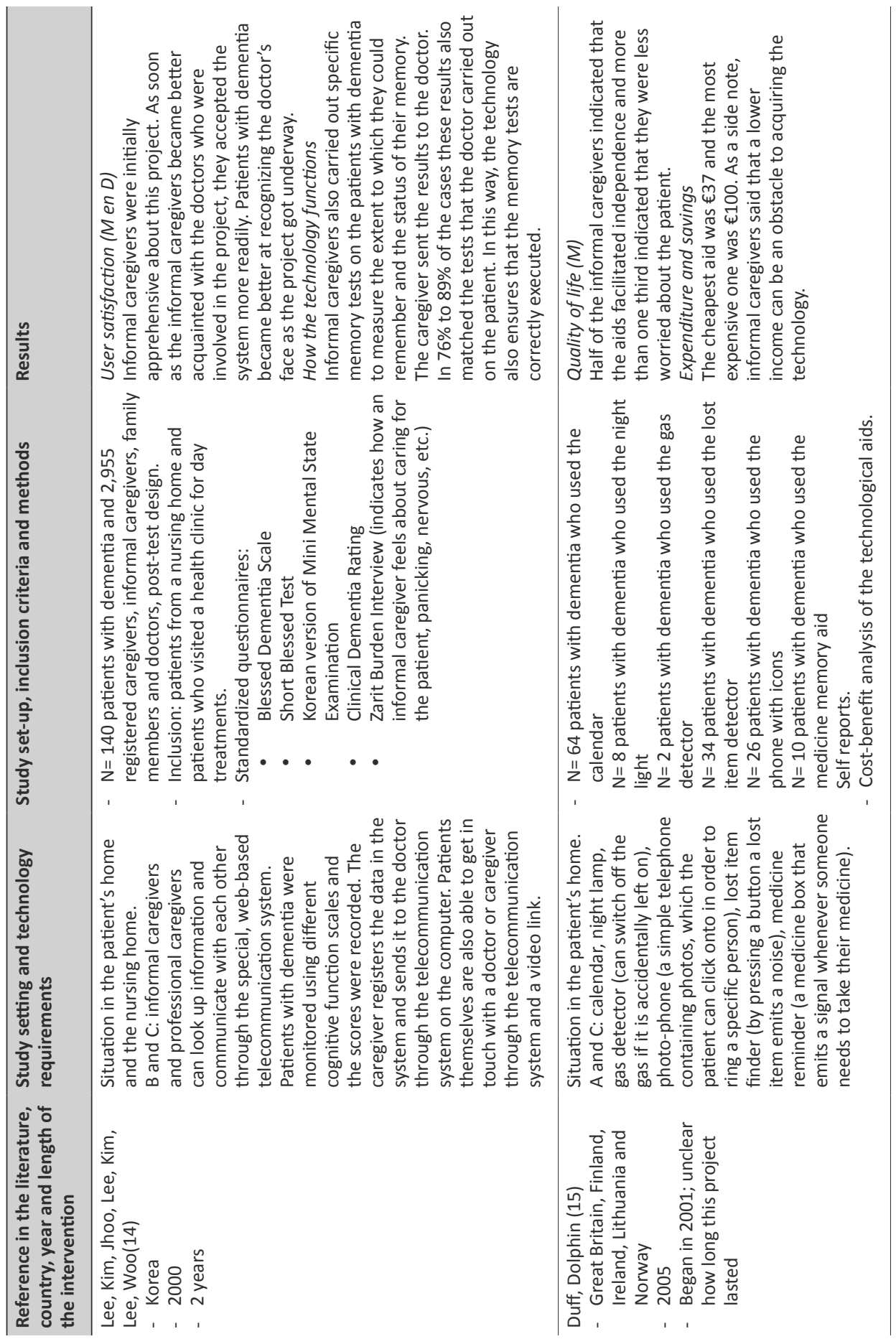




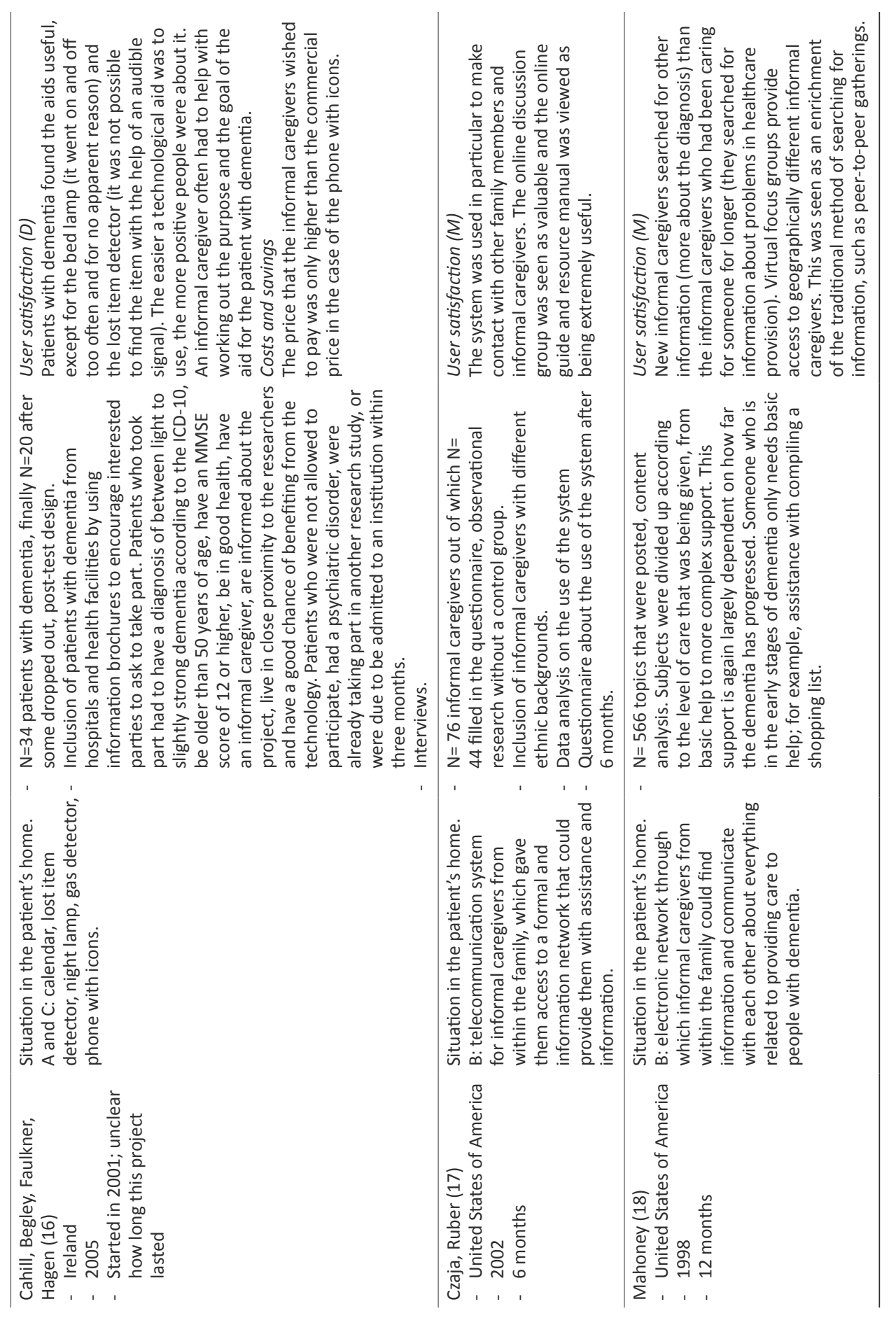

R1

R2

$\mathrm{R} 3$

R4

R5

R6

R7

2

R8

R9

R1

R1]

$\mathrm{R} 12$

R1

R14

R15

R16

R1

R1s

R1S

$\mathrm{R} 2$

$\mathrm{R} 2$

R2

$\mathrm{R} 2$

R2

$\mathrm{R} 2$

$\mathrm{R} 2$

$\mathrm{R} 2$

R2

$\mathrm{R} 2 \mathrm{~S}$

$\mathrm{R} 3 \mathrm{C}$

R31

$\mathrm{R} 32$

R33

R34 


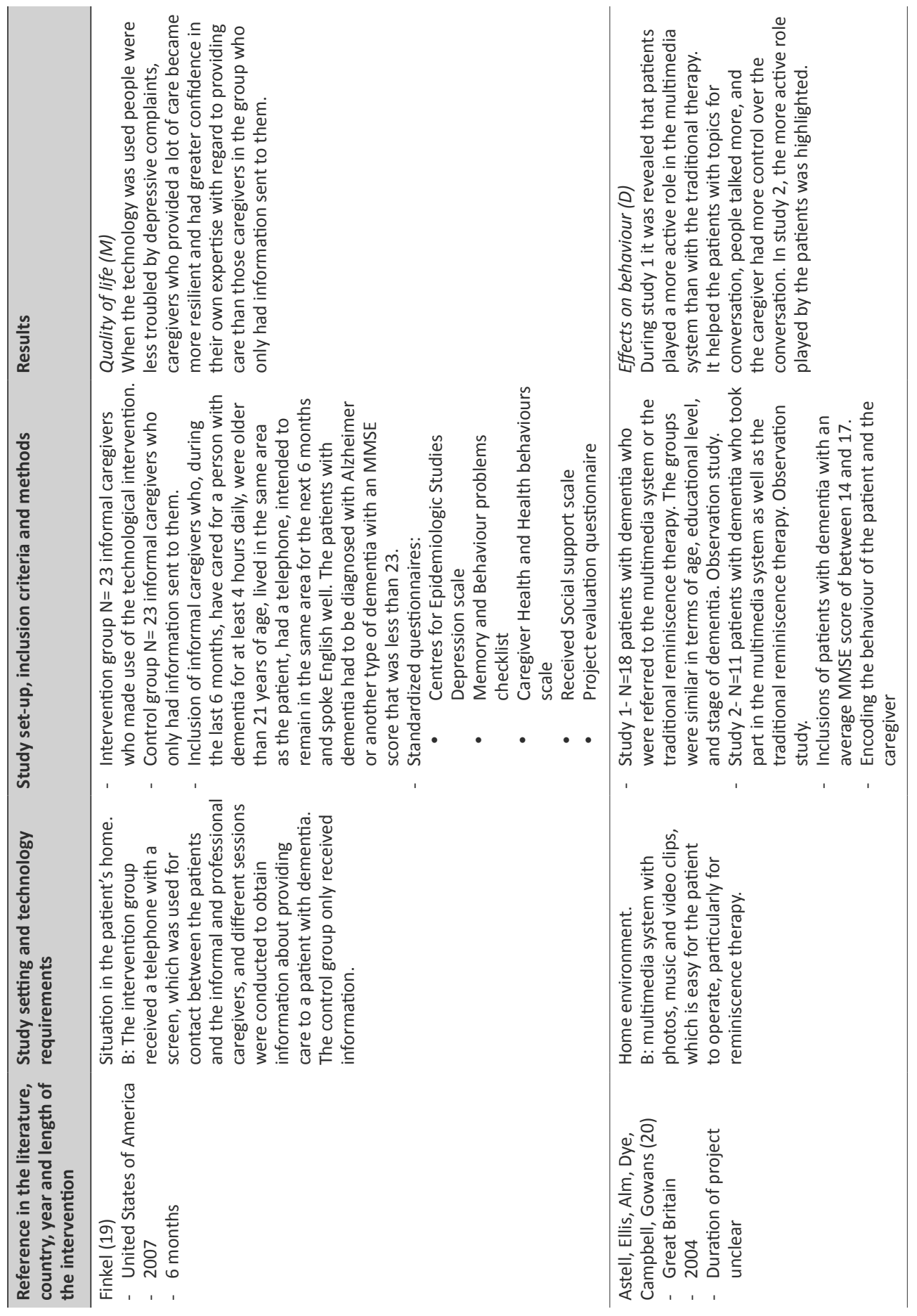




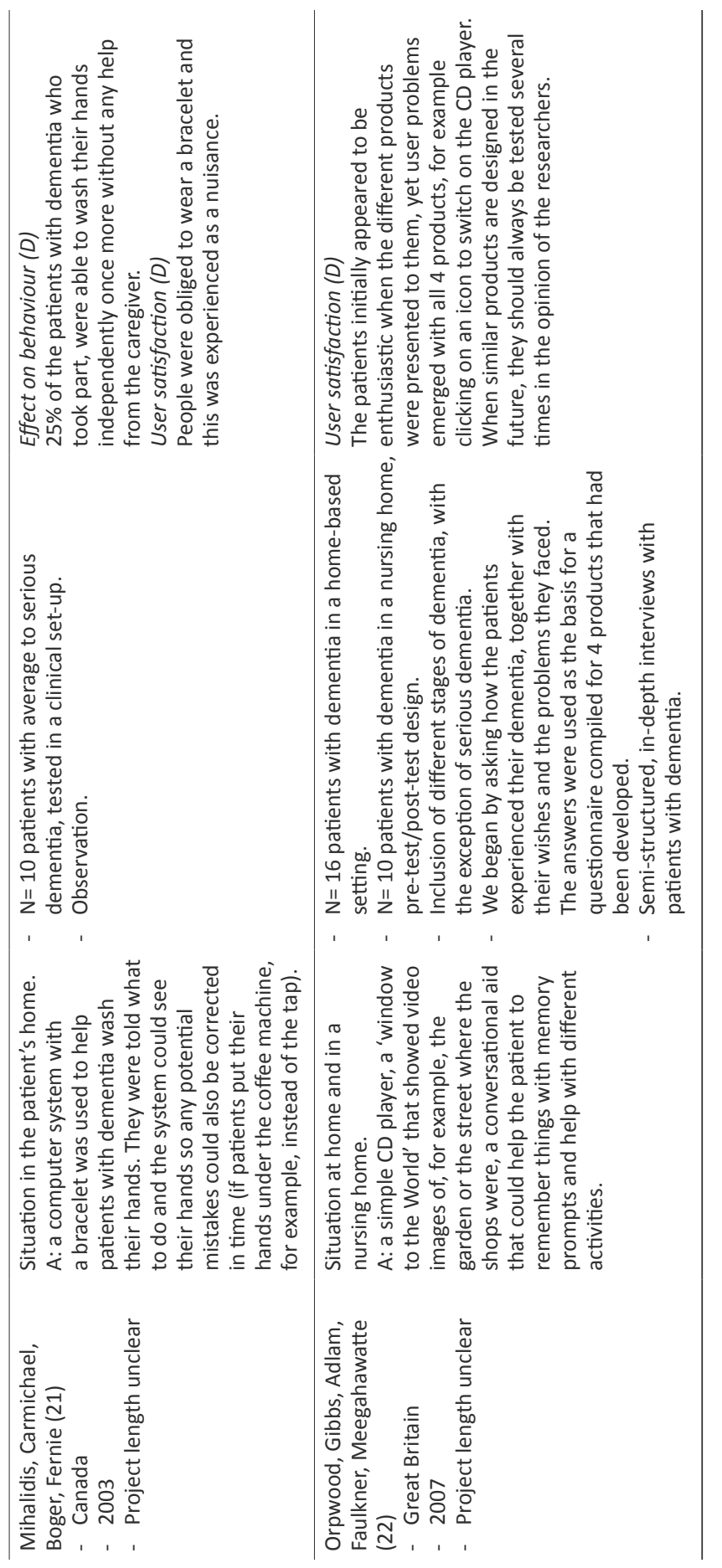

R1

R2

R3

R4

R5

R6

R7

$\mathrm{R} 8$

R9

R1C

R1

R1

R1

R1

R15

R16

R17

$\underline{\mathrm{R} 18}$

R1S

$\mathrm{R} 2 \mathrm{C}$

$\mathrm{R} 2$

$\mathrm{R} 2$

$\mathrm{R} 2$

$\mathrm{R} 2$

R2

$\mathrm{R} 2$

$\mathrm{R} 2$

$\mathrm{R} 2$

R2S

$\mathrm{R} 3 \mathrm{C}$

R31

$\mathrm{R} 32$

R33

R34 
Chapter 2

The international studies are described below.

\section{Study setting and study design}

The study environment in which the various studies took place, was usually in the patient's own home. A few studies were conducted simultaneously in several different healthcare settings. The length of the intervention varied. There were five studies that lasted for six months or less $(7,9,10,17,19)$. Three studies had an intervention that lasted between six and twelve months $(8,13,18)$. Three studies had a technological intervention that lasted longer than 12 months $(5,11,12)$ and one study (14) had an intervention that lasted longer than 24 months. In six of the research studies, the length of the intervention was unknown $(6,15,16,20-22)$.

The technologies that were studied were divided in three sections.

A. The need for help with the symptoms associated with dementia (for example, forgetfulness, boredom, inactivity).

There are various types of technology applications that can be used to assist patients with their day-to-day activities, enhance their quality of life, and support their intake of medicine. These include an electronic calendar for scheduling daily activities which caregivers can easily create themselves. A picture phone whereby the patient can simply click on someone's picture to dial their number. A computer system with a sensor bracelet, which helps people with dementia when they wash their hands. The system uses a pre-recorded voice to let the person know how he or she should wash their hands. Through the bracelet, the system can record the position of the patient's hands so that any mistakes can be corrected. Other examples are a lostproperty tracking device (by pressing a button, the lost item is detected by sound), or a music sound system that can be turned on and off with the press of one single button. Yet another technology application offers a 'window to the world' by making video recordings of everything that goes on outside the building such as activities in the garden or the shopping centre. There is also a tool which uses a voice-recording to jog a patient's memory about issues that were discussed earlier, for example. Finally, the medicine-alarm which emits a signal to remind a patient to take his or her medication was also studied. 
B. Dementia patients' need for social contact and companionship

Telecommunication systems for informal caregivers are used to search for information

and to establish contact with professional caregivers or other informal caregivers. A

multimedia system consisting of photos, music and video clips that can be easily

operated by people with dementia is used for companionship. Technology geared

R5

towards stimulating social contact and companionship for the person with dementia is also used as an advisory resource for caregivers and can take the form of internet communication between family members and the professional caregivers or between doctors and patients.

C. The need to monitor the health and safety of patients with dementia.

There is a wide variety of technological applications that can be used to monitor people with dementia, both in terms of their state of health and their personal safety. These include sensors; examples of which are described in more detail in table 2 below, like a bed, window, noise, door, gas electricity and water sensor. 
Chapter 2

Table 2 Examples of sensor technology

\begin{tabular}{|c|c|c|}
\hline Sensor & Role & Alarm \\
\hline Bed sensor & $\begin{array}{l}\text { Detects when the person is in - or } \\
\text { out of - bed and switches the light } \\
\text { on or off accordingly. }\end{array}$ & $\begin{array}{l}\text { The alarm can also go off if someone } \\
\text { gets in or out of bed. For example, } \\
\text { this can be installed on the DECT } \\
\text { telephone of the professional } \\
\text { caregivers and even on the informal } \\
\text { caregiver's mobile phone. }\end{array}$ \\
\hline Window sensor & $\begin{array}{l}\text { Detects whether a window is } \\
\text { open or closed. }\end{array}$ & $\begin{array}{l}\text { Can emit an alarm when the window } \\
\text { remains open. }\end{array}$ \\
\hline Noise sensor & $\begin{array}{l}\text { Detects whether a specific noise } \\
\text { exceeds a pre-determined level. }\end{array}$ & $\begin{array}{l}\text { Can emit an alarm if the noise level } \\
\text { exceeds a certain level (if someone } \\
\text { shouts loudly, for example, or falls out } \\
\text { of bed at night). }\end{array}$ \\
\hline Door sensor & $\begin{array}{l}\text { Detects whether the door is open } \\
\text { or closed. }\end{array}$ & $\begin{array}{l}\text { Can emit an alarm when the door } \\
\text { remains open. }\end{array}$ \\
\hline Gas detector & $\begin{array}{l}\text { A sensor that detects whether the } \\
\text { gas is still on and in some cases is } \\
\text { also able to switch the gas off. }\end{array}$ & $\begin{array}{l}\text { Can emit an alarm when the gas } \\
\text { remains on, but also as soon as the } \\
\text { gas is switched off. }\end{array}$ \\
\hline Electricity sensor & $\begin{array}{l}\text { Detects whether electricity is } \\
\text { being used. }\end{array}$ & $\begin{array}{l}\text { Can emit an alarm if the electricity is } \\
\text { used for an unusually long time, or } \\
\text { not at all. }\end{array}$ \\
\hline Water sensor & $\begin{array}{l}\text { Detects the presence of water } \\
\text { (the sensor can be installed } \\
\text { beside the bath, for example). }\end{array}$ & $\begin{array}{l}\text { Can emit an alarm if water is } \\
\text { detected, which can happen if the } \\
\text { bath or shower starts to overflow. }\end{array}$ \\
\hline
\end{tabular}

In addition to sensors, some technology applications focus on detecting activity and inactivity. For example, a power sensor placed in a gas cooker can show when someone cooks less frequently; if necessary, additional measures can then be taken. This is one example of the ambient intelligence technology referred to earlier.

\section{Effects on behaviour}

Three studies examined the behaviour of a patient with dementia. In the study that used a motion sensor by the bed, a bed mat and a bed sensor with an SMS function, that transmitted SMS messages directly to the caregiver, the goal was to support the personal safety and normalize the sleep pattern of the partner/informal caregiver by monitoring the patient's sleep rhythm (8). However, this proved difficult because people with dementia tend to take a very long time to get in or out of bed. The sensors continuously emit signals indicating that the patient is in or out of bed, which makes it hard to interpret the patient's behaviour. In the case of the multimedia system, the 
patient appeared more active and the caregiver had more control over the discussion

(20). When the computer system that helped patients wash their hands was used,

\section{Quality of life}

In four studies the effects of the technology on the quality of life of the caregivers was examined $(5,9,15,19)$. The caregivers reacted positively towards the sensory technology. The technology makes life easier because caregivers did not have to be continuously on the look-out for possible dangers (the sensor would emit an alarm in such instances) and they could organize their time more effectively. For example, they could now go on an errand to the shops at any time of the day. However, some caregivers indicated that the technology also gave them an extra carerelated concern, because they had to remember to switch it on (9). The residents also had greater freedom of movement as a result of the sensor technology. In one of the studies, a videophone was used to give the caregivers a direct link with the professional caregivers or other informal caregivers. Through this technology, informal caregivers had fewer problems with depression and could keep up the care they were providing because they had greater confidence in their own ability (19).

\section{Job satisfaction}

In one of the studies with motion sensors in a nursing home the effects on the job satisfaction levels of the professional caregivers was examined in more detail. Job satisfaction, the perceived quality of care, personal development and internal motivation all appeared to increase in the experimental group compared to the control group. The workload and work-related stress increased in the intervention group because there was a lot more to deal with during working hours (13).

\section{End-user satisfaction}

End-user satisfaction was examined in ten studies. The informal caregivers were satisfied with technology applications such as the sensors, the information networks and the telecommunication systems. However, in the case of the sensor technology,

$\underline{\mathrm{R} 7}$

$\mathrm{R} 8$

R9

R10

$\underline{\mathrm{R} 1}$

R1

R13

R1

R1

R1

R1

$\underline{\mathrm{R} 18}$

$\underline{\mathrm{R} 1 \mathrm{~S}}$

$\mathrm{R} 2$

R2.

R2

R2

$\mathrm{R} 2$

$\mathrm{R} 2$

R2

$\mathrm{R} 2$

$\mathrm{R} 28$

R2S

R3

$\mathrm{R} 3$

R32 
it was reported that the requirement to have a computer with an internet connection to send data can sometimes be a problem. Informal caregivers were also concerned about having to fine-tune the technology to the personal wishes of a patient with dementia. The telecommunication and information systems for caregivers were perceived as being very valuable as they offer a lot of advice and information about issues relating to health care $(7,17,18)$.

Some studies focused on the views of the actual patients themselves, which were sometimes obtained through the agency of the formal or informal caregiver. It appears that patients found the GPS telephone too troublesome and bulky to take around with them, similar to the electronic bracelet, which was perceived as a nuisance. The light that automatically switches on when a patient gets out of bed also caused a lot of confusion among patients with dementia. They are not used to it and sometimes thought that someone else was in the room with them and had switched the light on. In one of the studies it was revealed that the dementia patient was more likely to accept the technology being installed in their own home if the people installing it told them that it was part of a scientific study, rather than to help them personally with their problems. When problems associated with dementia are discussed this is often experienced as stigmatization by people with dementia, in fact dementia patients often tend to deny, that they are experiencing any specific problems $(6,10-12,16,21,22)$.

\section{Functionality of the technology}

In three studies, the way in which the technology functioned was examined. The studies focused on technologies that were designed to detect when patients wandered off and consisted of a mobile phone with GPS, an electronic bracelet that transmits a signal to a pager if the patient strays out of a safe area, and a telecommunication system. The GPS technology worked well. Various incidents in which patients might have wandered off were prevented. The mobile phone did not function very well in buildings and on public transport $(10,11)$. Caregivers also carried out some memory tests on their dementia patients to measure how much they recalled and the status of their memory. They forwarded the results to the doctor. These results matched 
the findings of the doctor's own tests on the patients in $76 \%$ to $89 \%$ of the cases.

The technology also ensured that the memory tests were carried out correctly (14).

\section{Costs and savings}

In four studies, an inventory of all the procurement costs related to the technology and in fact should be cheaper than the cost of admitting a patient to a nursing home. Often, admitting a patient to a nursing home was a cheaper option than providing home-based care, which usually involved frequent and costly visits to the patient's home (7). The initial cost of procuring the technology must not be too high for those on lower incomes $(15,16)$. One study carried out over a period of 21 months showed a saving of 1.5 million pounds compared to the control group, because admission to a nursing home, hospice or hospital could be delayed and the patients could continue living independently in their own homes (5).

\section{Results of national studies in the Netherlands}

Table 3 National inventory of technological interventions for caregivers of people with dementia

1. With regard to technology requirements.

A: Requirements for help relating to the symptoms of dementia;

B: Requirements for social contact and company for the person with dementia;

C: Need to monitor the health and safety of the patient with dementia (by requirements we mean the needs of patients with dementia themselves or their caregivers as described in the study by Lauriks et al. 2007)

2. With regard to results:

D. Patients with dementia;

Z. Professional caregivers;

M. Informal caregivers (e.g. family members) 


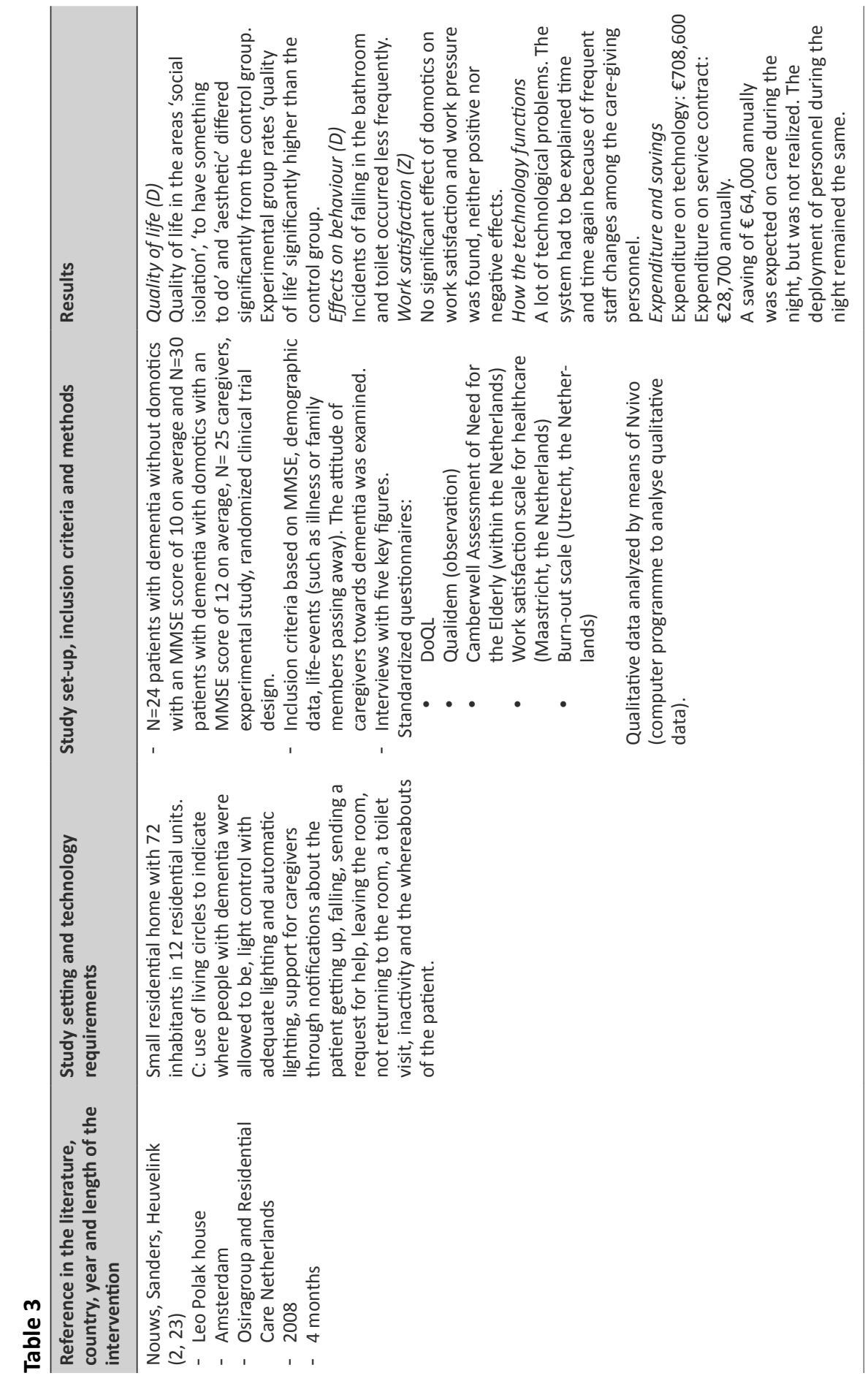




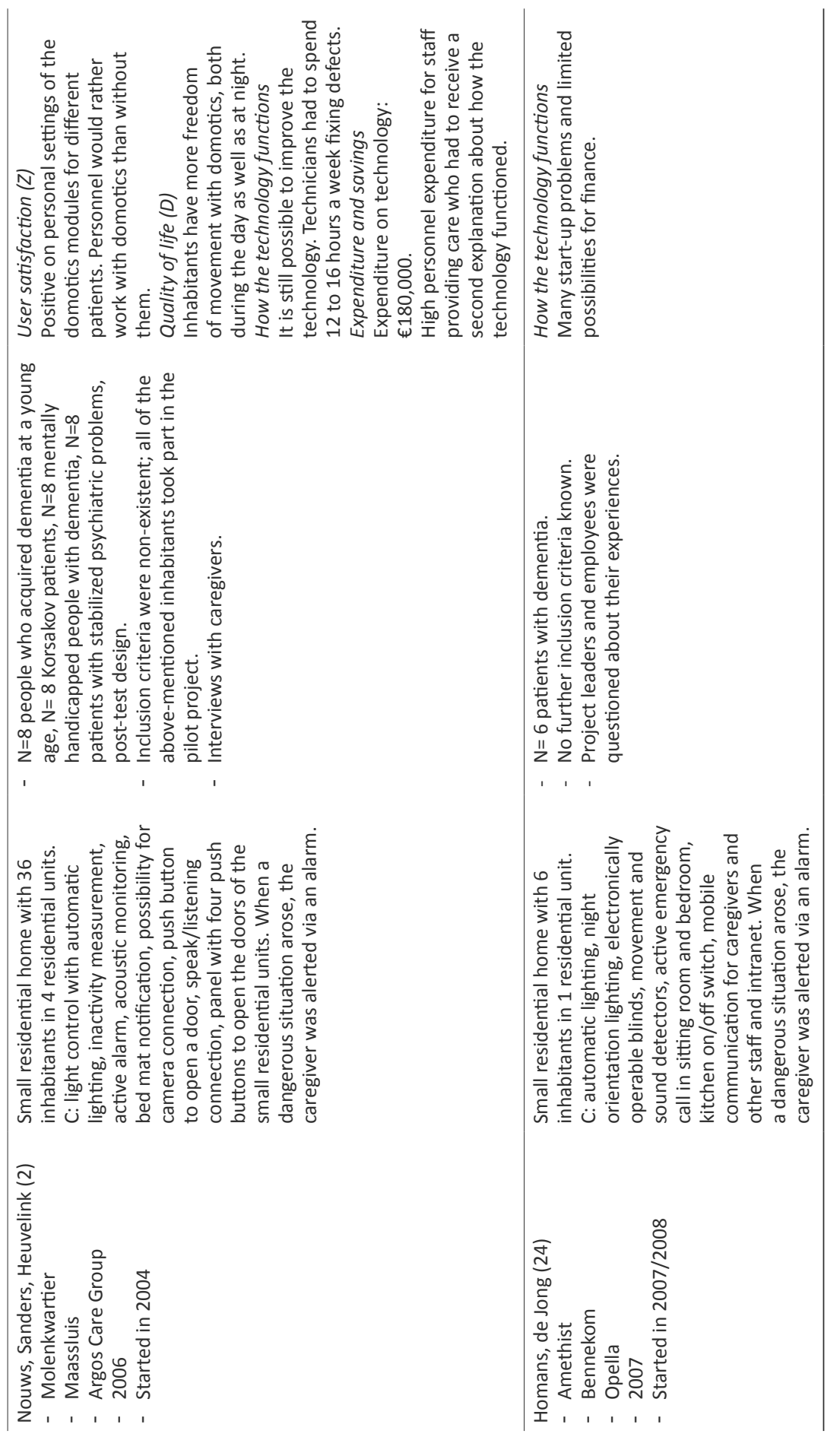

R1

R2

$\mathrm{R} 3$

R4

R5

R6

R7

R8

R9

R1C

R1

R1

R1

R1

R1

R16

R1

$\underline{\mathrm{R} 18}$

R1S

R2

R2

R2

$\mathrm{R} 2$

$\mathrm{R} 2$

R2

$\mathrm{R} 2$

R2

$\mathrm{R} 2$

$\mathrm{R} 2 \mathrm{~S}$

$\mathrm{R} 3 \mathrm{C}$

R31

$\mathrm{R} 32$

R33

R34 


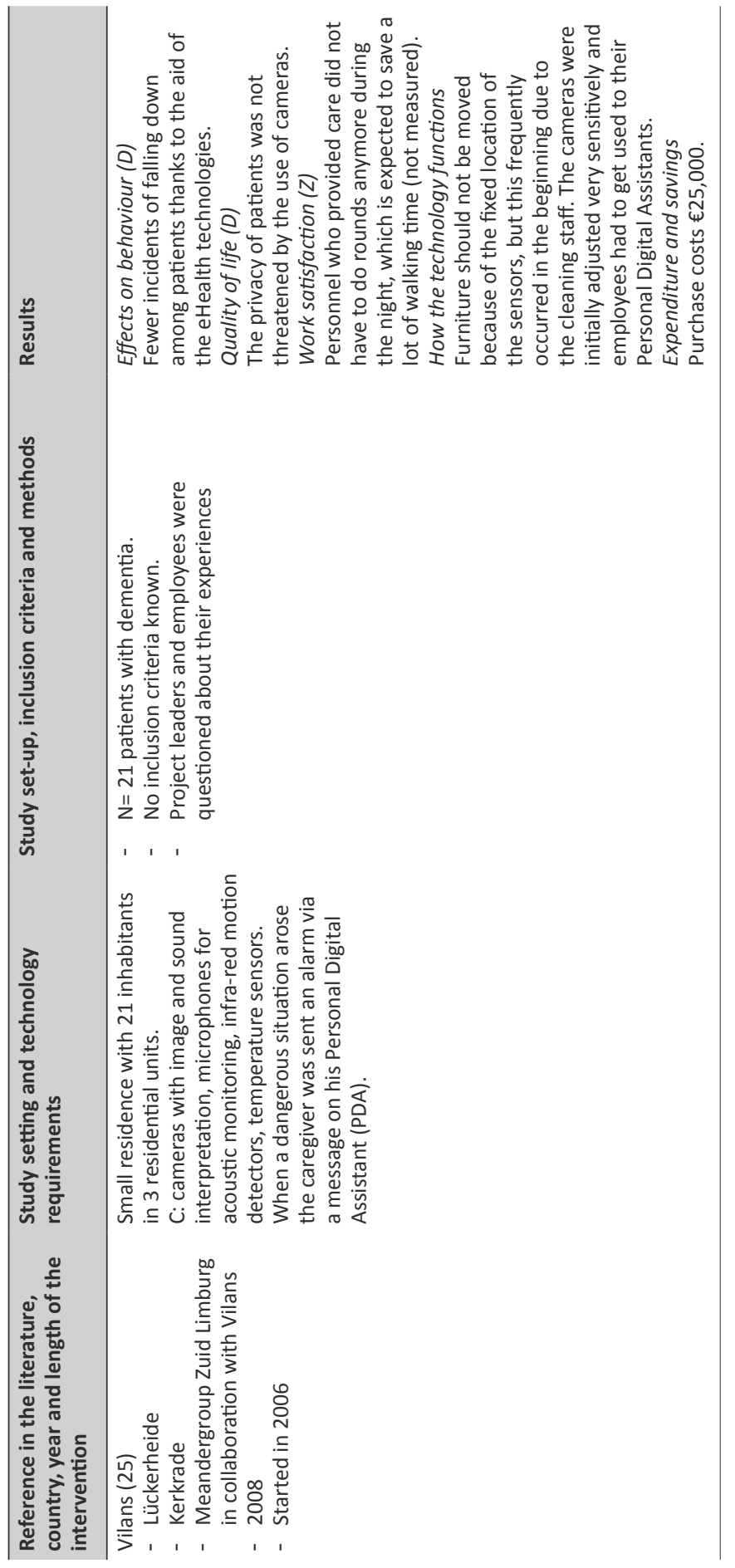




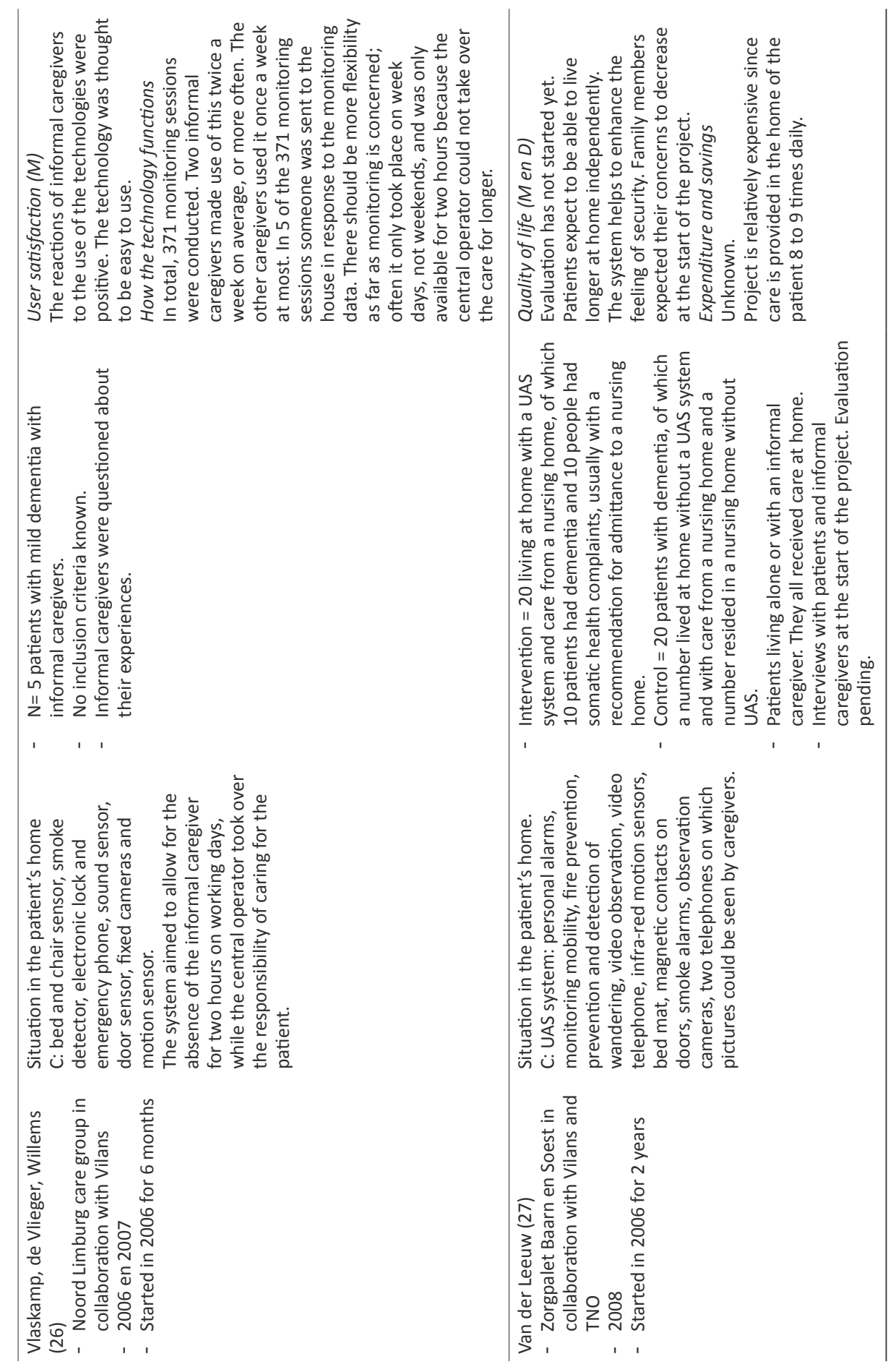

R1

R2

$\mathrm{R} 3$

R4

R5

R6

R7

2

$\mathrm{R} 8$

R9

R1C

R11

$\mathrm{R} 12$

R1

R14

R1

R16

R1

$\underline{\mathrm{R} 18}$

R1S

R2C

R21

R2

$\mathrm{R} 2$

$\mathrm{R} 2$

$\mathrm{R} 2$

$\mathrm{R} 2$

$\mathrm{R} 2$

$\mathrm{R} 2$

$\mathrm{R} 2 \mathrm{~S}$

$\mathrm{R} 3 \mathrm{C}$

R31

$\mathrm{R} 32$

R33

R34 


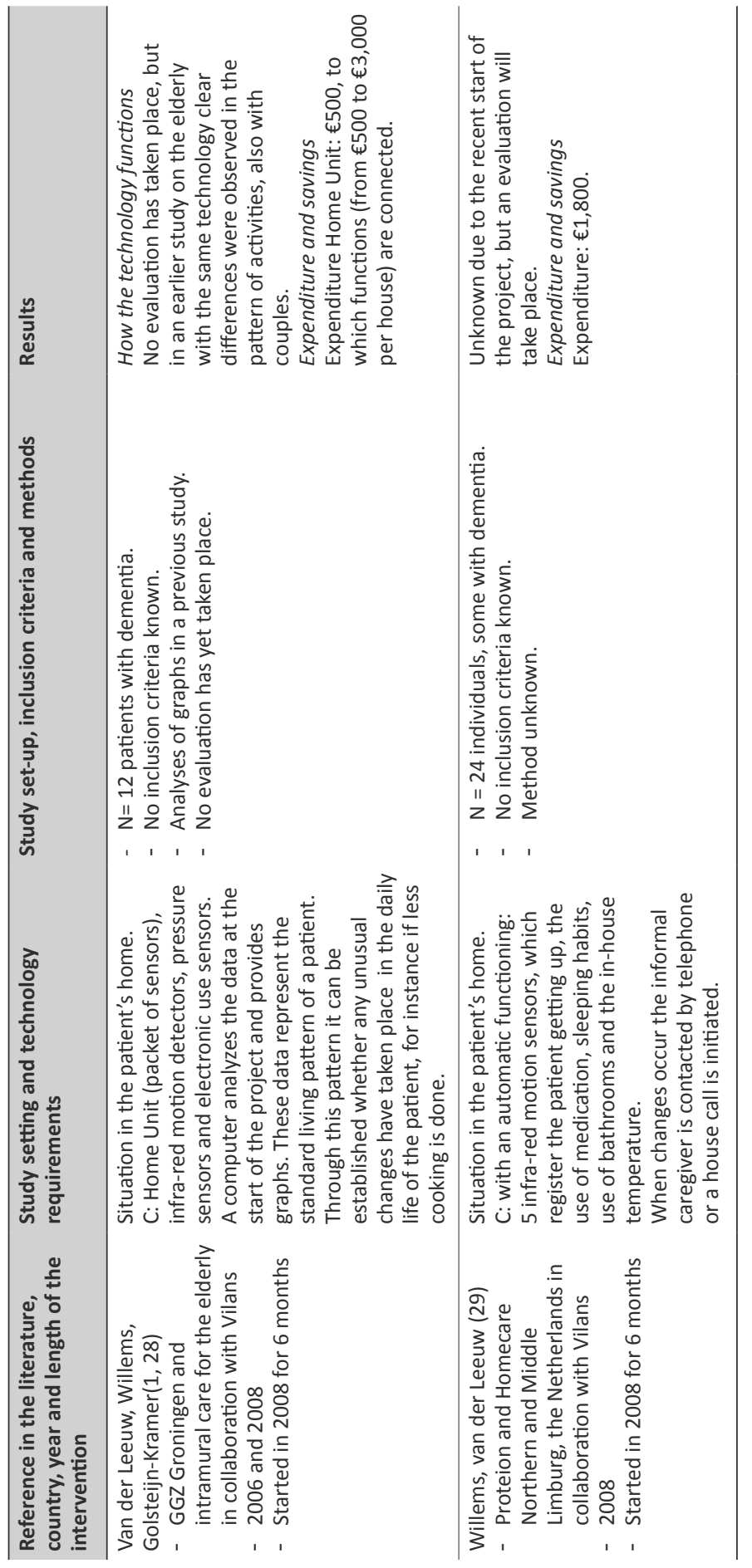


The national studies only examined those technologies that were associated with

\section{Study setting and study design}

Four studies were conducted within the setting of a small-scale residential nursing

The duration of the intervention varied from less than six months to two years (2, $24,28)$.

\section{Effects on behaviour}

The three studies in which sensor technology was examined reported the most radical behavioural changes: a drop in the number of patients falling down in the bathroom and the toilet (23), calmer behaviour and improved eating habits (24), and fewer falls (25).

\section{Quality of life}

The quality of life was examined in four studies. In one study, which took place in the setting of a small-scale residential nursing home, the quality of life improved significantly, as was subsequently tested with the help of the Dementia Quality of Life scale (DQoL) in the areas of 'social isolation', 'something to keep them occupied', and 'aesthetics', compared to the control group. Patients in the experimental group also rated their quality of life much higher than patients in the control group (23). In another small-scale residential nursing home setting, the technology gave the residents greater freedom of movement during both the day and the night. Doors were no longer locked and each patient was assigned a certain area that was considered safe for them. As soon as the patient stepped out of this area, an alarm signal was sent to the caregivers (2). The third study, which took place in a smallscale, residential nursing home setting, revealed that the personal privacy of the patients was not compromised by the cameras that had been installed. The patients 
of 28 patients who still lived at home revealed some initial findings in terms of the quality of life of both the informal caregivers and people suffering from dementia. A more extensive evaluation has yet to be carried out. However, it did appear that patients expected to be able to live independently in their own homes for longer and that the system helps to increase their sense of personal safety. At the beginning of the project, family members indicated that they had fewer worries (27).

\section{Job satisfaction}

Job satisfaction among caregivers was examined in two studies. In one study, no significant impact was indicated as a result of the domotica on the workload of the caregiver; no negative effect, but no positive effect either (23). In another study it was revealed that nightly rounds no longer had to be carried out by the caregivers any more, which was viewed as a positive outcome (28).

\section{End-user satisfaction}

User-satisfaction among healthcare staff in the nursing home and informal caregivers was examined in two studies. The caregivers indicated that they were satisfied with the way in which the home automation modules had been personalized for the different patients. They also preferred to work with the domotica technology that had been installed in the residential care home, rather than without it, because it was viewed as a support in the health sector and was very easy to work with (2). The study that focused on home-based informal caregivers revealed that they were very positive about the use of certain tools such as the video monitor, bed and chair sensors, smoke detectors, electronic lock, health telephone line, sound sensors, door sensors, permanent camera installations, and movement sensors (26). No problems were encountered with the use of the technology; they found the technology easy to apply in practice.

\section{Functionality of the technology}

All of the studies examined how the technology functioned. The most striking results are that the systems are often very expensive and that at the start of the project in particular a lot of different technical problems occur, such as the technology not 
being adequately fine-tuned to the needs of an individual patient. During the course

of the project, the technology often works much better because various adjustments

\section{Costs and savings}

In three studies the costs and savings of the project were investigated $(2,23,27)$.

The procurement costs were high. In one study, it was hoped that an annual amount of $€ 64,000$ could be saved on the cost of providing night care, however this was not achieved and the number of night-time staff employed remained the same (23). Another study indicated high staff costs as a result of repeatedly having to explain how the technology worked to new staff members. On top of this, the technical staff had to work for 12 to 16 hours each week to solve specific bottlenecks, which also incurs a lot of costs (2). In another study, the dementia patients who took part in the project had already been earmarked for a place in a residential nursing home, although it was possible to continue living at home with the help of technology, nevertheless this meant that the professional caregivers sometimes had to come along between eight or nine times a day, which was a lot more expensive than being admitted to the residential nursing home (27).

\section{Discussion}

\section{Technology}

The international literature review searched for three categories of technology using the classification drawn up by Lauriks (4). They include the following:
A. The need for help to cope with the symptoms of dementia
B. The need for social contact and companionship
C. The need for monitoring health and personal safety. 
In the national studies only the last category was examined: "The need for monitoring health and personal safety". In the Netherlands, this type of project is the most advanced, while projects that focus on "The need for help to cope with the symptoms of dementia" and "The need for social contact and companionship" are hardly ever applied in the Netherlands, or not applied at all. In the Netherlands the focus tends to be more on preventing dangerous situations from materializing, rather than improving social contact and a sense of well-being.

This literature review revealed that the technologies frequently used to help with 'The need for help to cope with the symptoms of dementia' focus in particular on supporting day-to-day activities, improving the quality of life and supporting the intake of medication. "The need for social contact and companionship" often concerns the contact between the patient, their family, and the caregivers through telecommunication or information networks. Multimedia systems for patients that enable one to view photos, listen to music, etc. also play a role here. Finally there is 'The need for monitoring health and personal safety', which came up in both the national and the international studies. In all of the studies it was all about technology that could be used to safeguard patients and raise an alarm to alert a professional caregiver in a nursing home/informal caregiver whenever a dangerous situation arose. In some cases it was also possible to get in touch with the patient during the period in which the alarm went off (for example through a speaking/listening functionality on the personal alarm).

\section{Methodology}

The majority of the studies focused on qualitative data, not quantitative data and the number of patients that took part is relatively small; an average of 12 per study (with the exception of 140 and 406 patients in two studies, respectively, who are not included in this average). Studies on the behavioural impact factors of technology applications among patients with dementia are rare. In the Netherlands there is currently no overview of technology applications that are being used for people with dementia, nor the effect that these technologies could have on them, the professional caregivers who care for them, or their 
informal caregivers. This article attempts to provide this overview, with the aim

\section{Effects}

The first results from using technology for people with dementia seem promising, studies show significant improvements with regard to the effects on patient behaviour (patients are less likely to fall down) and the quality of life for both the informal caregivers as well as the patients with dementia. For the informal caregivers, the technology made life easier, ensured that time was saved, stimulated independence and fewer feelings of depression. In addition to this, the user-friendliness of the different technologies is also good; they appear easy to use in practice. Very little research has been carried out in the area of job satisfaction. The national studies show no effects. An international study in this literature review shows definite improvements in job satisfaction for professional caregivers in residential nursing homes who work with supportive technology. The procurement cost of the technologies is usually quite high. The preliminary positive results of this literature review correspond with the results of the review of Lauriks et al. (4).

\section{Critical assessment}

Systematic scientific research into the application of technology for people with dementia has been limited, both nationally and internationally. Studies are being carried out, but these are not always evaluated in a scientifically responsible manner, nor are they systematic. Moreover, the studies often fail to show the extent to which the characteristics for a possible control group differ from with those of the experimental group. At the moment there is only one study in the Netherlands that was carried out and evaluated with the aid of scientific theories and research. This was carried out in a small-scale residential nursing home; scientific studies in the home situation are lacking. In addition, national studies usually focus on how the technology works and do not include the target group in the development of the technology. Many studies fail to determine the phase of dementia from the participating patient. Research into the job satisfaction levels of the caregivers is also absent. In addition, it remains

$\underline{\mathrm{R} 7}$

R8

R9

R10

$\underline{\mathrm{R} 1}$

R1

R13

R1

R1

R1

R1

R1

R1S

R2

$\mathrm{R} 2$

R2

R2

$\mathrm{R} 2$

$\mathrm{R} 2$

R2

$\mathrm{R} 2$

$\mathrm{R} 2$

R2

R3

R3

$\underline{\mathrm{R} 32}$ 
unclear whether the technology can ensure the postponement of admittance to a nursing home or reduce the number of the patients' visits to the doctor. The latter in particular should be the subject of further research. Fewer visits to the doctor and the ability to stay at home longer, for instance, will further stimulate the use of technology.

In short, many so-called half-baked products are now being marketed which have either not been researched at all, or only superficially researched. To some extent this is inevitable with the constant introduction of new technologies. However, it is questionable whether implementing a partially-developed technology for people with dementia is entirely without risk. Is this ethically sound? For the effectiveness of the technology it is important that professional and informal caregivers together with the patients themselves are involved with its design from the outset.

One could also wonder whether the lack of effectual studies is solely linked to the technology. There are plenty of technologies on the market that could be applied, but it is questionable whether or not the effectiveness of these have been systematically and reliably investigated. It is difficult to test the experiences and findings with people with dementia. On top of that, qualitative and experimental research is needed to measure the effect of technology on the patients' behaviour and well-being. Are the methods needed to research this in more detail missing? Or is the technology still too sparsely applied in practice? Are ethical questions hampering the application of these technologies? All of this should be researched in more detail.

\section{Recommendations}

This literature review reveals that not all of the different types of technology can be applied arbitrarily to people with dementia. People with dementia represent a very specific target group and this should be taken into account, when technology is being selected. From the initial development onwards and during the later stage of implementation, the technology has to be continuously readjusted until it meets the needs of patients and of the informal caregivers and professional caregivers. Additional research into the effects of home-based healthcare technology for people 
with dementia is required. What are the effects of these technologies for the patient

and the informal caregiver? What do these people actually need in practice? Which

methods are feasible to study the impressions and experiences of people with

dementia? This entails a lot more work than the standard market research that

usually takes place following the introduction of a new technology. In the following

R5

chapters we focus on the evaluation of monitoring and signalling technologies as described in the introduction. 


\section{References}

1. van der Leeuw JJ. Domotica voor thuiswonende mensen met dementie. Stand van zaken. Utrecht: Vilans,2008.

2. Nouws H, Sanders L, Heuvelink J. Domotica voor dementerenden. De eerste ervaringen in het Leo Polakhuis te Amsterdam en het Molenkwartier te Maassluis. Amersfoort: De Vijfde Dimensie, 2006.

3. van der Leeuw JJ. Ambient intelligent- technologie in de (woon) zorg. Utrecht: Vilans,2007.

4. Lauriks S, Reinersmann A, van der Roest HG, Meiland FJ, Davies RJ, Moelaert F, Mulvenna MD, Nugent CD, Dröes RM. Review of ICT based services for identified unmet needs in people with dementia. Aging Research Reviews. 2007;6(3):223-46.

5. Woolham J. Safe at Home. The effectiveness of assistive technology in supporting the independence of people with dementia. London: Hawker publications; 2006.

6. Adlam T, Faulkner R, Orpwood R, Jones K, Macijauskiene J, Buraitiene A. The Installation and Support of internationally distributed equipment for people with dementia. IEEE Transactions on Information Technology in Biomedicine. 2004;8(3):253-7.

7. Kinney JM, Kart CS, Murdoch LD, Ziemba TF. Challenges in caregiving and creative solutions: using technology to facilitate caring for a relative with dementia. Ageing International. 2003;28(3):295-314.

8. Vilans. Verenigde Staten: Univerisiteit van Florida, Alzheimerwatcher. Utrecht, 2006 [cited 2008 June 5]; Available from: http://www.domoticawonenzorg.nl/smartsite. dws?id=103539.

9. Kinney JM, Kart CS. Not quite a panacea: Technology to facilitate family caregiving for elders with dementia. Technology Innovations and Aging. 2006;30(2):64-6.

10. Miskelly F. A novel system of electronic tagging in patients with dementia and wandering. Age and ageing. 2004;33(3):304-6.

11. Miskelly F. Electronic tracking of patients with dementia and wandering using mobile phone technology. Age and ageing. 2005;34(5):497- 518.

12. Orpwood R, Sixsmith A, Torrington J, Chadd J, Gibson G, Chalfont G. Designing technology to support quality of life of people with dementia. Technology and Disability. 2007;19(2-3):103-12.

13. Engstrom M, Ljunggren B, Lindqvist R, Carlsson M. Staff perceptions of job satisfaction and life situation before and 6 and 12 months after increased information technology support in dementia care. Journal of Telemedicine and Telecare. 2005;11(6):304-9.

14. Lee JH, Kim JH, Jhoo JH, Lee KU, Kim KW, Lee DY, Woo Jl. A telemedicine system as a care modality for dementia patients in Korea. Alzheimer Disease \& Associated Disorders. 2000;14(2):94-101.

15. Duff $P$, Dolphin C. Cost-benefit analysis of assisitive technology to support independence for people with dementia - Part 2: Results from employing the ENABLE cost- benefit model in practice. Technology and Disability. 2007;19(2-3):79-90.

16. Cahill S, Begley E, Faulkner JP, Hagen I. Findings from Ireland on the use and usefulness of assistive technology for people with dementia. Technology and Disability 2007;19(23):133-42.

17. Czaja SJ, Ruber MP. Telecommunications technology as an aid to family caregivers of persons with dementia. Psychosomatic Medicine. 2002;64(3):469-76.

18. Mahoney DF. A content analysis of an Alzheimer family caregivers' virtual focus group. American Journal of Alzheimer's Disease. 1998;13(6):309-16. 
19. Finkel S, Czaja SJ, Schulz R, Martinovich Z, Harris C, Pezzuto D. E-Care: A Telecommunications technology intervention for family caregivers of dementia patients. American Journal Geriatry Psychiatry. 2007;15(5):443- 8.

20. Astell AJ, Ellis M, Alm N, Dye J, Campbell J, Gowans G. Facilitating communication in dementia with multimedia technology. Brain and Language. 2004;91(1):80-1.

21. Mihalidis A, Carmichael B, Boger J, Fernie G, editors. An intelligent environment to support aging-in-place, safety, and independence of older adults with dementia. Ubi Health symposium: The 2nd International workshop on Ubiquitous Computing for Pervasive Healthcare Applications; 2003.

22. Orpwood R, Gibbs C, Adlam T, Faulkner R, Meegahawatte D. The design of smart homes for people with dementia- user interface aspects. Universal Access in the information society. 2005;4(2):156-64.

23. Lauriks S, Osté JP, Hertogh CMPM, Dröes RM. Effectenonderzoek naar de toepassing van domotica in kleinschalige groepswoningen voor mensen met dementie. Amsterdam: GGD, 2008.

24. Homans $\mathrm{H}$, de Jong R. Opella, ondersteuning op maat. Wageningen: Opella; 2007 [cited 2008 June 6]; Available from: http://www.imtech.eu/eCache/DEF/5/538.bGFuZz1lbg. pdf.

25. Vilans. Groepswoningen/ verpleeghuis Lückerheide. Kerkrade2008 [cited 2008 June 6]; Available from: http://www.domoticawonenzorg.nl

26. Vlaskamp F, de Vlieger S, Willems C. Pilot Monitoring gedrag. Advies aan Zorggroep Noord Limburg. Hoensbroek: iRv, 2006.

27. van der Leeuw JJ. Pilot met unattended autonomous surveillance (UAS) van TNO. Utrecht: Vilans, 2008.

28. Willems C, Golsteijn-Kramer D. Lifestylemonitoring. Mogelijkheden voor innovaties in de zorg. Hoensbroek: iRv,2006.

29. Willems C, van der Leeuw J, editors. De praktijk: domotica voor thuiswonende mensen met dementie. Evaluatie Leo Polakhuis; 2008; Ede. 


\section{Chapter}

Monitoring technology at home:

An evaluation of preventive sensor technology for dementia care

Chapter 3 is based on: Nijhof N, van Gemert-Pijnen JEWC, Woolrych R, Sixsmith A. An evaluation of preventive sensor technology for dementia. Journal of Telemedicine and Telecare. 2013. doi: 10.1258/jtt.2012.120605

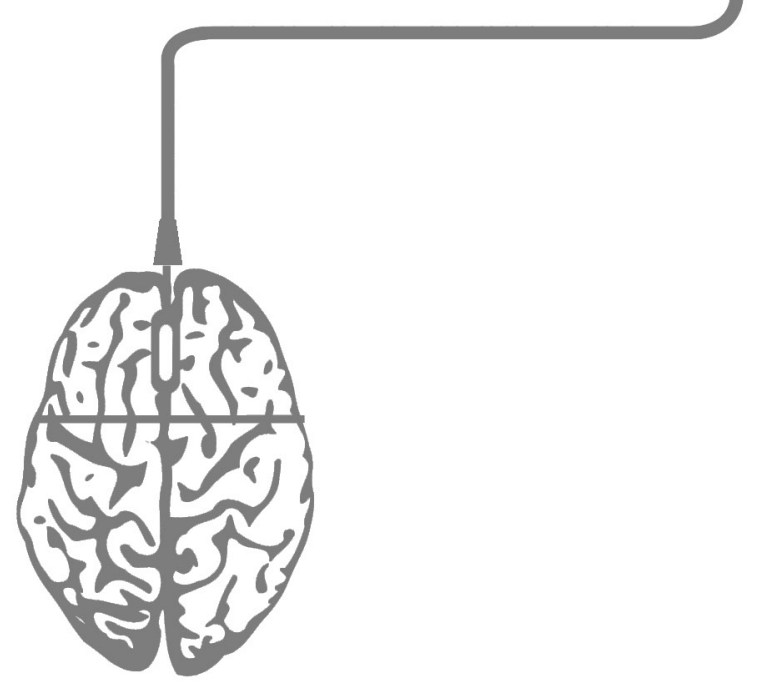




\section{Abstract}

The ADLife preventive technology system is a commercially-available monitoring technology, designed as an early warning system for older people with dementia living at home to detect problems before they require crisis intervention. This paper presents the results of an evaluation of ADLife over 9 months with 14 clients in two healthcare organisations in the Netherlands. A mixed-method approach was used, involving interviews with formal and informal caregivers, researcher observations during project group meetings, analysis of nurse diaries and a cost analysis. Clients and informal caregivers reported enhanced feelings of safety and security as a result of having ADLife installed within the home. The system also reduced the burden of care upon the informal caregiver and provided the potential for supporting older people to live at home for longer. The cost analysis showed savings for clients staying at home with ADLife compared with the costs of staying in a nursing home. For 10 clients living at home two months longer as compared to clients residing in a nursing home, the savings were $€ 23,665$, while projected savings for 50 clients were $€ 124,122$. A process evaluation highlighted a number of key recommendations for the future design and implementation of the ADLife technology: improving operation and design issues related to the storage and presentation of the system data; better organisational support and education for the formal caregiver; removal of barriers to the widespread adoption of the technology in care delivery. 
In 2010 an estimated 35.6 million people worldwide were living with dementia, with projections suggesting that this figure will rise to 115.4 million by 2050 (1). The global costs of providing care and support for those living with dementia in 2010 was 604 the direct costs of social care (community care and residential home) contributing a similar proportion of these overall costs (42\%), contrasting with direct medical care costs which account for only $16 \%$ of total costs (1). There is widespread recognition that innovative approaches are required to meet the demands that will be placed upon formal and informal care systems in the future (2) and to promote the independence and well-being of an ageing population. The emergence of assistive technologies is one such area of development, yet relatively little is known about their effectiveness (3). This is particularly evident with technologies for people with dementia who often have varied and complex needs that require flexible and responsive supports (4). This paper presents the results of an evaluation of the commercially- available ADLife preventive technology system, designed as an early warning system to detect problems before they require crisis or emergency intervention, such as admission to hospital or institutional care.

The ADLife system is installed in the home of the older person and compromises a gateway with an alarm button, three door sensors, electronic usage sensor, bed mat sensor, chair mat sensor and a movement sensor, which registers the pattern of a person's behaviour within the home. The gateway sends this information to a server through an analogue telephone line which can be accessed remotely by a formal caregiver who is able to use the readings to assess the condition of the older person and as a support for clinical decision-making. The formal caregiver from the participating healthcare organization contacts the person with dementia or an informal caregiver (such as a friend or family member) if changes in activity occur which might indicate a problem (5). To our knowledge, this is the first scientific published study evaluating the ADLife system. A case study evaluating the ADLife system has been conducted in the Netherlands, but has not been scientifically published (6). The key findings 
were that ADLife had the potential to generate valuable information that could be of benefit when supporting those with dementia, but that the interface for healthcare professionals to interpret the data needs to be more user-friendly, if it is to become an acceptable part of the working practices of formal caregivers.

Delivering support for those living with dementia brings about specific challenges to the older person and those that care for them (7). Currently, generalized service provision does not satisfy the more specialized needs of people with dementia and their caregivers, which can result in increased distress, loss of skills amongst older people and caregiver breakdown (8). Research indicates that technology may provide a useful tool for supporting older people within the home environment, reducing the care burden on informal caregivers, whilst encouraging patient education and self management $(9,10)$. Current dementia care services often fail to deliver care when it is needed, requiring a more customized and flexible approach to service delivery. Research has demonstrated that the use of technology within the home environment can better support people with dementia and their caregivers through promoting independent living, earlier identification of problems and improved self-monitoring $(9,11-15)$. The use of intelligent home monitoring systems has been associated with enhanced feeling of safety and security for older people (16).

Research also suggests that assistive technologies can assist older people in staying at home for longer, which is more cost effective than admission into a hospital or care facility (17). The largest global evaluation of telecare technologies identified a range of benefits, including reduced mortality rates, reduced hospital admission, reduction in emergency admissions and reduced tariff costs (18). Despite these benefits, concerns remain in respect to individual choice, privacy, risk-taking and the quality of the technology, which have implications for policy and practice (19). Despite their potential (20), there has been very little empirical evidence to justify the widespread adoption of telecare systems $(21,22)$, particularly in respect to people with dementia. Moreover, the market is still undeveloped and the care industry has only recently begun to apply recent technological developments to dementia care (23). To partly address the research shortfall, the evaluation addressed the following questions: 
- How was ADLife installed and introduced within the homes of clients?

- How was ADLife introduced within the participating healthcare organization?

- In what ways did the formal caregivers use the ADLife system within their everyday working practices?

- How was ADLife evaluated in relation to the usability of the system?

- What was the impact of ADLife in terms of interventions, well being and

The evaluation used a mixed methods approach which involved interviews with informal and formal caregivers, analysis of project group meetings and diaries from two nurses who worked daily with ADLife. The informal caregivers were interviewed at the start, after 3 and after 9 months of using the technology. The formal caregiver was interviewed only once, at the 9 month stage, prior to the end of the evaluation. Analysis of cost savings compared the costs of staying at home with the technology against those costs accrued through a nursing home admission.

\section{Methods}

Van Gemert et al. (2011) provide an eHealth research roadmap that identifies the need for a holistic approach to the research and development of eHealth technologies, including contextual inquiry, value specification, design, operationalization and summative evaluation. This approach suggests that eHealth impact should be determined by the extent to which the intended objectives of the technology are realized. To this end, the evaluation of ADLife focused on (i) technology uptake: usage behaviour and usability and (ii) the technology impact: care interventions, client wellbeing, impact upon informal caregivers and cost savings. As ADLife was already an operational system, a summative evaluation of the technology implementation and subsequent operation and maintenance was conducted. This approach was adopted because the introduction and implementation of the technology can have an impact on subsequent usability and acceptability by end-users (24). Data collection at month 3 was undertaken with service users to establish the early barriers and facilitators to the adoption of the system, while further evaluation at month 9 was undertaken with 


\section{Research design}

A field trial was conducted in the homes of 14 older people with dementia from April to December 2010. The same suite of sensors was installed in each home, at similar locations within the home environment, although exact room layout differed. Two homecare organizations in the Netherlands participated in the evaluation. The first homecare organization was involved in initiating the evaluation (by financing the evaluation and assisting in the design of the objectives), and were part of a project group that also included researchers. This organisation was actively involved in recruiting and interpreting the ADLife client data. The clients recruited from this organization were regularly visited for personal guidance and education on their dementia by the formal caregivers and were also engaged as project group members. The second homecare organization only participated in recruiting clients for the evaluation, and did not participate in the project group or in the interpretation of the data.

\section{Study participants}

The inclusion criteria for clients participating in the evaluation was that they currently received homecare (housekeeping, nursing, personal guidance), but they were not all personally known to the formal caregiver who interpreted the data. The clients did not all commence their involvement at the same time as there were delays in recruiting clients from the homecare organizations; three clients commenced later in the project and did not participate for the full trial duration of 9 months (one participated for a duration of 4 months, one for 7 months and one for 8 months). The formal caregivers selected clients diagnosed with dementia with a forecasted expectancy to live at home for a minimum of 9 months. This was a subjective assessment undertaken by the same two formal caregivers interpreting the ADLife data (for the first organization) and by the team leader (for the second organization). The age of the participants ranged from 58 to 87 years with a mean of 78 and the MMSE ( $1=$ severe dementia and $30=$ no dementia) ranged from 13 to 29 with a mean of 23. The fourteen participants consisted of six females and eight males, seven participants were recruited from the first homecare organization and seven from the second homecare organization. 
The formal caregivers (two nurses, occupational therapist, specialist elderly care

medicine, project manager, technician and research assistant) participated in the

project group and reports of their meetings were used as data to determine their

opinions of ADLife. Two female nurses who worked daily with the ADLife system

were interviewed and asked to keep a diary. Both had a college-level education and

$\underline{\mathrm{R} 5}$

each had worked for the organization for 27 years. The project group members were

all female, except the technician, two of whom were college-level educated and

five were university educated. All formal caregivers, except the technician, had no

Fourteen informal caregivers included four partners of ADLife clients (three living in the same house as the client), four daughters, one daughter in law and five sons. Their ages ranged from 35-79 years and gender distribution was eight females and six males. The total number of years spent caring for the client ranged from less than 1 year to 12 years with a mean of 4.2 years.

\section{Using ADlife}

The formal caregivers monitored the ADLife sensor data for six weeks to establish typical daily activity patterns of clients. These typical patterns then allowed the formal caregivers to identify changes which might require an intervention. During this time they received initial training in how to read and interpret the data. Following this, the data were monitored for duration of nine months (trial length) by the formal caregivers. The formal caregiver was required to contact the person with dementia or a nominated informal contact person (friend or family member) if deviations in the normal activities of the client highlighted the need for intervention. Algorithms within ADLife generated a "red alert" to highlight sudden deviations in the thresholds for each client. The data collected from the ADLife system can be seen on the website screenshots in figures 1 and 2. Figure 1 shows daily data for the specific sensors, where darkest grey (normally red) indicates a situation requiring intervention (as can be seen on December 8, 2011 for the movement sensor in the bathroom, row 5), light grey (normally yellow) identifies a potentially emerging situation and middle 
the last 28 days, allowing for a longitudinal interpretation. Figure 2 shows the activity data from one sensor across the duration of one day, providing an example of when a client has been located in the hallway, determined by a movement sensor. Figure 3 is activity from one sensor for different hours which describes the number of activities in the hallway during that time period.

\begin{tabular}{|l|c|c|c|}
\hline \multicolumn{1}{|c|}{ Activity } & $08-12-2011$ & last 7 days & last 28 days \\
\hline PIR Slaapkamer & 3.0 & 5.1 & 6.2 \\
\hline Bedmat & 0.0 & 4.1 & 8.6 \\
\hline Senseo Koffiezetter & 15.0 & 13.6 & 12.1 \\
\hline PIR Badkamer & 3.0 & 4.9 & 5.9 \\
\hline Voordeur & 9.0 & 6.3 & 5.6 \\
\hline Tussendeur Kamer/Hal & 44.0 & 40.1 & 32.4 \\
\hline Koelkast & 29.0 & 17.7 & 18.1 \\
\hline Bank links & 0.0 & 0.0 & 0.0 \\
\hline Toilet & 11.0 & 13.4 & 14.3 \\
\hline PIR Eethoek & 20.0 & 18.6 & 14.7 \\
\hline
\end{tabular}

Figure 1 Data screenshot ADLife, dark grey (normally red) =emerging situation, light grey (normally yellow) = slightly emerging situation and middle grey (normally green) =no emerging situation.

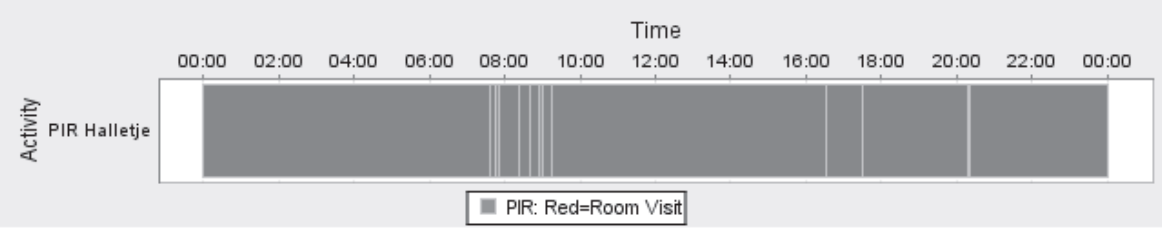

Figure 2 Data screenshot ADLife, with daily activities at a specific time in the hallway.

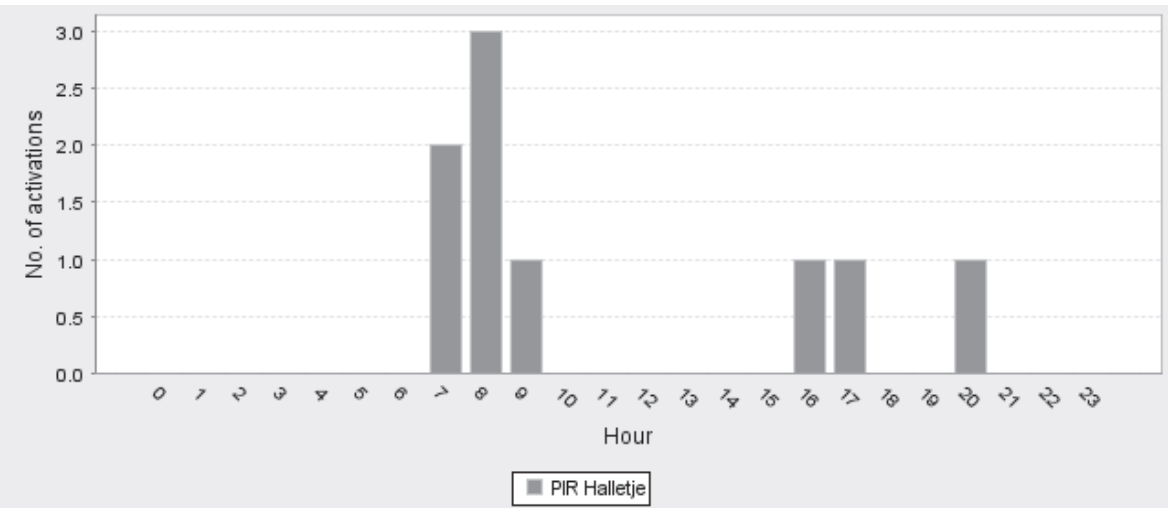

Figure 3 Data screenshot ADLife with the number of activities on a specific time in the hallway. 
A total of 38 semi-structured interviews were conducted with informal caregivers; 13

of these were undertaken immediately prior to using the technology, 11 follow-up interviews were conducted at or after the three months stage and 14 post-interviews were conducted. As three participants joined the study at a later stage, a decision $\underline{\mathrm{R} 5}$ was made not to conduct the month 1 and month 3 interviews. For one informal caregiver, the interview at month 3 was not conducted due to personal reasons. Undertaking interviews with clients was considered, but not conducted because of $\underline{\mathrm{R} 8}$ the levels of cognitive impairment. However, in some cases the client was present at the interview with the informal caregiver and also contributed to the discussion.

All participants were provided with an information sheet describing the aims and objectives of the evaluation and a consent form was signed where participants agreed for their comments to be used in the publication of the research findings. For those clients engaged in the trial who were unable to provide their consent due to an advanced stage of dementia, their informal caregivers were asked to sign on their behalf. A semi-structured interview guide was used which included the following topics: implementation of ADLife system, usability of the technology, impact on care intervention and effects on well being, as key dimensions defined in the CeHRes roadmap (24). All interviews were tape recorded and transcribed for analysis purposes.

\section{Interviews and diaries with formal caregivers}

An interview at the end of the evaluation was conducted with the two nurses that worked with the ADLife system daily, using an adapted semi-structured interview guide from the one used for the informal caregivers but which focused more specifically on the impact of technology on the working practices of caregivers and the usage behaviour of ADLife. All the interviews were tape recorded for analysis purposes. The two nurses were asked to keep a diary of their usage of ADLife, comprising columns for the date, readings for any deviant or abnormal data from the sensors, subsequent contact initiated with client or contact person, action taken as a result and general operational issues (for example if a sensor was not working 
or the data were not visible on the website). Nurses were asked to keep records for individual clients. As the trial progressed, the nurses did not maintain the use of all fields in the diaries due to the level of additional work, but the data were used in the evaluation and as a stimulus within the interview situation to discuss specific cases.

\section{Project group meetings}

The researcher was a member of the project group and recorded the key findings and action points from the meetings of the group. In total there were 8 project meetings over a period of 14 months (the first project group meeting was 4 months prior to client recruitment). All the formal caregivers signed a consent form agreeing that the content of the meetings could be used in the evaluation and in subsequent publications. In these meetings, the evaluation specifically focused on recording information related to caregiver experiences whilst using the ADLife system.

\section{Cost analysis}

A key objective of the evaluation was to determine the costs of living at home with ADLife, compared with living in a nursing home. Costs (in euro) included:

- Cost of living in a nursing home. In the Netherlands there is a legally fixed price for the expenses of a person with dementia living in a nursing home and this figure was used;

- Cost of purchase and installation for ADLife sensors;

- Initial fee for activating ADLife (not related to number of clients);

- Monthly fee for the use of ADLife per client (including troubleshooting service);

- Average monthly cost for homecare per client;

- Average monthly cost per user (formal caregiver required to interpret the data);

- Average monthly cost of formal caregivers for analysing ADLife data per client (number of hours multiplied by the wages of the caregivers). 


\section{Data analysis}

The interviews with the informal and formal caregivers were thematically analyzed

(25), which involved reading the transcripts several times and subsequently identifying and coding recurring themes across the transcripts. A second researcher also coded the interviews to minimize single researcher bias. The notes from the project group $\underline{\mathrm{R} 5}$ meetings and the data from the caregiver diaries were also thematically analyzed. For the cost analysis a number of calculations were undertaken in Excel 2007:

- Total governmental expenses of someone living at home with technology;

- Total governmental or health insurance expenses for someone living in a nursing home;

Comparison between living at home with technology and living in a nursing home:

- Calculations for a comparison of 10 clients up to 150 clients (in increments of 10);

- Calculations for a comparison from 1 month up to 12 months of living at home or in a nursing home;

- Calculations for the use of ADLife at home with increasing costs of homecare.

\section{Results}

The evaluation provided a number of key results: the introduction of ADLife, the usage and usability, the impact on care interventions, the wellbeing of the clients and informal caregivers and the cost analysis.

\section{Introduction of ADLife}

The research findings indicated that the way in which ADLife was introduced to caregivers and users needed to be improved. As formal caregivers had no prior experience with the system they had problems clearly describing ADLife during the recruitment process. Subsequently, informal caregivers had misconceptions about ADLife which impacted on levels of acceptability:

- Perception that ADLife would work as an alarm, for example when a client 
- Perception that the movements of the older person might be visible through real time video images, when in actuality only frequency of sensor activation was recorded. This resulted in two informal caregivers deciding not to participate because they felt the system was too intrusive.

- $\quad$ Being unaware of the minimal costs to the client involved in transferring the client data across the server. Although this was not seen as an issue which would influence their decision to have the system installed, they felt that they should have been informed from the outset.

These results highlight the need to fully inform clients and informal caregivers prior to installation. This could be undertaken by skilled technicians, but it was felt that this information would better come from the formal caregivers, given their role in delivering care and their regular interaction with ADLife. Effective training is required if formal caregivers are to be in a position to reassure clients, address everyday issues and challenge perceptions of privacy and confidentiality and ensure better levels of acceptability.

Informal caregivers also reported a number of issues relating to the presence of ADLife within the home environment. Some clients appeared unsettled by noises and flickering lights from the ADLife base unit, potentially raising concerns about deteriorating health. The informal caregivers felt that a user manual would have been helpful in alleviating concerns and providing information and guidance. This further highlight the importance of patient education. While this could be provided by a technician, it is more meaningful when provided by the formal caregiver, such that the technology becomes more situated in the context within which care is being delivered.

A number of issues were also reported within the project team meetings. The formal caregivers commented that they felt isolated and 'all alone in the project', because other formal caregivers outside the project group were not aware of the ADLife evaluation. This deprived formal caregivers of an outlet to share their experiences and the challenges of being involved in the trial. Whilst it was the responsibility 
of the internal project manager to publicize the project across the healthcare,

time constraints hindered her progress. This resulted in the feeling amongst

A number of the informal caregivers felt ADLife was unnecessary, because the clients were only experiencing mild forms of dementia and did not require any intervention. However, some caregivers suggested that installing the sensors prior to the onset of more serious dementia was advantageous, as the client had the mental capacity to understand the purpose of the sensors, be more able to gain proficiency in the workings of the system and be in a position to exercise individual choice when agreeing to have the equipment installed. Embedding the system at an early stage has the potential to increase levels of acceptability in the long-term, as opposed to introducing the technology as a reaction to a sudden deterioration and often when the patient is not in a position to 'learn' new technology.

\section{Usage and usability of ADLife}

At the beginning of the evaluation, the formal caregivers experienced difficulties in reading and interpreting the client data. A manual was not available that provided guidelines for how to analyze the data readings and output graphs, and a technician was required to provide extra training, which was judged positively by the nurses.

For most of the 'deviations in data' which required an intervention, the formal caregiver contacted the informal caregiver as opposed to the client themselves. Whilst excluding the client might potentially undermine the autonomy of the older person, informal caregivers were often key stakeholders in the decision-making process. The was an issue discussed in the interviews. Informal caregivers felt more informed 
information within the context of the clients' condition. Informal caregivers felt that this communication could have been a more regular, systematic aspect of the care delivery process. However, formal caregivers felt it was inappropriate to share client details (regarding their health and well-being) with the informal caregivers, given issues of privacy and confidentiality. This raises the broader issue of which individuals have access to ADLife data and the extent to which this should be shared across different groups to assist in the decision-making process. Whilst the relationship between the informal caregiver and the older person is an important aspect of care delivery, the sharing of data is a sensitive issue, given that the older person may not wish to share personal or private information.

Formal caregivers reported that the act of interpreting the ADLife data was valuable in providing a better understanding of the home context of individual clients. An example of this was a client who had a housekeeping service on a specific day, which triggered an alert by ADLife. The two nurses reading the data requested information from the organization responsible for housekeeping to provide further details on their participating clients, so they could better monitor activity in and out of the home. Thus, the system had the potential to generate data which stimulated a form of enquiry that further strengthened the knowledge of the caregiver, thus establishing a more holistic understanding of the client.

The in-built email alerts provided by ADLife to the caregivers was reported as being valuable to ensure continuous monitoring of the older person. Given their time commitments nurses were often only able to directly access the ADLife data twice per week, and the alerts provided an extra layer of security for the older person and ensured a timely response. ADLife had the potential to 'fill the gaps' between caregiver visits, furnishing the formal caregiver with information to which they previously had no access.

Formal caregivers suggested possible improvements to the interface of the ADLife website which would promote overall usability and included: 
- The graphs for each sensor were only visible for the specific day being

monitored, whilst the caregivers felt it would have been useful to see data from previous days to identify long-term trends.

- A number of the bars in the graphs were too small, making them difficult to interpret.

- The meaning of some bars was not intuitive, preventing easy readability of the data.

There were a number of initial operational issues which impacted on the reliability and accuracy of the data. The most commonly reported operational issue was that the data were not transferred, resulting in formal caregivers being unable to access information on the condition of the patient, raising the possibility that they would not be alerted to situations which require intervention. Second, continuous transmission of data through the telephone line prevented the client from making outgoing telephone calls. This was a source of frustration and anxiety for a number of clients and was resolved by adding a redundant server, while a restriction was put on the number of attempts for sending the data. Third, a number of the bed mat sensors were particularly sensitive, reporting higher number of bed visits than was the case, and had to be replaced several times before the readings were reliable. Although formal caregivers were able to remove outliers in the data (through their knowledge of the client), this had the potential to generate 'false positives', providing caregivers with erroneous data when making important clinical decisions. These 'teething' issues created a feeling that the data were unreliable, undermining confidence in using the system as a decision-making tool.

Informal caregivers felt that ADLife would be more useful if it also monitored emergency situations, for example to identify a fall event, rather than as a preventive tool. This would require combining the monitoring of long-term trends with an alarm response system to alert the authorities when in need of assistance. The future development of ADLife may consider the potential to integrate an alarm response system within the existing system architecture, or to combine with existing technologies currently on the market. 
Finally, the formal caregivers commented that it would be valuable if clients were able to inform them when fluctuations from the typical ADLife data could be expected (for example, leaving the house to visit friends for the day). In this way formal caregivers would know that they do not have to unnecessarily respond. However, requesting input from the user should not challenge the freedom and autonomy of the older person such that it creates a feeling of dependency each time the older person wishes to leave the home or deviate from 'normal' patterns of activity.

\section{Impact of care interventions}

Although not quantitatively proven, formal caregivers in the project group believed ADLife could assist those living with dementia to remain at home for a longer period of time, as the system provided the possibility for earlier, timely interventions to reduce the need for hospital visits and delay admittance to nursing home care. For example, when the ADLife data demonstrate that an older person is not cooking their own meals independently, then a meal service can be implemented. The formal caregivers noted that they were unable to visit and observe clients every day and may not be aware of the rapidly changing needs of the older person and an alert could provide a prompt recommending early intervention.

In this project, two 'situations' occurred where ADLife data prompted 'just in time care' in contrast to 'just in case care'. In the first situation, a person was identified from the sensor data as sleeping in his chair in front of the television instead of his bed, prompting informal caregivers to commence a 'bedtime' service. This involved calling their father on the telephone to prompt him to go to his bedroom. In the second situation a person was identified as not using the salt dispenser, which was in the closet with a door sensor, normally the client always used this for cooking. This identified that the person was not eating hot meals anymore. This prompted the caregivers to implement a meal service for the client. Thus, ADLife data combined with the experience of both the formal and informal caregiver prompted interventions to address the deteriorating condition of the client. Conversely, the formal caregivers mentioned that if a person can prepare their own meals and the sensors show evidence of this, then it would be possible to discontinue the meal service. Thus, 
ADLife has the potential to support the person-centred needs of the older person,

tailoring service provision to the emerging needs of the client and not one that

\section{Impact on well-being}

Whilst concerns of privacy were expected to be raised as a result of the visibility of sensors within the homes of the clients, informal caregivers reported that most clients were not aware of the sensors in the home, even when they witnessed the installation. They reported that the small size of the ADLife sensors ensured that they quickly became an acceptable feature of the home environment immediately following installation. For those clients who were aware of the sensors, ADLife afforded a sense of safety and security, knowing that they were being monitored by the formal caregiver and that the caregiver was in a position to respond if there was any notable deterioration in condition.

A particular concern amongst clients and caregivers is that dementia is characterized by periods of forgetfulness which can compromise health and well-being. One of the clients, who was conscious that she experienced episodes of forgetfulness, often failed to remember to undertake important everyday tasks which were important, for example taking medication or remembering to eat. Having a system which alerted caregivers to deteriorations in condition provided the client with a perception that there was an additional 'security net', which was continuously monitoring him. Whilst this can be deemed a positive feature of the system, further work is necessary to determine if this may be a disadvantage over time, if the older person develops an over-reliance upon the system as opposed to acting independently. However, ensuring that older people are supported within their home was seen as integral to older people retaining a sense of personhood, providing a private domain to express their freedom and autonomy. If ADLife could provide an useful tool in helping people 
Chapter 3

delivery) then this was seen as beneficial to the welfare of the older person.

\section{Impact on well-being of the informal caregiver}

In addition to the safety and security benefits highlighted by formal caregivers and clients, the informal caregivers reported that ADLife alleviated their anxieties and concerns when they were not able to undertake personal visits or make telephone calls. Although the caregivers did not report a reduced burden of care, the system was seen as supportive to the tasks they carried out, freeing up their time to engage in activities and tasks that were restorative of their well-being. One of the caregivers mentioned that she felt more comfortable spending time outside, for example shopping or visiting a friend. Another informal caregiver reported that they would feel more comfortable going away on holiday, knowing that the formal caregivers were assisted with ADLife and could monitor the client in their absence. This reduced the necessity for informal caregivers to make contact with the clients everyday, reducing the demands on their time and alleviating worry. However, further investigation is required to establish if the use of ADLife would reduce visits from friends and family members, and the impact that this will have an on the overall well-being of the older person given the importance of face-to-face social contact. ADLife appeared to have no direct impact on supporting caregivers with those care giving tasks which caused the greatest burden, such as grocery shopping, contacting service providers, and managing the clients' finances. One of the caregivers reported that in some circumstances ADLife may even provide an extra burden of care, given that the sensors might detect certain situations where additional care was required, requiring further caring responsibility.

A number of the caregivers commented that they valued the extra information provided from the ADLife sensors, providing them with additional information through which they were able to establish a more nuanced understanding of the activity patterns and conditions of the person they were caring for. For example, to identify if the person they are caring for is as active as they say, using the ADLife system as a form of validation to confirm self-reports by the older person. Others used ADLife to provide more specific information on behaviours and movements as 
related to the condition of the older person. For example the number of times that

one of the clients living with prostate cancer had frequented the toilet during the day. While ADLife can provide a more holistic picture of health and well-being of the

Other caregivers reported that the person they were caring for did not experience any situations which directly required an intervention. However, they did feel that the system could potentially be useful if the state of dementia of the client was to deteriorate, requiring closer monitoring and more frequent intervention. For one client, the ADLife system highlighted deteriorations in health status and condition, such as a disturbed sleep rhythm, which might provide a useful piece of information in deciding when it was appropriate to admit the client to a nursing home. This demonstrates that assistive technologies can be powerful decision-making tools in their own right, yet also highlights the potential dangers arising from decisions that are based solely on the output from the technology, rather than balanced decisionmaking which considers the needs and rights of the older person.

\section{Cost analysis}

The cost analysis indicated savings for clients remaining at home with technology

compared with admission to a nursing home (Table 1 ). The cost calculation comprised:

Costs at home with technology: Purchase and installation (2597.75) * Number of

clients + Onetime fee (1300) + Monthly fee ADLife and homecare (2788.69)* Number

of clients*Number of months + Monthly cost formal caregiver (70.59)* Number of

clients*Number of months + Monthly costs for user (1 person) (74.17)* Number of months = Final costs living at home with homecare and technology.

\section{Minus}

Costs of nursing home: Monthly cost per client * Number of months. 
Table 1 Cost (in euro) for staying at home with technology versus staying in nursing home

\begin{tabular}{|c|c|c|c|}
\hline \multicolumn{2}{|c|}{ At home } & \multicolumn{2}{|c|}{ Nursing home } \\
\hline Type & Cost in euro & Type & Cost in euro \\
\hline $\begin{array}{l}\text { Purchase and installation } \\
\text { ADLife per client }\end{array}$ & 2597.75 (one time cost) & $\begin{array}{l}\text { Monthly fee } \\
\text { per client }\end{array}$ & 5413.86 \\
\hline $\begin{array}{l}\text { Onetime fee for starting with } \\
\text { ADLife (not related to number } \\
\text { of clients) }\end{array}$ & 1300 & & \\
\hline $\begin{array}{l}\text { Monthly fee ADLife per client } \\
\text { (including troubleshooting } \\
\text { service) }\end{array}$ & 67.50 & & \\
\hline $\begin{array}{l}\text { Average monthly cost for } \\
\text { homecare per client }\end{array}$ & 2721.19 & & \\
\hline $\begin{array}{l}\text { Average monthly cost per } \\
\text { user (person reading out the } \\
\text { data). In this project } 1 \text { person. }\end{array}$ & 74.17 & & \\
\hline $\begin{array}{l}\text { Average monthly cost formal } \\
\text { caregivers for using ADLife } \\
\text { per client }\end{array}$ & 70.59 & & \\
\hline Subtotal per client: & $\begin{array}{l}2597.75 \text { onetime fee } \\
4233.45 \text { per month }\end{array}$ & & \\
\hline Total: & $\begin{array}{l}2597.75 \text { (one time) }+ \\
4233.45 \text { (per month) }+1300 \\
\text { (one time fee not related to } \\
\text { number of clients) }\end{array}$ & Total & 5413.86 \\
\hline
\end{tabular}

Compared to staying in a nursing home, for 10 clients living at home with ADLife for duration of two months, the savings were $€ 23,665$, while for 50 clients the savings were $€ 124,122$ (Figure 2). The black line demonstrates the forecasts for 10 clients and the grey line for 50 clients. On the $y$-axis, the amount of savings in euro can be seen and the $x$-axis displays the number of months living at home as opposed to the nursing home. 


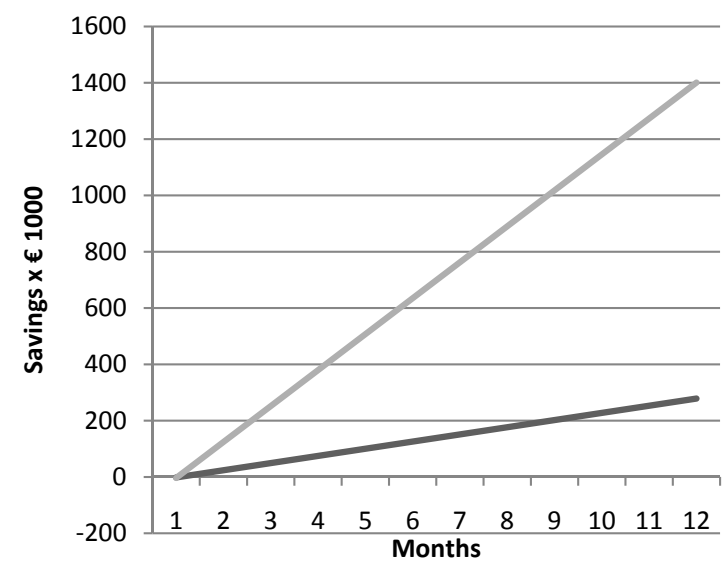

Figure 4 Cost for staying at home minus staying at a nursing home (y-axis=savings in euro and

If the quantity of home care has to be increased (given an expected deterioration in condition as the person ages), there will eventually be a breakeven point at which a nursing home is less expensive than the private home. For example, if a client in the Netherlands receives 15 hours of homecare, 4 hours of housekeeping service, 3 hours of personal guidance and visits to a day-care centre totalling 20 hours a week, this will result in approximately $€ 5000$ of monthly care. This approximates the maximum which can be spent on homecare before a nursing home becomes more cost effective. With this amount of homecare, the cost savings for 10 clients can only be reached after a duration of 10 months staying at home compared to living in a nursing home (as can be seen in figure 5). If the homecare expenses increase above the $€ 5000$ a month it will be more cost effective for an older person to be admitted into a nursing home. 


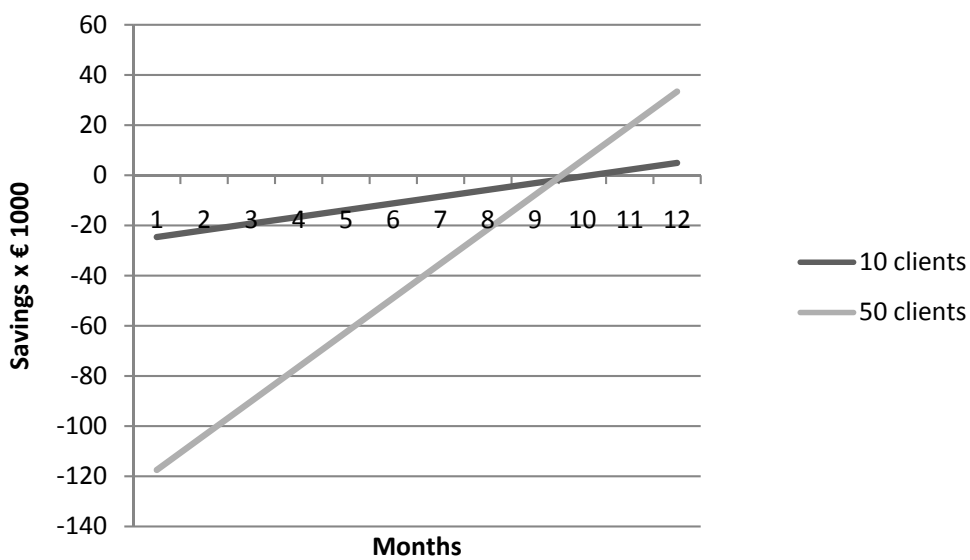

Figure 5 Cost for staying at home with $€ 5000$ homecare in a month minus staying at a nursing home ( $y$-axis=savings in euro and $x$-axis=months)

\section{Discussion}

Overall this evaluation demonstrated promising results for the adoption of ADLife within the homes of older people living with dementia and the potential of the system to act as a supportive decision-making tool for formal and informal caregivers. The evaluation indicates that ADLife has considerable potential in supporting people with dementia through increased feelings of safety and security for the client and through ongoing monitoring of the condition of the older person, which is comparable with results of other studies in the field of dementia and technology $(9,11-16)$. As evidenced in other research (6), ADLife provides a potentially useful tool to assist in the decision-making process to enable older people with dementia to remain at home for a longer period of time, through the provision of an early warning system to detect a situation before it requires emergency intervention. ADLife provided the potential to deliver more personalized care and achieve cost savings when compared to costs of staying in a nursing home. These savings are more pronounced when projected for an increased number of clients or when clients use ADLife over a longer period of time. However, the literature on ageing-in-place suggests that the home environment is a locus of meaning for the older person, as a place where they can retain a sense of independence and well-being (17). The privacy of older people living 
at home may be compromised through the use of monitoring technologies (19), as

the ways in which the information was generated, shared and made visible to others

was a concern. Those responsible for commissioning care should consider both the

The issue of innovation and deployment of technologies such as ADLife also emerged as a key issue. Technology adoption requires top-down support from the homecare organization to provide formal caregivers with the capacity and flexibility to integrate ADLife within their everyday working practices. Technologies have the potential to change the care delivery process, and formal caregivers need the freedom within their role to 'learn' how to best utilize the technology such that it yields efficiency savings and becomes an integral part of the care delivery routine. Organizational commitment is also required to 'push' the technology, such that it is seen by formal caregivers, clients and informal caregivers as key component of care and is more deeply embedded in the culture of supporting older people.

In addition to organizational support, there were a number of operational and design issues which needed to be resolved before the system could be introduced and relied upon as a decision-making tool. Firstly, the data need to be presented in a way that it can be easily interpreted by formal caregivers. Formal caregivers need to be actively involved in determining the ways in which data are presented to them, in a format which supports their time constraints and the requirement to receive mobile updates of the condition of a patient whilst 'on the move'. Secondly, formal caregivers need to be appropriately up skilled such that they are in a position, where they can make best use of the client data and translate the information into action. To facilitate this, the role of the formal caregiver needs to be revisited, as they have a role to play as 'educator' to the informal caregiver and client. Thirdly, the information provided needs to be more closely aligned to the everyday concerns and decision-making requirements of formal and informal caregivers. For example, informal caregivers themselves reported that the ADLife system would function more effectively if it also incorporated an alarm response system in the event of a fall or situation requiring emergency intervention. The current iteration of ADLife 
may be perceived as technology driven, as opposed to being built around the needs of the actors and stakeholders. A closer fit could be achieved through utilizing the holistic framework of Van Gemert et al. (2011) where the various stakeholders are involved at all stages of product application and development (24). Future iterations of ADLife should consider further user involvement to ensure that the product is deeply rooted in the experiences of the various actors involved in delivering care to the older person.

While the results of the evaluation provide strong indications of the benefits of ADLife, the study had a number of limitations. Firstly, it did not provide quantitative evidence that ADLife could assist older people to avoid nursing home admission and a longitudinal study is required to assess these benefits over time. Secondly, the cost analysis was limited to a simple comparison of costs between homecare and care delivered in a care facility. The study did not include mandatory personal contributions under the Dutch system, the costs of informal care provision for those people who live at home, or implementation costs which will vary across different jurisdictions. Thirdly, the evaluation relied on the accounts of formal and informal caregivers and future work should attempt to include the perspectives of clients, even when they have dementia (26). Finally, it would have been beneficial to systematically collect data on the "traffic light" system (red-yellow-green) used to alert emerging situations for clients. These data would help in establishing the extent to which clients maintained within the stable areas of green and yellow, as well as documenting the ability of ADLife to highlight crisis situations and the subsequent responses. This would provide evidence for the potential of ADLife in terms of keeping people at home, preventing crisis interventions and subsequent cost benefits. The present study provides an excellent platform for further research on ADLife, which should include a larger cohort of participants and in-depth analysis of costs to establish the benefits/disadvantages of using such technologies in dementia care. Funding has been granted to broaden the work detailed in this paper, specifically to expand the scope and timescales of the evaluation. The evaluation methodology will be refined in light of the study limitations detailed above. 


\section{Acknowledgements}

Thanks to the healthcare organization "Bruggerbosch", "de Posten" and the company

Focus Cura BV for their support in conducting this evaluation. 


\section{References}

1. Wimo A, Prince M. World Alzheimer Report. London: Alzheimer's Disease International, 2010.

2. Bharucha AJ, Anand V, Forlizzi J, Dew MA, Reynoalds CF, Stevens S, Wactlar H. Intelligent Assistive Technology Applications to Dementia Care: Current Capabilities, Limitations and Future Challenges. American Journal of Geriatric Psychiatry. 2009;17(2):88-104.

3. Wherton J, Monk A. Technological opportunities for supporting people with dementia who are living at home. Journal of Human Computer Studies. 2008;66(8):571-86.

4. Cash M. Assistive technology and people with dementia. Reviews in Clinical Gerontology. 2003;13(4):313-9.

5. Tunstall. ADLife An Activities of Dailiy Living (ADL) monitoring Yorkshire: Tunstall UK; 2009 [cited 2011 December 21]; Available from: http://www.tunstall.co.uk/assets/ literature/solution\%20sheets/adlife_solutions_sheet.pdf.

6. Willems C. Team 290 Lifestyle Monitoring. Utrecht, The Netherlands: Vilans; 2009 [cited 2011 December 20]; Available from: http://www.domoticawonenzorg.nl/ smartsite.dws?ch=def\&id=134101.

7. Brown J, Hillan J. Dementia. Edinburgh: Churchill Livingstone; 2004.

8. Bamford C, Bruce E. Defining the outcomes of community care: the perspectives of older people with dementia and their carers. Ageing and Society. 2000;20(5):543-70.

9. Cahill S, Begley E, Faulkner JP, Hagen I. "It gives me a sense of independence"Findings from Ireland on the use and usefulness of assistive technology for people with dementia. Technology and Disability. 2007;18(2-3):133-42.

10. Carswell W. A review of the role of assistive technology for people with dementia in the hours of darkness. Technology Health Care. 2009;17(4):281-304.

11. Lauriks S, Reinersmann A, van der Roest HG, Meiland FJ, Davies RJ, Moelaert F, Mulvenna MD, Nugent CD, Dröes RM. Review of ICT based services for identified unmet needs in people with dementia. Aging Research Reviews. 2007;6(3):223-46.

12. Nijhof N, van Gemert-Pijnen JEWC, Dohmen D, Seydel ER. Dementie en technologie. Een studie naar toepassingen van techniek in de zorg voor mensen met dementie en hun mantelzorgers. Tijdschrift voor Gerontologie en Geriatrie. 2009;40(3):113-32.

13. Topo P. Technology studies to meet the needs of people with dementia and their caregivers.A literature review. Journal of Applied Gerontology. 2009;28(5):5-37.

14. Duff P, Dolphin C. Cost-benefit analysis of assisitive technology to support independence for people with dementia - Part 2: Results from employing the ENABLE cost- benefit model in practice. Technology and Disability. 2007;19(2):79-90.

15. Cahill S, Macijauskiene J, Nygård AM, Faulkner JP, Hagen I. Technology in dementia care. Technology and Disability. 2007;19(2-3):55-60.

16. Sixsmith A. An evaluation of an intelligent home monitoring system. Journal of Telemedicine and Telecare. 2000;6(2):64-72.

17. Tinker A. Housing for elderly people. Reviews in Clinical Gerontology. 1997;7(2):171-6.

18. Department of Health. Whole system demonstrator project: headline figures. 2011 [cited 2012 January 23]; Available from: http://www.dh.gov.uk/en/ Publicationsandstatistics/Publications/PublicationsPolicyAndGuidance/DH_131684.

19. Percival J, Hanson J. Big brother or brave new world? Telecare and its implications for older people's independence and social inclusion. Critical Social Policy. 2006;26(4):888909. 
20. Kubitschke L, Cullen K. ICT and Ageing European Study on Users, Technologies and Markets. European Commission; 2010 [cited 2012 June 6]; Available from: http:// www.ict-ageing.eu/ict-ageing-website/wp-content/uploads/2010/D18_final_report. pdf.

21. Barlow J, Singh D, Bayer S, Curry D. A systematic review of the benefits of home telecare for frail elderly people and those with long-term conditions. Journal of Telemedicine and Telecare. 2007;13(4):172-9.

22. Meyer I, Muller S, Kubitschke L. AAL markets: knowing them, researching them. Evidence from European Research. In: Augusto JC, Huch M, Kameas A, Maitland J, McCullagh P, Roberts J, Sixsmith A, Wichert R, editors. Handbook on AAL for Healthcare, Well-being and Rehabilitation. Amsterdam: IOS press; 2012. p. 346-68.

23. Sixsmith A. New technologies to support independent living and quality of life for people with dementia. Alzheimer's Care Quarterly 2006;7(3):194-202.

24. Van Gemert-Pijnen JEWC, Nijland N, Ossebaard HC, van Limburg AH, Kelders SM, Eysenbach G, Seydel ER. A holistic framework to improve the uptake and impact of eHealth technologies. Journal of Medical Internet Research. 2011;13(4):e111.

25. Braun V, Clarke V. Using thematic analysis in psychology. Qualitative Research in Psychology. 2006;3(2):77-101.

26. Sixsmith A, Hammond M, Gibson G. Quality of Life and dementia. In: Vaaram M, Pieper R, Sixsmith A, editors. Care-related Quality of Life in Old Age. New York: Springer; 2008. p. 217-33. 


\section{Chapter 4}

Monitoring technology residential care:

How assistive technology can support dementia care: a study about the effects of the IST Vivago watch on patients' sleeping behavior and the care delivery process in a nursing home

Chapter 4 is based on: Nijhof N, van Gemert-Pijnen JEWC, de Jong GEN, Ankone JW, Seydel ER. How assistive technology can support dementia care:

a study about the effects of the IST Vivago watch on patient's sleeping behavior and the care delivery process in a nursing home. Technology and Disability. 2012; 24 (2): 103-115. doi:10.3233/TAD-2011-0339

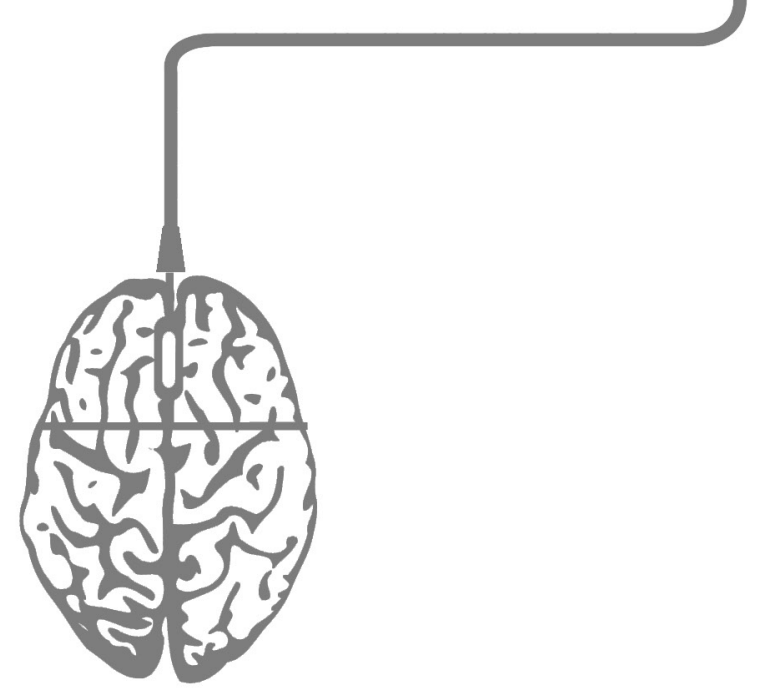




\section{Abstract}

In this study, patients with dementia who exhibited a disturbed sleep/wake rhythm wore a special watch which measured their sleep/wake rhythm. The main purpose of this study was to gain insights into the effects of the watch on the sleep/wake rhythm and on the care delivery process of patients with dementia. The research questions focus on the introduction of the watch, its usage and usability, the interventions that have been taken based on using the watch and the effects of the watch on the sleeping behaviour of the patients. These questions were answered by means of a mixed methods design: monitoring data about the sleep/wake rhythm, keeping a diary about usage and care interventions related to the monitoring data; observations, and in-depth interviews with caregivers about the implementation and usage of the watch. It can be concluded that the watch has the potential to improve the sleeping behaviour and the care delivery process. However, if the effects are to be up scaled, a supportive infrastructure and adequate communication channels and conditions for implementation, such as the possibility to try the technology, will be required at first. 
The use of technology for people with dementia has received a lot of attention in recent years due to the rapid rise in the number of people being diagnosed with dementia. Worldwide, an estimated 35.6 million people suffered from dementia in 2010. By 2050 an increase of 115.4 million is expected. In $201057.7 \%$ of all people with dementia are expected to live in low and middle-income countries, rising to $70.5 \%$ in 2050. The global costs for dementia in 2010 were 604 billion US dollars (1).

Sleeping problems are common for people with dementia. Ancoli-Israel (2005) reported that patients with dementia have increased sleep fragmentation (periods of being awake), longer sleep onset latency (length of time from wakefulness to sleep), decreased sleep efficiency (minutes of sleep compared with minutes of being in bed), decreased total sleep time (hours of sleep), and decreased slow wave sleep (deep sleep). These changes in sleep result in excessive daytime sleepiness, night-time wandering, confusion and agitation (sun downing)(2). When compared to patients who live in their own homes, patients who live in a nursing home have an even poorer quality of sleep, longer sleep onset, more phase-advanced sleep periods, and a higher use of sedative-hypnotics (3). The psychological and medical causes for sleeping problems among people with dementia are not only related to the illness, but are also linked to getting older (4). Poor sleep patterns correlate with issues such as health complaints, mental problems, a poorer subjective quality of life, and an increased risk of having an accident or falling down (5-7). Support for these sleeping problems is still urgently needed; one possible solution could be the supportive use of technology.

Different studies show that technology can be supportive in caring for people with dementia (8-13). Nijhof et al. conducted a literature review in 2009 into how different kinds of technology can support dementia care. The technologies used to support dementia care can be divided into monitoring, signalling and social contact technology for people with dementia. It can be concluded that technology can 
less falling down). Effects related to supportiveness in the caregivers' work in a social care setting have not been researched in any great detail in these studies (10).

The limitation of the studies mentioned in this review is that they only deal with small groups of patients. On top of this, the studies often focus on the end-users' satisfaction with the technology used, but not on the overall impact the technology has on the organization of care and fulfilling the needs of the patients, their informal caregivers and the professional caregivers. The overall conclusion that can be drawn from the reviews is that the majority of projects are too technology-driven, a mismatch exists between dementia patients' needs and the existing technologies, and that there is an even worse implementation strategy for the use of the technology in the nursing home.

Despite the shortcomings of the above-mentioned studies, the use of technology in the field of caring for patients with dementia is necessary because of the growing number of patients and the dwindling number of healthcare professionals. The use of technology for vulnerable people in particular should be the focus area in eHealth research. The gaps in existing eHealth research in general can be found in the field of 'missing best practice guidelines', for the effective development and absence, of any deployment strategies. There are a lot of ongoing eHealth initiatives, but the number of evaluations being generated is rather small (14-16). Next to the evaluation of an eHealth application, in the view of van Gemert et al. (2011) the development of eHealth is intertwined with implementation. Implementation must be taken into account right from the start, but upcoming implementation issues should also be accounted for in the subsequent stages. The usability has his impact on the use of the system also (17).

When looking into the research gaps described above in more detail, this research specifically examines the subjects of these gaps in a study that focused on people with dementia. Given the aforementioned limitations, this study therefore focused on the critical factors required for creating a match between technology, its users and the context of usage $(14,16,18-20)$. The focus in this research is how the watch has been implemented and used, as well as the preliminary effects of the watch (21). 
The technology used in this specific study is a monitoring technology: the IST Vivago

watch as mentioned by Nijhof et al. (2009). It measures the sleep time, sleep periods

and circadian rhythm of the person who is wearing the watch. The Vivago watch has

been used before in several studies to measure whether the watch was comparable

with polysomnography and actigraphy; it showed comparable results $(22,23)$. In an

$\underline{\mathrm{R} 5}$

earlier study with the IST Vivago watch, a comparison was made between nursing

R6

home residents who did not suffer from dementia and those who did, because

people with dementia often have sleeping problems. The residents with dementia

were found to have a lower daytime activity $(p=0.05)$ and higher nocturnal activity

studies have been carried out to date regarding the implementation of the watch and the effects on the healthcare delivery process. This study will focus on these subjects using the following research questions:

- How was the watch introduced in the nursing home?

- How was the watch used by patients and caregivers?

R1:

- How was the usability of the watch and the system judged by the caregivers?

- What kind of interventions did the caregivers carry out as a direct result of using the watch?

- What kind of effects were observed relating to the effect on sleeping behaviour and the care delivery process?

\section{Methodology}

\section{System description}

In this research monitoring technology for patients with severe dementia who were

living in a nursing home has been used. As these patients are not capable of using the IST Vivago Watch seems to be the most appropriate option. The Vivago watch, 


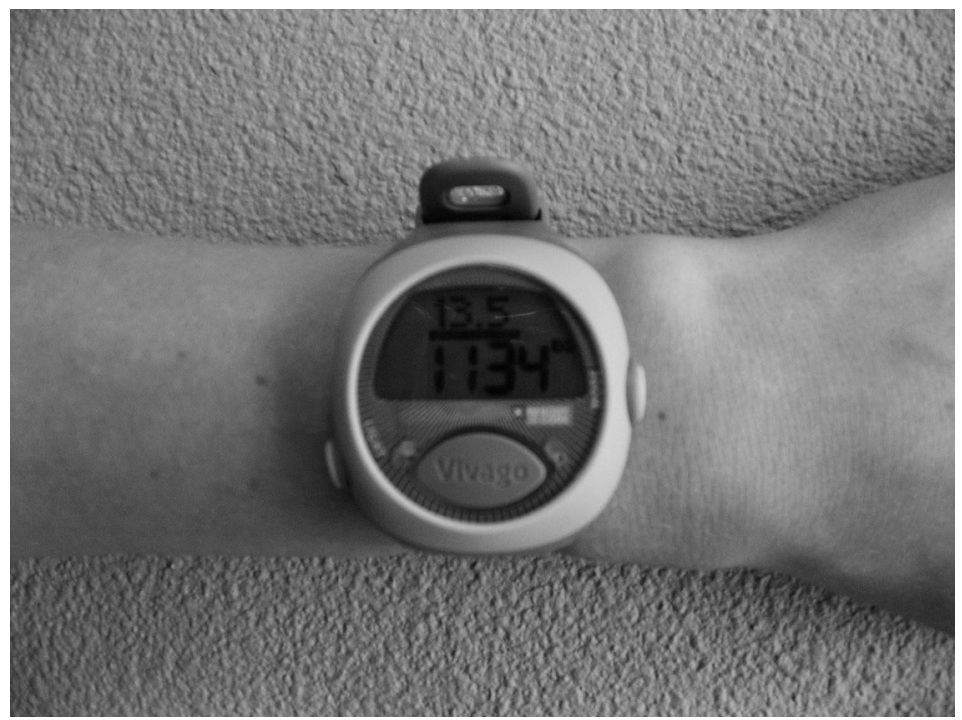

Figure 1 IST Vivago watch

The micro and macro movement measures the sleep/wake rhythm. An accelerometer is embedded into the system. This is a sensor which measures the acceleration of the wrist and the time-frame of this acceleration. The Vivago watch measures this with a frequency of 33 times per second. This creates a curve which is opposed to a calibration from 0 to $100 \%$. This calibration is created by an auto-learning algorithm which recognizes a patient's sleep pattern, their waking hours and their movements after 4 weeks.

The computer system contains several options for activating the different functions of the watch and to monitor the data it collects. In this study the only function used was the measurement of the sleep/wake rhythm for people with dementia. The social alarm system was not used because the nursing home wanted to focus on one aspect at that time. The watch gives the following measurements for monitoring: sleep period (periods asleep), sleep time and circadian rhythm (index night activity/ index mean activity). To use the Vivago watch it is necessary to have the watch, the software, a receiver and the technical installation that comes with it. The watch itself costs around $€ 315$ and the total technical installation will cost around $€ 1000$. These 
costs are only the costs of the technology itself. To implement it in the organization, an agreement of approximately 100 working hours for an external project manager than planned in order to successfully introduce the Vivago watch into the nursing home. This was mainly due to a missing internal project leader within the nursing

\section{Research design}

A mixed methods design was used. Firstly, a qualitative approach was used to collect in-depth information through observations, interviews and a diary. For the quantitative approach the monitoring data collected by the watch have been used. The research questions were answered using several methods.

- How was the watch introduced to the nursing home? Interviews

- How was the watch used by patients and caregivers? Diary, observations and interviews

- How was the usability of the watch and the system judged by the caregivers?

Diary, observations and interviews

- What kind of interventions did the caregivers carry out as a direct result of using the watch?

Diary and interviews

- What kind of effects were observed relating to the effect on sleeping behaviour and the care delivery process? 
All these methods combined gave an insight into the implementation and effect of technology in a nursing home. The data were linked to each other in the following ways:

- Diary and monitoring data; so if a specific intervention was noted in the diary, the effect of this intervention in the monitoring data was checked.

- Diary and interviews: if an intervention or remark was made and the researcher decided that he/she would like to have more information about it, then it became a question during the interview.

- Interviews and monitoring data: if a specific intervention was mentioned during the interview, the effects were checked by looking in the monitoring data in more detail, in order to see whether someone, for example, slept longer as a result of the intervention.

- Observations and interviews: aspects seen by the researcher during the observation process which needed more clarification were mentioned during the interview.

This selection of data collection methods was chosen because carrying out research with a group of people who suffer from dementia is quite difficult. Directly asking a patient with severe dementia to indicate what he or she thinks and feels about the watch is not possible. So quantitative data was used to monitor the sleeping behaviour from the perspective of patients and qualitative data was used to obtain information about the introduction, usage, interventions and effect on the care delivery process from the perspective of the professional caregivers. The integration of different methods is likely to produce more quality and scope in this research.

\section{Sample}

A total of 7 patients (out of 18) in the same department in a nursing home, which consisted of patients with severe dementia, were selected to wear the Vivago watch for a period of 6 months. Patients were selected by the caregivers using the following 
inclusion criteria: that they were living in one specific department of the participating

nursing home, that they exhibited a disturbed sleep/wake rhythm, and that they patient kept taking her watch off during night (because this was her normal day-to-

Family caregivers agreed to participate in this study and signed a consent form to observations, diary and interviews for research and publication purposes.

The caregivers were selected by their mid-level education. The interviews took place

The study included a 3-month period of using the watch which lasted from November

\section{Data collection instruments}

\section{Monitoring data}

The data gathered by the watch consisted of data which provide insights into the sleeping and waking rhythm of a person with dementia and, with that, into the effect on their sleeping behaviour. The exact data consist of measuring the sleep/ wake rhythm in minutes, the sleep periods in frequencies of periods during which that person was awake, and the circadian rhythm on a scale of 0 to 1 . The circadian rhythm measures night activity (22h-8h) divided by the mean activity (6h-24h). For healthy sleepers the outcome is between 0.1 and 0.3 , for poorer sleepers the score is between 0.3 and 0.5 , for worse sleepers it is between 0.5 and 1.0 and for the poorest 


\section{Diary}

The second method involved having the caregivers keep a diary which provided insights into the use, usability, interventions and effects of using the watch. At the start of the project, the caregiver participated in an initial didactic training course about this diary conducted by the project manager. They were given the diary for a period of three months and were instructed how to fill out the daily log sheets. The diary contained 7 columns; date, name of each individual patient, their sleep time, their sleep period, the circadian rhythm (data from the watch), possible intervention, and remarks about the watch. The caregivers were asked to report the details of all the project participants every morning. The date was given in the format of dd$m m-y y$, the name of the patient was their last name, the sleep time was written down in the total number of minutes, the sleep period in the number of periods they were awake, the circadian rhythm could be seen in the log on the computer and the possible intervention or remarks were transcribed in the caregiver's own words. The project manager contacted the caregivers each month to remind them about the daily logs and encourage them to complete them.

\section{Observations}

A qualitative and non-participatory observational study was conducted to obtain insights into the use and usability of the watch. The caregiver was observed from 10 am to $4 \mathrm{pm}$ of a normal weekday. The researcher kept a log of events and described them. The observations were based on the research questions, namely subjects such as the use and usability of the watch. The purpose of this observation was to gain a clear insight into the use of the watch in the organization and to do a contextual inquiry.

\section{Interviews}

Interviews (60 minutes) were carried out by the researcher with 5 caregivers individually to gain insights into all the research questions as a more in-depth method in relation to the other data. An interview session has three stages, orientation, interview and wrap-up. The orientation (approximately 5 minutes) included an explanation about the purpose of the interview, the caregiver could then ask any 
questions that they might have and the caregiver had to sign a consent form so the interview could be audio-taped and collect artifacts. After the orientation, the real was used with questions related to the introduction (how was the introduction and what did they think about this?), actual usage behaviour (is the way the caregiver use

\section{Data analysis}

\section{Monitoring data}

The monitoring data obtained from the IST Vivago watch were analyzed using SPSS 16.0 and Excel 2007, using frequencies for the sleep time in minutes, sleep period in the number of periods $(1 ; 2 ; 3$, etc.) and circadian rhythm in numbers between 0 and 1 ; the lower the better $(0.1 ; 0.2$ etc.). The data collected through the IST Vivago watch were analyzed in several ways. First of all the mean of the sleeping time was calculated, the mean sleeping periods, and the mean circadian rhythm for all the patients separately for the three months use of the IST Vivago watch. This means gave an impression of the sleep from the persons in this study. Within this calculation the intervention data were excluded, specifically the night after the intervention. The interventions were no structural interventions, except one intervention. The intervention of taking someone for a bath is an one-time only intervention. Because of the one-time only frequency of this occurrence it was difficult to analyze the effects of the interventions statistically. For the one-time only interventions we compared the mean with the night results from the night after the intervention. For example, did someone have a better sleep time in the night after taking a bath? These results were compared with the standard deviation for that patient. A t-test was used to compare the means before and after a specific structural intervention to conclude whether there were any significant differences in sleep-period, sleep time, and circadian rhythm. 


\section{Diary}

After a period of 3 months, the data from the diary were analyzed to count the number and type of interventions, including the names of the patients and the dates of the interventions. As noted earlier, the dates of these interventions were linked to the monitoring data. This has been done for a specific patient on the specific date of the intervention to see if the interventions had any effect on the sleep/wake rhythm. The remarks were coded in usage, usability and effects in a coding scheme for the diary.

\section{Observations}

The analysis focused on our reports of the observations. These were analyzed thematically by noting and coding each piece of information in the observation notes and allocating these to the themes of the research (actual usage and usability). This was done by two researchers who discussed and iteratively reviewed the notes into the research questions. This process involved transferring each relevant note in the coding scheme in Excel.

\section{Interviews}

For the analysis of the interviews a coding scheme in Excel has been used. The coding scheme was related to the topics based on the research subjects. The transcripts were read several times in their entirety to capture the experiences of the caregivers and to aid in identifying the coding scheme. Two researchers coded these interviews. In the event of a disagreement, the researchers discussed the categorization of the problems in order to reach consensus.

\section{Results}

\section{Sample description}

In total, $40 \%$ of the people from one single department within this particular nursing home wore the watch. Seven (7) women wore the watch and the average age of the patients was 87 years, with a minimum of 71 and a maximum of 95 years of age. All of them had entered the phase of severe dementia and were identified as bad sleepers by the caregivers. 
In total, five (5) caregivers were interviewed after they had used the Vivago watch

for a period of 3 months. These mid-level educated caregivers were all woman and the average age was 51 (age range 45-57). They were the caregivers of the people

\section{Introducing the Vivago watch}

The interviews showed us that introducing the watch to the caregivers was planned to take place at a regular team meeting. The project manager from the Vivago watch team meeting. This was especially the case because the nursing home was in the middle of a re-organization process at that time and the caregivers expected to hear something more about this re-organization instead of a protracted presentation about the Vivago watch. Moreover, the project did not start at the right time because of this re-organization. All the caregivers were sceptical at the start of the project: they did not think that the watch could be useful in their care-giving tasks.

From the interviews it appeared that several activities were carried out to introduce interested in the project themselves) and participated in the project group and received training from the project manager in how to use the watch. These caregivers

At the start of the project the caregivers themselves wore the watch as well, to let the patients get used to the watch which was judged positively by the caregiver. patient and insert these data into the healthcare record of that specific patient. During this stage, the caregivers and patients were introduced to, and began getting used to, wearing the watch and using the computer system for a period of 6 weeks.

In the interview the caregiver told us that the patients' family members were 
especially organized for this purpose. The project manager informed the family about the watch, after which family members were able to ask questions and give permission for their elderly relative to wear the watch.

\section{Usage of the watch}

The observations showed us that at the start of the day the caregivers began by writing down details of the monitoring data in the diary. Every morning they would walk down to the ground floor where the computer which contained the monitoring data was located, press the "print" button, walk to a different room to get the printout, walk back to their office on the first floor, write down the details of several patients, and place a print-out in the healthcare record of the patient in question. This way of usage can also be seen in the diary entries and interviews.

The interviews also showed us that during regular team meetings they did not discuss the watch or the interventions that were used. Not all the caregivers knew about the various interventions that had already been conducted with the different patients.

\section{Usability of the watch}

In the interviews and diary entries, the caregivers mentioned that the appearance of the Vivago watch is not user-friendly and should be improved. At the moment, the fact that the Vivago watch is far too big for the small and fragile arms of elderly people is often mentioned in the interviews. Furthermore, it was noted down in the diary that the watch has a hard strap which irritates the patients' skin when it comes into contact with water under the shower.

"The watch was too big: one of my patients has very fragile arms and her blouse couldn't go over the watch. She didn't like this at all."

"If I would be the designer of the watch I would make it with a normal clock face, because this is more familiar for elderly people - especially demented people." 
"One of our patients thought it was some kind of sports watch. That's how it looks

and so she gave it to her grandchildren. We couldn't find the watch for a week or so."

In the case of one patient they changed the strap of the watch to an 'irremovable'

strap because the patient kept removing her watch during the night. This intervention

R5

did not help because she figured out how she could open the new strap as well.

The observation showed us that the actual computer system for generating the data appeared to be easy to read and interpret for the caregivers. A screenshot of this computer system can be seen in figure 2 , with a zoom-in of the activity curves in the computer system in figure 3 . Figure 2 shows the screen the caregivers start from, for printing out the monitoring data, figure 3 shows the specific data of a patient for one week, where the part which is the horizontal stripes under the line is sleeping and the part with the peaks signifies being awake.

R1.

$\underline{\mathrm{R} 12}$
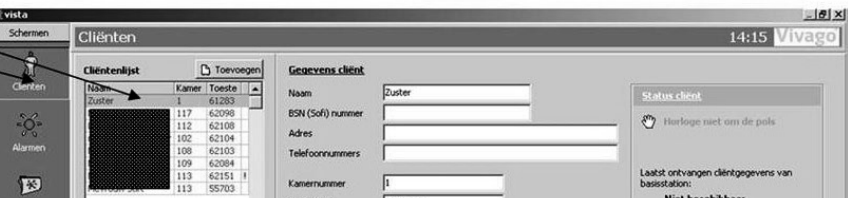

16

R17

R18

R1S

$\mathrm{R} 2$

$\mathrm{R} 2$

$\mathrm{R} 2$

$\underline{\mathrm{R} 2}$

Figure 2 Start-screen of the computer system from the IST Vivago watch 


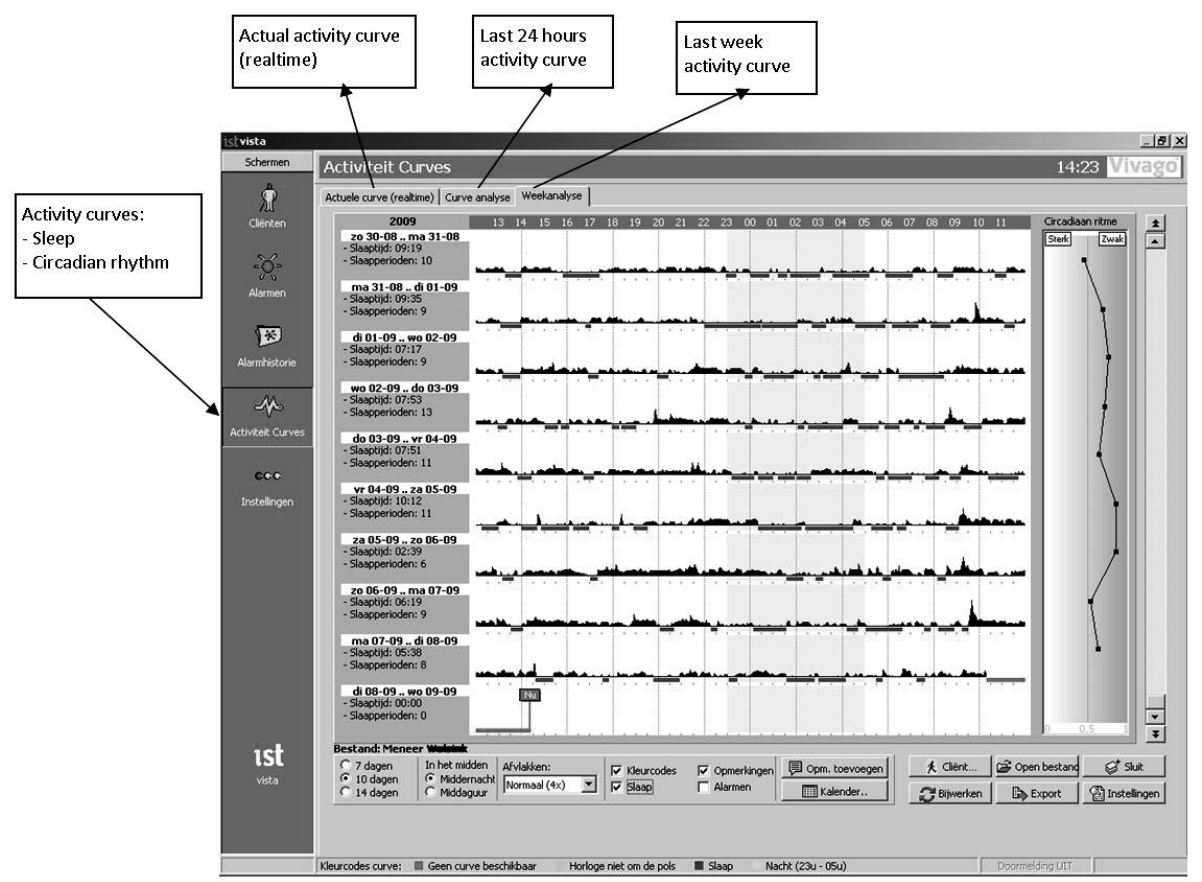

Figure 3 Activity curves screen (zoom-in screen) of a computer system from the IST Vivago watch

In the interviews the caregivers indicated that in the case of another patient, they could not believe that she really did not sleep at all during the night. The caregivers therefore used a video camera one night to monitor, whether the patient indeed did not sleep at all. The watch was proved right because the videotape also showed that the patient was not sleeping. The family members of the patient gave consent for this.

In the interviews, several caregivers mentioned the absence of a good environment for printing out the data. All in all, the computer system itself was good, but the infrastructure was not good, because the system to print out the data or see the data was located downstairs, not at the same level as the department where the patients were wearing the watch. 
Caregivers could see from the monitoring data that a patient was not sleeping very circadian rhythm. The diary and interviews showed us that the interventions the caregivers used can be divided into four categories; sleep interventions (change sleep position), quality of life (teddy bear, entertainment by playing a billiard game, taking a bath before going to bed), medication (changing the time of the medication or changing the sort of medication), and no intervention. This categorization was made by the researchers according to the activity carried out during the intervention. The interventions were done intuitively, based on the outcomes of the watch and were not carried out systematically. The caregivers came up with something which they thought might be helpful, for example giving a teddy bear to a person who slept badly because of anxiety, or giving someone a bath to relax them a little more.

\section{Effects of the interventions on sleeping behaviour}

Concluding from analyzing the data, the mean sleeping time during the project of 3 months (November 2008 till February 2009) was 389 minutes (= 6.5 hours), the sleeping periods were 5.66 and the circadian rhythm was 0.546 (the lower the better). For the one-time only interventions we compared the mean with the night results from the night after the intervention. For example, did someone have normal change like everyone has in their sleep pattern. During the data analysis, 
interviews, there could be concluded that 3 out of the 5 interventions resulted in an improved sleep time, 2 out of 5 interventions for improved sleeping periods and 3 out of 5 for improved circadian rhythm.

These results should be interpreted with caution. Only one (1) positive change in sleep time (someone who slept more minutes than before) and 1 negative change in sleep periods (someone who slept for more periods and, because of that, had more periods of being awake) came above or under the level of the standard deviation.

As mentioned in the method section, there was one structural intervention. In this structural intervention they changed the time of a person getting his sleeping through medication, in the new situation they gave it at $9 \mathrm{pm}$, the same time as they gave the person the sleeping medication. A t-test was used to compare the means before and after a specific structural intervention to conclude whether there were any significant differences in sleep-period, sleep time, and circadian rhythm. The time before the intervention was 74 days and the time after the intervention 18 days. For the t-test a significant difference was found in the sleep time, the minutes have changed from $\mathbf{3 3 2}$ minutes of sleep to $\mathbf{4 3 4}$ minutes of sleep $(p=0,024)$.

In figure 4 you can see the data of a patient who get her sleeping-in medication at $9 \mathrm{pm}$ and her sleeping-on medication around midnight, during that period she was awake for several hours as can be seen by the peaks. In figure 5 they changed her sleeping-on medication time from midnight to $9 \mathrm{pm}$ and you can see she has longer periods of sleep (horizontal stripes) 


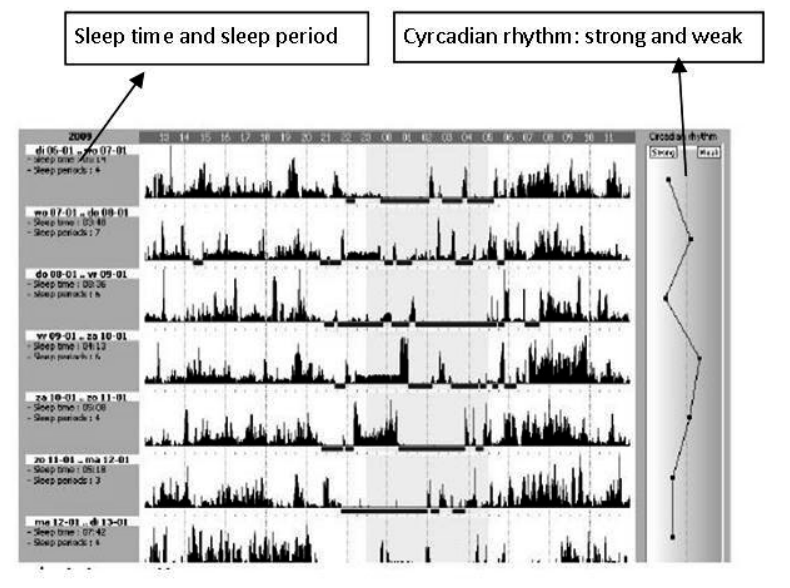

Figure 4 Activity curves before the change of medication time

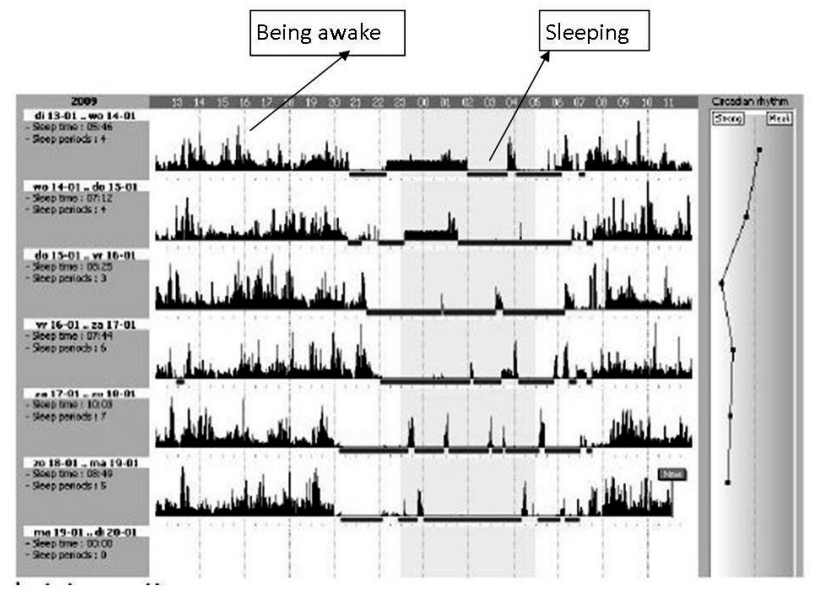

Figure 5 Activity curves after the change of medication time 


\section{Effects of interventions on the care delivery process}

In the interviews, the caregivers mentioned that - thanks to the Vivago watch - it had become easier to coordinate care during the day and the night. The coordination of care can be divided up into various categories. First of all, there is the coordination of sleep, for example in the morning they could see if someone had slept very badly during the night and so decided to let that person sleep a bit longer, to make sure he or she would at least have a couple of hours sleep. The next one involves coordinating the sleep medication: with the data compiled by the watch they could examine the sleeping behaviour of a specific patient. If the data show that a person wakes up and stays awake while getting his sleep on medication, the time of this medication could be changed or even the doses of the medication changed. The last possibility is the coordination of work activities for the caregivers. In the morning the caregivers used the data to decide which persons they would start washing and getting dressed. The same could be done in the evening.

\section{Discussion}

Prior work has documented the positive effects of the use of technology in dementia care. Technology can be supportive for the patient's family and professional caregivers and improve the quality of life of patients themselves (8-13, 26-29).

A mixed method design was used to see how the IST Vivago watch, which measures the sleep and wake pattern, was used for people with severe dementia in a nursing home. Generally speaking the interventions based on the watch showed positive results in the sleep time period and circadian rhythm for the dementia patients. The results were preliminary for a small group of patients, but indeed positive. The caregivers give several implications for the improvement of the care delivery process, for example using the watch during night shift. They found in the watch an extra sensory organ. The infrastructure of the computer system for monitoring the data and the functionalities of the watch itself could be further improved. 
These first results seem to be positive, but there should have been more of a focus

on the process of the total implementation of technology in healthcare. There should have been a match between organization, users and technology as mentioned in several articles in the introduction of this article $(14,16,18-21)$. In this section an explanation will be given of the important missing or fulfilled conditional criteria for the diffusion of the technology, in this case the watch in this nursing home.

First of all relative advantage is very important. The advantages became clear in positive results in the sleeping behaviour of patients. The caregivers mentioned several implications for an even better coordination of care with the watch. For example, using the watch during the night shift to see if someone is really asleep and to carry out surveillance rounds and security checks during the night according to the data compiled by the watch.

The trialability before really starting to use the watch was not done properly during this study. The caregivers were told to start using the watch, but there was no time for trialability and deciding how to use the watch.

In the way of observability the caregivers started using the watch themselves to let the patients get used to the watch as well, which is a good method. It is necessary to share the different kind of interventions with all the caregivers working with the watch. In this project, the different caregivers did not even know from each other which interventions they used and which had an effect.

With this, the communication channels about the use of the watch and especially about the interventions which have been done could be improved. The interventions were discussed in the multidisciplinary meetings, but not all the caregivers joined this meeting. The communication channels at the start of the project for introducing the whole project could be improved for the caregivers. In this project, the duration and exact timing of the introduction was far from ideal. The introduction for family members which took place during an evening especially reserved for this purpose was fine. 
To bring about the widespread use of the watch, involve the other departments that also have patients with dementia; this is a homophilous group, which makes it easier to disseminate the advantages for this group. Later on in the project you could decide to include different kinds of elderly patients, for example.

In relation to the pace of innovation in this project, it became clear that reinventing the watch in specific ways would help to encourage its widespread use. Caregivers mentioned that the watch was too big, that it looked like a sports watch and that it did not have an analog clock. For patients themselves, some changes would make the watch more user-friendly, but the caregivers will also feel that they have some influence on the watch if something is done with their suggestions as well.

An innovation gets shaped into norms, roles and a social network which exists in the social care setting. For example, in this project they already started printing out the data for the patient's existing healthcare records. They should use regular team meetings more for a discussion about the watch and the possible interventions.

One thing they did well in this project was using two interested caregivers as opinion leaders. If the watch has to be used in different departments of the social care setting then the use of opinion leaders can be very effective.

The caregivers mentioned the fact of compatibility. They mentioned that it would be great to let the watch give out an alarm too if a patient is getting into the lift, which goes to another department of the nursing home, which is not allowed.

One of the main drawbacks in this project was the lack of a good infrastructure. Caregivers had to go downstairs to print out the monitoring data. As an organization starts to work with technology one of the primary things that should be done is to make sure that the required infrastructure is well organized. For caregivers, using any kind of technology is already new to them; it is therefore important that using it does not require a lot of extra effort. 
The above-mentioned criteria are conditionally for the diffusion of an innovation,

but next to that the whole process of implementation and the match between

technology, organization and users is important. The problems which occurred

during the project are the result of a strategy that was too technology-driven. They could use the holistic framework of Van Gemert et al. $(17,20)$, where the whole technology for their end-users $(17,20)$. The chosen technology needs to fit with its the watch can do to address these needs and how, create the right facilities and infrastructure for using the watch, start doing something with the recommendations that caregivers give about the watch and, most of all, make sure that the watch and all interventions related to the watch will be tabled on the agenda, and discuss the effects of the watch and the patients for whom the watch is working for.

More interventions could have been done if the project had not been technologydriven, but focused more on organizational improvements. In the interviews, the caregivers stated that they conducted fewer patrols during the night because they could see which patient was awake and which patient was asleep. The passage ways in the nursing home are pretty long, around 80 metres, so it saves a lot of time if you do not have to walk the entire length of the passage way just to conclude that someone is sleeping normally and then have to walk all the way back to the office. The spare time gained could be used for a lot of other activities, for example preparing the medicines for the next morning or doing administrative work. Patients do not have to be waken up by opening the door of their room; instead you can see if they are still asleep on the computer. Even in the morning shifts, the Vivago watches helped to save time because the caregivers could immediately see who was awake and who could be helped to get washed and dressed. Some caregivers also mentioned the fact that the watch could help patients be less frustrated during the day which would make them more cooperative with the care workers. This would 
time and effort. If there would be a greater focus on these needs, the technology would become needs-driven instead of technology-driven.

There are some limitations to this study. It should be noted that the quantitative data analysis and specifically the comparisons between monitoring data before and after one intervention is preliminary, yet despite this, the results showed improvements in the sleep/wake pattern. It is evident together with the qualitative results that the watch might have positive results.

The role of the patient with dementia is minimal in this research; the focus was on the professional caregivers and the data analysis. A study by Topo (2009) also describes the difference between studies with caregivers or people with dementia. Caregivers have a tendency to emphasize care issues such as the management of instrumental activities of daily living (IADL), activities of daily living (ADL) and safety issues. People with dementia report more often on how difficult it is to find something to do, to sleep or to live with the insecurity that you do not know where you are or what year it is. Consequently, there is a marked difference in the needs of people with dementia themselves and the interests of the family members who provide care or the professional caregivers. In this study, patients were not asked themselves about their occasional poor sleep/wake rhythm. It is a challenge to ask people with dementia who are living in a nursing home questions about passive technology. Although it might be a challenge the best way of using a technology in healthcare is to start with this contextual inquiry, as mentioned before in the holistic framework (20).

No control group or pre-test was used in this research. The reasons for this were that people with dementia are not comparable in an intervention and control group (the size of the project group was too small to carry out a random comparison between a control and an intervention) and people with dementia have a progressive disease and using a pre-test for this might influence the results because a patient's health might decline. 
The potential bias in the qualitative research approach was overcome by relating the

quantitative data to the interviews, the diary and the observations. Evidence from

different sources was used to confirm the same fact or finding.

Acknowledgments

$\underline{\mathrm{R} 4}$

R5

I would like to convey my thanks to Limez for the project organization, the nursing

home Diafaan, and van Dorp Installations which coordinated this project and made it $\underline{\mathrm{R} 7}$ possible for me to conduct my research. 


\section{References}

1. Wimo A, Prince M. World Alzheimer Report London: Alzheimer's Disease International, 2010.

2. Ancoli-Israel S. Sleep disturbances among patients with dementia. A Clinical Journal of the American Geriatric Society. 2005;12(12):13-4.

3. Middelkoop HAM, Kerkhof GA, Smilde-van den Doel DA, Ligthart GJ, Kamphuisen HAC. Sleep and ageing: The effect of institutionalization on subjective and objective characteristics of sleep. Age and Ageing. 1994;23(5):411-7.

4. Better Health Channel. Dementia and sleeping problems. Melbourne: Better Health Channel; 2009 [updated 2009,November; cited 2010 August 10]; Available from: http://www.betterhealth.vic.gov.au/bhcv2/bhcarticles.nsf/pages/Dementia_and sleeping_problems?open.

5. Brassington GS, King AC, Bliwise DL. Sleep problems as a risk factor for falls in a sample of community-dwelling adults aged 64-99 years. Journal of the American Geriatric Society. 2000;48(10):1234-40.

6. Foley DJ, Monjan AA, Brown SL, Simonsick EM, Wallace RB, Blazer DG. Sleep complaints among elderly persons: an epidemiologic study of three communities. Sleep. 1995;18(6):425-32

7. Sommeren EJW, van. Circadian and sleep disturbances in the elderly. Experimental Gerontology. 2000;35(9-10):1229-123.

8. Topo P. Technology studies to meet the needs of people with dementia and their caregivers.A literature review. Journal of Applied Gerontology. 2009;28(1):5-37.

9. Lauriks S, Reinersmann A, van der Roest HG, Meiland FJ, Davies RJ, Moelaert F, Mulvenna MD, Nugent CD, Dröes RM. Review of ICT based services for identified unmet needs in people with dementia. Aging Research Reviews. 2007;6:223-46.

10. Nijhof N, Gemert-Pijnen JEWC, van, Dohmen D, Seydel ER. Een studie naar toepassingen van techniek in de zorg voor mensen met dementie en hun mantelzorgers. Tijdschrift voor Gerontologie en Geriatrie. 2009;40(3):113-32.

11. Cahill S, Macijauskiene J, Nygard AM, Faulkner JP, Hagen I. Technology in dementia care. Technology and Disability. 2007;19(2-3):55-60.

12. Duff $P$, Dolphin C. Cost-benefit analysis of assisitive technology to support independence for people with dementia - Part 2: Results from employing the ENABLE cost- benefit model in practice. Technology and Disability. 2007;19(2-3):79-90.

13. Cahill S, Begley E, Faulkner JP, Hagen I. "It gives me a sense of independence". Findings from Ireland on the use and usefulness of assistive technology for people with dementia. Technology and Disability. 2007;19(2-3):133-42.

14. WHO. Medical devices: managing the mismatch. Geneva, Switzerland: World Health Organization, 2010.

15. Atienza AA, Hesse BW, Gustafson DH, Croyle RT. E-Health research and patientcentered care examining theory, methods, and application. American Journal of Preventive Medicine. 2010;38(1):85-8.

16. Black AD, Car J, Pagliari C, Anandan C, Cresswell K, Bokun T, McKinstry B, Procter R, Majeed A, Sheikh A. The impact of eHealth on the quality and safety of health care: a systematic overview. PLoS Medicine. 2011;8(1):1-16.

17. Van Gemert-Pijnen JEWC, Nijland N, Ossebaard HC, van Limburg AH, Kelders SM, Eysenbach G, Seydel ER. A holistic framework to improve the uptake and impact of eHealth technologies. Journal of Medical Internet Research. 2011;13(4):e111. 
18. Yusof MM, Kuljis J, Papazafeiropoulou A, Stergioulas LK. A evaluation framework for health information systems: human, organization and technology-fit factors (HOT-fit). Journal of Medical Informatics. 2008;77(6):386-98.

19. Resnicow K, Strecher V, Couper M, Chua H, Little R, Nair V, Polk TA, Atienza AA. Methodologic and design issues in patient centered eHealth research. American Journal of Preventive Medicine. 2010;38(1):98-102.

20. Nijland N. Grounding eHealth. Towards a holistic framework for sustainable eHealth technologies [Dissertation]. Enschede, the Netherlands: University of Twente; 2011.

21. Cain M, Mittman R. Diffusion of Innovation in Health Care. Oakland: California Health Foundation, 2002.

22. Lotjonen J, Korhonen I, Hirvonen K, Eskelinen S, Myllymaki M, Partinen M. Automatic Slaap-Wake and Nap Analysis with a new wrist worn online activity monitoring device vivago wrist care. Sleep. 2003;26(1):86-90.

23. Lamminmaki E, Saarinen A, Lotjonen J, Partinen M, Korhonen I. Differences in light sleep and deep sleep measured with IST Vivago wristcare. The 3rd European Medical and Biological Enigineering Conference; 2005, November 20-25; Prague, Czech Republic2005. p. 1727-983.

24. Paavilainen P, Korhonen I, Lotjonen J, Cluitmans L, Jylha M, Sarela A, Partinen M. Circadian activity rhtym in demented and non demented nursing home residents measured by telemetric actigraphy. Journal of Sleep research. 2004;14(1):61-8.

25. IST Vivago. Application guide activity curve. Helsinki, Finland: IST Vivago,2005.

26. Miskelly F. Electronic tracking of patients with dementia and wandering using mobile phone technology. Age and ageing. 2005;34(5):497-518.

27. Miskelly F. A novel system of electronic tagging in patients with dementia and wandering. Age and ageing. 2004;33(3):304-6.

28. Lee JH, Kim JH, Jhoo JH, Lee KU, Kim KW, Lee DY, Woo JI. A telemedicine system as a care modality for dementia patients in Korea. Alzheimer Disease \& Associated Disorders. 2000;14(2):94-101.

29. Nijhof N, Gemert-Pijnen JEWC, van, Seydel ER. Technical support at home for people with dementia. Evaluation report. Enschede, Netherlands: University of Twente,2011. 


\section{Chapter 5}

Social contact technology at home:

A personal assistant for dementia to stay at home safe at reduced cost

Chapter 5 is based on: Nijhof N, van Gemert-Pijnen JEWC, Burns CM, Seydel, ER. A personal assistant for dementia to stay at home safe at reduced cost. Gerontechnology. 2013; 11 (3):469-479. doi :10.4017/ 


\section{Abstract}

Purpose: This paper presents the results of an evaluation of the commercially-available PAL4-dementia system, a supportive touch screen for people with dementia. The main purpose was to study the advantages and disadvantages of the system from the perspective of the client, family and professional caregiver and the potentials to upscale its use.

Method: The evaluation was conducted over 9 months with 16 clients of two healthcare organizations in the Netherlands. A mixed-method design was used in this pilot, involving log files of system use, interviews with family caregivers, a focus group made up of professional caregivers, observations of project group meetings and a cost analysis.

Results: Clients and family caregivers reported good support of daily life activities. They thought the system could help the client to live at home for a longer period of time. The cost analysis showed monthly savings per client as compared to living in a nursing home ranging from around $€ 820$ (10 clients) to $€ 860$ (50 clients). Despite these positive results, numerous problems were detected: (i) interruptions of technology, (ii) insufficient operation knowledge of professional caregivers, (iii) insufficient active involvement of family caregivers, and (iv) limited user-friendliness of the lay-out. 
The use of eHealth for people with dementia has received substantial attention in recent years due to the rapid rise in the number of people with dementia and the challenges of developing technology to support clients with dementia. Worldwide, an estimated 35.6 million people suffered from dementia in 2010, with this figure expected to rise by 115.4 million by 2050 . In 2010, the global costs attributed to dementia were 604 billion US dollars (1). A change in the care for people with $\underline{\mathrm{R} 8}$ dementia is clearly necessary in order to control costs and to improve quality of care.

\section{Technology and dementia research}

Technology applied effectively can allow people with dementia to live at home longer, resulting in improved quality of life, social interaction and significant cost-savings (27). Nijhof et al. (2) conducted a literature review to investigate how different kinds of technology can support dementia care most effectively. Monitoring and signalling technology appeared more suitable for people in a severe stage of dementia and provides a feeling of safety, both for them and their families. Social contact technology is most useful when it is used for people in the early stages of dementia and can be used to improve their quality of life(2). Technology can help clients stay at home longer which is often a more cost effective and convenient option than admission into a nursing home (3).

Research on the application of social contact technology has shown that it is engaging and enjoyable for people with dementia and caregivers, and may encourage people with dementia to remain actively engaged and participating in their normal lives with friends and family $(4,5)$. Furthermore, social contact technology might also increase quantity and quality of social interaction. In terms of other features, one study, that of Meiland et al (6), found that useful functionalities for people with dementia for a touch screen interface included the capability to set reminders, the ability to navigate a phone directory by photographs, support for leisure activities, and safety warnings for when for example the front door was not closed. These findings were based on 
literature research, user workshops and user interviews. This touch screen (Cogknow Day Navigator, CDN) was developed and the evaluation showed that people with dementia themselves and caregivers valued the CDN as user-friendly and useful. The mobile device of the CDN was also valued positively. The system had no effect on the autonomy of the person with dementia or the burden of the caregiver, but this could be, because of the short testing period (8). The follow up project of the CDN is called Rosetta, whereby the same touch screen is used, but linked with different sensors (so if someone is not cooking, they get a reminder), sensors to register daily patterns and an alarm detection system. The first preliminary results look promising as well, especially for the caregivers to create a feeling of safety and get more insight in the life of the people with dementia (9).

Generally, there is a lack of scientific evidence about the overall impact of eHealth in healthcare in general (10-12) and it is in this context that the present research was conducted.

\section{Aim of the study}

This paper presents the results of an evaluation of one care technology, the commercially-available PAL4-dementia system (PAL4 BV, Driebergen-Rijsenburg, The Netherlands). Its main purpose is to investigate the advantages and disadvantages experienced by clients and caregivers and to identify possible improvements. Insights from the study of this system have implications for eHealth home care systems in general, because of the similarities in implementing an eHealth technology.

The following research questions were asked:

- Which activities are undertaken for introduction of the system?

- What uptake has this system in relation to usage and usability?

- What impact has the system upon health care delivery, well being and cost savings? 


\section{Methodology}

To address these questions we used a mixed method design to gain a rich picture

of the effectiveness of the system. For the evaluation of an eHealth application a

mixed-method approach is often the best option, since it combines both qualitative methods and quantitative methods (13-17). The data from the different sources can complement one another to provide a broader view (17). For example details about the results of usage log files can be asked during in-depth interviews. To answer the questions, the usage log files, interviews with family caregivers, a focus group have been used. To assess cost savings, we carried out a quantitative cost analysis comparing the costs of living at home and using the system with the costs of living in a nursing home.

\section{Theoretical framework}

The successful development and deployment of eHealth technologies requires a rich and multi-faceted approach to the design and evaluation of these technologies. In particular, Gemert et al. (18) have proposed the CeHReS roadmap as a holistic approach for the research and development of eHealth technology moving from contextual inquiry, value specification, design, operationalization to summative evaluation. The main topics measured for uptake are: usage behaviour and usability. Impact in this study is related to the influences of the system on healthcare delivery, well being and how it affects the costs. The well being measured in this study is things independently and staying home for a longer period of time were asked. The well being of the family caregiver was measured by support and reduce from burden savings were measured by comparing the costs of technology and homecare with staying in a nursing home (on a monthly basis).

Since PAL4-dementia was already an operational system, a summative evaluation was conducted. This means that the evaluation could only be started from the 
through to the operation and maintenance of the system. Since the introduction and implementation of such a system has a strong effect on its impact (19), these phases are of particular interest. In addition the usability results will be used to optimize the system to users' needs.

\section{Describing PAL4-dementia}

The system is used as a supportive and social contact technology (2), and provides daily organizer functions, specific 'PAL4 features', and video contact with caregivers or family. It can be obtained as a general assistant for healthy elderly clients, or as a specific one, such as the PAL4-dementia used in this study. The features used in PAL4-dementia were chosen and decided by several experts in the field of dementia care: a specialist elderly care medicine and two homecare nurses with expertise in caring of people with dementia (20). The features were built by PAL4 BV employees.

The basic system has been sold in the Netherlands to approximately 1000 older adults, while the dementia version is currently in use by around 50 people (21).

In the dementia version, a touch screen is used which shows people an agenda of their day, a diary, a life album and a 'PAL4 button'. Pressing the PAL4 button opens a menu with memory games to play, information about dementia, and information for the client about their own village, in which they live. The system also provides two-way video contact with family or professional caregivers. PAL4-dementia was specially designed to be less complicated and easier to learn than the system for healthy older adults. Its purpose is daily use to improve the well being of clients by doing daily activities independently, improving the well being of family caregivers by supporting them in their care to create less burden, and with this all, let people with dementia live at home for a longer period of time.

The interactive touch screen consists out of a touch screen and so called Bidi box, which is a little box creating the secured two way video connection. The touch screen first shows the start-up screen (Figure 1a). The first line of text is used for entering the program (PAL4 button), the second line is used for making video contact with a professional caregiver, the third line is used for video contact with a family caregiver, and the last line is used for television. This PAL4 TV button may access live television 
broadcasts, for example a church service that people can watch live. This feature was

not assessed in this study. Touching the PAL4 button, the PAL4 Dementia features

The button agenda (Figure 1C) shows all the appointments till 15:00H, after $15: 00 \mathrm{H}$ season (with a pictogram) can be seen.

The life album (Figure 1d) has four options: watching pictures, reading your personal history story, watching movies and listening music.

The diary (Figure 1e) itself can be used for writing the diary or reading the diary. Persons with dementia, family caregivers and professional caregivers are allowed to write and read in this diary.

Touching the last button, PAL4 (Figure 1f), reveals information about their own village, health and housekeeping, shopping (online shopping features), leisure (for example playing memory games), and family and contact (watching movies from other PAL4 members or meal preparation videos).

On the family caregiver website caregivers can enter appointments in the agenda, create a personal history story, upload pictures in the life album or read and write in the diary. The website can be reached from a family caregivers' own computer caregivers who can connect. The touch screen itself also offers the option to access this website, a feature developed because several clients had a family caregiver who was a partner living in the same house and did not have a computer. The website for the family caregivers has been made in the same easy-to-use style as PAL4 itself 

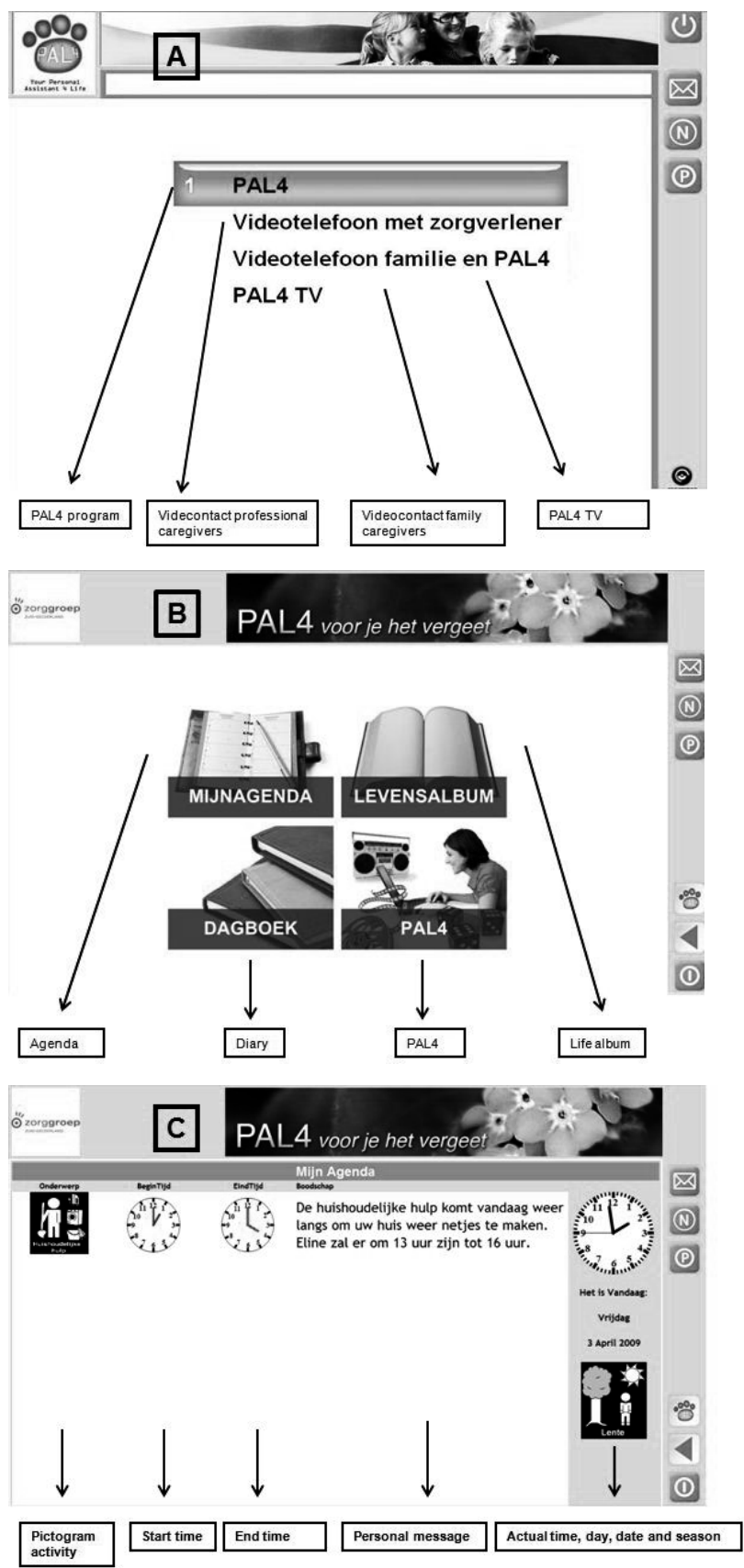

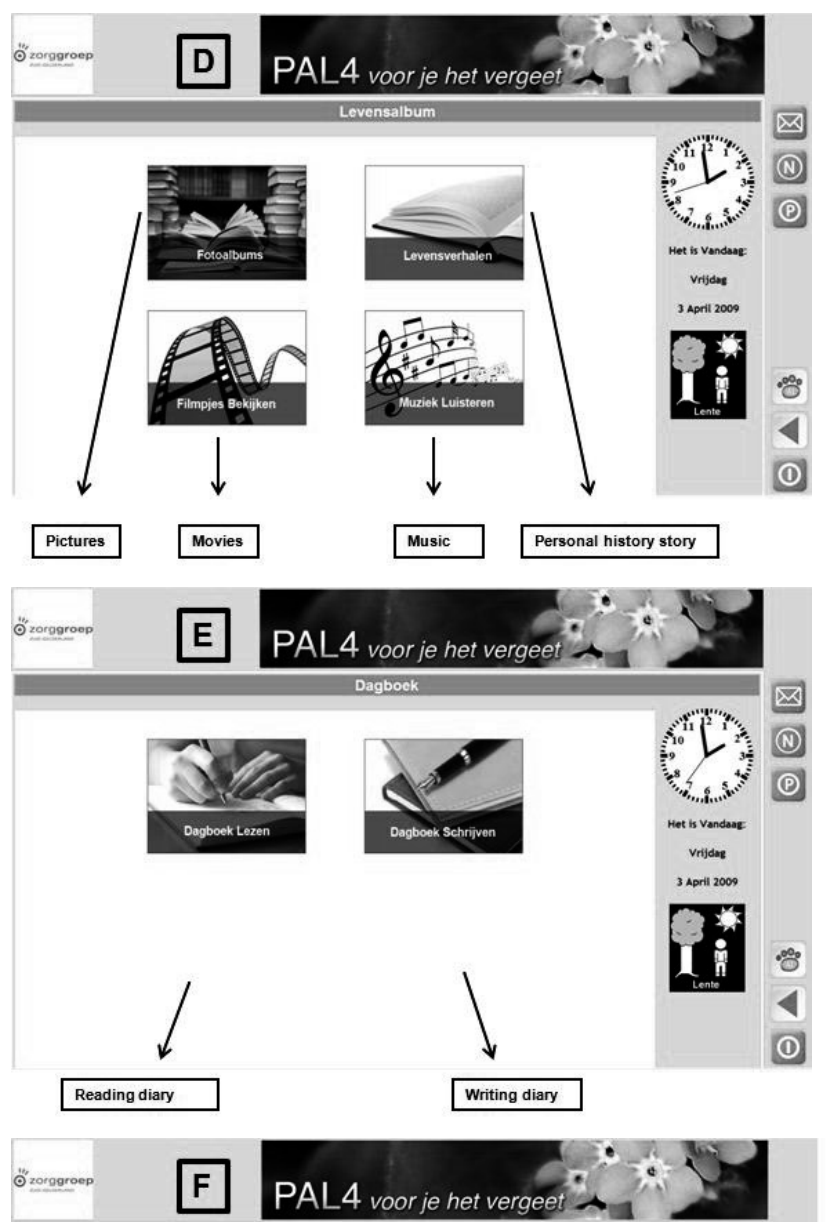

R2

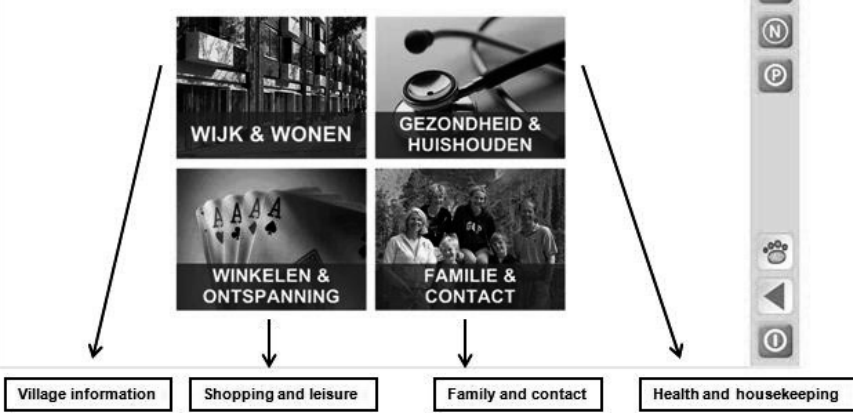

$\mathrm{R} 2$

$\mathrm{R} 2$

$\mathrm{R} 2$

$\mathrm{R} 2$

$\mathrm{R} 2$

$\mathrm{R} 2 \mathrm{~S}$

$\mathrm{R} 3 \mathrm{C}$

R31

Figure 1 Client's interface; A: Opening screen; B: PAL4-dementia program, C: Agenda; D: Life $\underline{\mathrm{R} 32}$

album; E; Diary F: General program 
To install the system, a basic internet connection ( $512 \mathrm{~kb} / \mathrm{up}$ ) is necessary. If people did not have this connection the healthcare organization would pay for its installation and use. The system itself was paid for by the healthcare organization with financial aid from the Dutch Healthcare Authority (supervisory body for all the healthcare markets in the Netherlands).

\section{Installation of the system}

The PAL4-dementia system was installed by a technician who made an appointment by phone and on a specific date and time went over to the clients' house. The procedure took around three hours and included the explanation of how the system works. The technician would leave a paper manual at the person's home; a short manual with the four buttons, the description of what was behind these buttons, and a more extensive manual with all the information people could find behind the buttons. One or two days after the installation an occupational therapist would come by to further explain the system and help the client work it in daily life. For questions or interruption of service, people were able to phone to or video contact with the service desk of the company, only open during office hours. If an interruption of service occurred, the technician would log into the system and first try to resolve the problem online. If this did not work (s)he had to visit the client to solve the problem.

\section{Study participants}

Two homecare organizations participated in this study that had not used the PAL4 dementia system before.

The project group consisted of 11 members ( 9 females, 2 males): two specialists elderly care medicine, five nurses, two project managers, one occupational therapist and the first author. None of them had prior experience with using touch screens for people with dementia. The members consented to observation during their meetings. 
The clients for this study were selected by professional caregivers of the participating homecare organizations. To be included in the study a client:

- $\quad$ had been diagnosed with dementia or had shown signs of being more forgetful than most people their age,

- $\quad$ was likely able to continue to live at home for at least 9 more months,

- needed care from one of the participating homecare organization,

- $\quad$ spoke and read Dutch, and

- $\quad$ was considered capable of using the system.

Clients with other cognitive disabilities, for example Parkinson's disease, were excluded. In total 16 clients participated, eight from each homecare organization. Informed consent was signed by the client or responsible relatives to allow for using the log files of the client.

Ten female and six male clients participated. The age from the clients ranged from 58 to 86 years, with a mean of 78 years. The Mini Mental State Examination (MMSE) ( $1=$ severe dementia and $30=$ no dementia) (22) ranged from 13 to 29 with a mean of 22, with 1 missing score (because the caregivers found testing too upsetting for the client).

The family caregivers' age ranged from 35 to 79, with a mean of 58 years. The relationships between client and family caregiver differed: seven daughters, four sons and five partners. The number of years caring for the client varied from 2 to 12 years, with a mean of 4.5 years. For nine clients there was no other family caregiver. Four family caregivers had a low level education (high school), four had mid level education (college) and nine completed a university education (high level education).

Selected clients would be invited, together with their family caregiver, to have the system installed in their home and use it, as well as to be interviewed.

After several months of using the system, a focus group was organized by the first author. The main reason for installing this focus group was to gain more insight from the perspective of the professional caregiver in relation to the uptake (usage and 
usability) and impact (well being and healthcare delivery). It consisted of two nurses who trained the clients at their home in using the system (from one participating organization), and the project manager and occupational therapist (of the other organization). In age they ranged from 39 to 46 years, with a mean of 44 years. Two members had a mid level education and the other two a high level education.

\section{Study design}

A field observation was conducted between August 2008 and December 2010. The first healthcare organization started project-group meetings in the fall of 2008 , while the other started at the end of 2009. The actual installation of the system followed a few months later in both cases. The log files were analyzed from the first nine months of a person using the system. The interviews and focus group meetings took place at the end of 2010. The clients started to use the system at different times. This is the reason for the broad range of time for collecting data.

\section{Data collection}

\section{Project group meetings}

In total, 24 project group meetings were held, ranging from approximately one to two hours in length. These project groups gave insight in the introduction, the uptake and impact of the system. The first author made reports of these meetings. At the start of the projects these meetings were about introduction issues (how to start up the project, who should be involved, how to recruit clients), later on the subjects changed to actual experiences and problems with using the system.

\section{Log files}

For each client the log files of system use were collected for the first nine months of use. It showed the total number of clicks a client made at each level of the system. The following limitation became obvious: to use a game a client had to click on three buttons in succession: PAL4, shopping and leisure, games, before s/he could select the specific game to play.

To answer the question related to usage the focus was on the total usage of the different features, the period of time of use and the amount of use. 
In each case family caregivers were interviewed by the end of this study to answer

\section{Focus group of professionals}

The focus group meeting took about 90 minutes, and consisted of a structured set of

\section{Cost analysis}

One of the main purposes of this study was to get more insight in the direct cost of living at home with the system in comparison to living in a nursing home (impact related to cost). All costs related were collected in euro.
- $\quad$ Living in a nursing home (in the Netherlands there is a legally fixed price for the expenses of a person with dementia living in a nursing home);
- Touch screen and installation;
- $\quad$ Subscription for the use of the system and internet connection
- $\quad$ Homecare for the clients
- Monthly fee for services, such as trouble shooting
- Monthly expenses for the professional caregivers to use the system, including house visits and video contact (number of hours per month

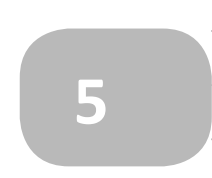




\section{Data analysis}

Overall the interviews, focus group and project group meetings were used to answer the questions related to uptake (usage and usability) and impact (well being and healthcare delivery). The log files were used to gain insight in the usage of the system. As last the cost analysis was used to answer the question related to the impact and specifically the cost aspect.

The interviews with the family caregivers were coded in a coding scheme related to the full range of research questions; usage, usability, healthcare delivery and well being. The transcripts were read by the first author several times to capture the experiences of the family caregivers, and to aid in the development of the coding scheme. A research assistant also coded the interviews to overcome potential researcher related bias and improve reliability. The focus groups with the professional caregivers and the project group meeting reports were coded in the same coding scheme. Again, the transcripts were read several times in their entirety to capture the experiences of the caregivers to aid in identifying the coding scheme.

In total there were 7 complete 9-months log files and 7 incomplete files. Five persons used the system for eight months, one person for four months and one person for three months. For one person the log files were missing, because the person quit earlier in the project and the log files were not saved due to regular clean up actions by PAL4 employees. For another person there were no log files, because the PAL4 system was not used by the client and picked up after about three weeks. Therefore only 119 months of logs of using the system became available for analysis.

Overall the log files were used to get insight in the general moments and feature. The first analysis consisted of sorting the number of button presses in the morning (6:00-12:00H), afternoon (12:00-18:00H), evening (18:00-24:00H) and night (0:00$6: 00 \mathrm{H})$. Second, the number of clicks on the start screen was sorted by the main button pressed. In case of the PAL4 button the underlying buttons were taken into account: shopping/leisure, health/housekeeping, village information and family/ contact, as well as the clicks of family caregivers to fill in the agenda. After these 
general analyses of the logs, the information was split up for every person to see the

For the cost analysis several calculations were made:

- $\quad$ Total governmental or health insurance expenses for someone living at home with the system;

Total governmental or health insurance expenses for someone living in

- Comparison between living at home with the system and living in a nursing home (for 10 to 150 clients in steps of 10 clients; for 1 to 12

\section{Results}

\section{System introduction}

The interviews, focus group and project group meetings indicated that the way the

First, professional caregivers had to recruit the clients, but having no prior experience

with the system, they sometimes had problems explaining it in a clear and concise

way. Clients could be recruited by other caregivers not in the project group, but

Second, it was not helpful that the members of the project group changed several times due to sickness, retirement and lack of time. The purpose and working of the

Third, some of the family caregivers thought the installation of the system was 
recruited earlier in their disease process, when they were more capable of learning new things. On the other hand, it was stated that higher functioning clients did not really need the system yet and might find it stigmatizing.

In one of the healthcare organizations, the occupational therapist went on long-term sick leave at the beginning of the project, and training had to wait. This was a big drawback according to the family caregivers, because the system was installed in the home but could not be used. A few clients stated that the training by the technician was too quick. They did not have the time to fully understand the system.

\section{Uptake of use}

The system was used most during the afternoon: $44 \%$ (14,722 clicks), $31 \%$ in the morning (10,534 clicks), $23 \%$ in the evening (7,687 clicks), and only $2 \%$ ( 825 clicks) at night. The "Agenda" was used the most (33\%) (5215 clicks), followed by the 'PAL4 button' (28\%) (4245 clicks), and below this button the 'Shopping and leisure' (24\%) (3680 clicks), then the "Diary" (4\%) (656 clicks), "Family and Contact" (3\%) (446 clicks), "Life album" (3\%) (450 clicks), "Family caregiver page" (3\%) (414 clicks), "Village information" (1\%) (147 clicks). The "Health and housekeeping" button was used the least (1\%) (143 clicks).

Usage of the system differed among clients (Table 1). Clients did not use the system every day. System use varied from $9-96 \%$ of the days that the system was present in the home. The average was $48 \%$ for the total of 14 clients with log files. Because the system was not used every single day we calculated the mean number of clicks on days of use. It ranged from 4.6 to 46.0 , with a mean of 20.2 clicks/day of use for the total of 14 clients with log files. 
Table 1 System usage by each client-family caregiver combination in relation to client characteristics and ranked by percentage of use days; n.d. = not done

\begin{tabular}{|c|c|c|c|c|c|}
\hline \multicolumn{3}{|c|}{ Client characteristic } & \multicolumn{3}{|c|}{ System use } \\
\hline$\#$ & $\begin{array}{l}\text { Age, } \\
\text { Years }\end{array}$ & $\begin{array}{l}\text { MMSE } \\
\text { score }\end{array}$ & $\begin{array}{c}\text { Days } \\
\text { installed }\end{array}$ & $\begin{array}{c}\% \\
\text { Use days }\end{array}$ & $\begin{array}{l}\text { Mean number of } \\
\text { clicks / Use day }\end{array}$ \\
\hline \multicolumn{6}{|c|}{ Women } \\
\hline 1 & 81 & 30 & 247 & 96 & 46.0 \\
\hline 4 & 78 & 24 & 234 & 82 & 21.9 \\
\hline 5 & 76 & 14 & 228 & 75 & 11.1 \\
\hline 12 & 82 & 18 & 73 & 52 & 45.4 \\
\hline 6 & 86 & 25 & 239 & 46 & 26.3 \\
\hline 9 & 88 & 23 & 262 & 19 & 11.5 \\
\hline 10 & 71 & 26 & 255 & 19 & 11.8 \\
\hline 11 & 88 & 23 & 247 & 19 & 7.4 \\
\hline 13 & 79 & 29 & 263 & 9 & 12.4 \\
\hline 15 & 80 & n.d. & 258 & - & - \\
\hline \multicolumn{6}{|c|}{ Men } \\
\hline 3 & 58 & 23 & 226 & 95 & 9.2 \\
\hline 2 & 83 & 16 & 254 & 93 & 22.4 \\
\hline 7 & 81 & 17 & 215 & 34 & 4.6 \\
\hline 8 & 65 & 22 & 268 & 25 & 32.2 \\
\hline 14 & 84 & 13 & 114 & 10 & 19.9 \\
\hline 16 & 71 & 25 & 20 & - & - \\
\hline
\end{tabular}

\section{Usability}

Most interviewed people cited electricity costs as a reason for not keeping the system active all day. In almost all clients' houses, the system was installed at a noticeable, frequently used place, so clients did get a visual reminder to use, but even so, almost half failed to do so regularly. Those people that only started the dementia features when they were actively using the system, decreased its usefulness (according to

Clients regarded the trouble shooting service as effective. Only one family caregiver mentioned that her relative was so dependent on the system that interruptions of service constituted a big problem since the service desk was only open at office hours. In the weekends it could take several days before the service would run again.

Almost all clients and family caregivers considered the system useful. 3 out of 16 
cases the relatives stated that the system would have worked when it had come earlier. Other clients, used to their own personal computer, preferred to keeping on using that one. Family caregivers would rather enter appointments into the client's agenda over the Internet from their own homes, instead of having to go to the clients' house.

Learning to use the system takes time. Some only needed a few learning runs. Most of these clients were familiar with computers. For other clients, less familiar with computers, it could take several weeks before they started to understand the system. None of the clients found using the system intuitive. 5 clients had some fear about breaking the system; several reassurances had to be given by the caregivers that pressing any button could do no harm.

Another drawback in usability for clients was the layering of the system, leading to the need to click on a number of buttons in succession. One family caregiver mentioned that her relative could easily find a game on her own computer with icons on the desktop, but failed to do so with the PAL4-dementia system. In addition, games in the system were partly in English instead of Dutch, or in too small print.

\section{Computer experience}

Clients experienced in computer use preferred the mouse over the touch screen. Those wanting to use e-mail through the system requested a separate keyboard instead of the touch keyboard of the PAL4-dementia system. The ringtone for reminders was a source of confusion since it resembled the tone of the telephone.

Family caregivers without computer experience found the user-interface easy to use and user friendly. However, family caregivers with computer experience considered the system slow, while making one mistake let you enter everything again, which was annoying.

Three of the elderly caregivers without computers of their own mentioned that the clients did not use the system much, but that they themselves did. For example they 
entered their own appointments, because they had to remember both their own

and the client's appointments. They also sometimes enjoyed playing the games for

Service interruptions and confusions

Technology interruptions were frequent at the start of the project. Common

- $\quad$ screen freeze,

- poor video contact,

- slow operation,

- $\quad$ opening a website overlapped the whole screen; the only way to exit was turning the system off, and

- $\quad$ when the healthcare centre was busy and could not take a video call, it would call back later without giving the client the option to accept the call. This last problem was solved later in the project.

The system got a regular update once every few months. With these updates, names and images in the system might change resulting in confusing among the clients. When this update was happening people were asked by the system if the update was "ok" and they had to click "yes". Those confused, immediately turned off the system.

\section{Professional issues}

The knowledge about the system among professional caregivers in the healthcare organization other than in the project group was limited, especially in the beginning of the project, making recruiting clients harder. The professional caregivers in the project group mentioned that they felt a bit like 'being alone on the project'. A few months after installation, the homecare nurses who came to the client's home, got to know the system and turned it on in the morning. A small number of professional caregivers coming into the home of clients wrote in the diary occasionally.

The video contact was used rather differently at the two healthcare organizations. At one organization, some house visits were replaced with by video contact. The other

R1 
healthcare organization used video contact as something 'extra'. One of the clients was even given restrictions about the number of times a day he was allowed to video call the caregivers. Several clients also mentioned that making video contact with a general practitioner would be appreciated.

Related to the well-being of clients several comments were made by both the clients and their family caregivers. For one healthcare organization, video contact with the family and professional caregivers were both possible; for the other organization only the professional caregivers could be contacted by video. The clients appreciated the option of making video contact with their family caregivers, and found it more convenient and enjoyable than making a phone call. But the option of making video contact with professional caregivers was also judged positively. One of the clients mentioned that she preferred having video contact with a professional caregiver instead of all the different persons coming into her house all the time.

\section{Well being}

For most of the clients, the agenda gave them structure during the day, as they could see the appointments. But for some seeing the day and season of the year was all that was possible, which was also judged positively. Some family caregivers or clients stated that the system had improved the clients' quality of life.

Family caregivers also saw clients laughing when playing a game at the system and mentioned that the clients did enjoy themselves. They were stimulated by the system.

Also some of the family caregivers said that the system stimulated clients to do things independently, which could help them to stay in their own home for a longer period of time. They also said that admission to a nursing home is mostly prompted by the increasing burden on the family caregiver or a deteriorating home situation. These factors cannot be changed directly by the PAL4-dementia system.

The system did not reduce the burden on the family caregiver, but it does support the lives of clients and indirectly those of caregivers. When family caregivers started 
using the system, they had to put extra time and effort to enter appointments,

A few caregivers mentioned that they liked the option of making video contact instead of going to the clients' home all the time. One of the caregivers, a partner,

\section{Financial aspects}

For the quantitative costs analysis, staying at home with support of the system and staying in a nursing home has been compared in relation to cost. (Table 2).

Table 2 Direct costs / client for staying one month at home with the system versus staying at a nursing home in the Netherlands (Prices of 2010 are cited); a=Investment

\begin{tabular}{|c|c|c|c|}
\hline \multicolumn{2}{|c|}{ At home } & \multicolumn{2}{|c|}{ Nursing home } \\
\hline Type & Cost in euro & Type & Cost in euro \\
\hline $\begin{array}{l}\text { Purchase and installation } \\
\text { PAL4 }\end{array}$ & $2385^{a}$ (one time cost) & $\begin{array}{l}\text { Monthly fee } \\
\text { per client }\end{array}$ & 5413,86 \\
\hline $\begin{array}{l}\text { Monthly fee for service } \\
\text { including troubleshooting } \\
\text { service (independent from } \\
\text { number of clients) }\end{array}$ & 500 & & \\
\hline $\begin{array}{l}\text { Subscription fee per month } \\
\text { per client with internet costs }\end{array}$ & 50,50 & & \\
\hline $\begin{array}{l}\text { Average monthly costs for } \\
\text { homecare per client }\end{array}$ & 1958.83 & & \\
\hline $\begin{array}{l}\text { Average monthly costs } \\
\text { professional caregivers for } \\
\text { using PAL4 per client }\end{array}$ & 145.78 & & \\
\hline Subtotal per client: & 4540.11 & & \\
\hline Total: & $\begin{array}{l}4540.11+500 \text { monthly fee } \\
\text { not related to number of } \\
\text { clients }\end{array}$ & Tota & 5413.86 \\
\hline
\end{tabular}

For 10 clients living at home with the system one month longer the cost reduction is about $€ 820 / c l i e n t$, while a roll out to 50 clients let to a saving of about $€ 860 /$ client 


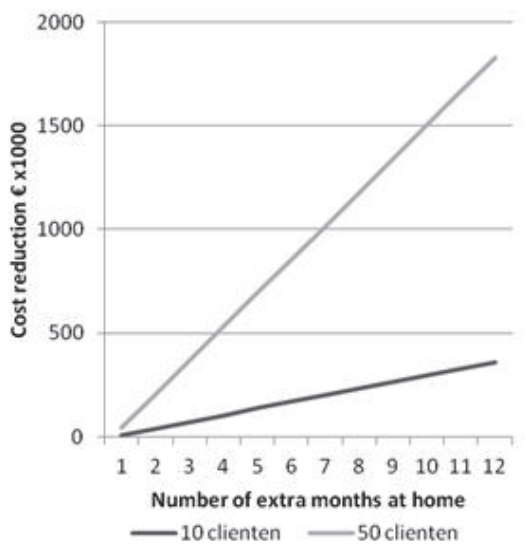

Figure 2 Cost analysis for living at home with a monthly spending on homecare of $€ 1958$ for a roll-out to 10 or 50 clients

However, since the quantity of homecare needed is increasing during the course of dementia, there will eventually be a breakeven point at which a nursing home is less expensive. In the Netherlands this point will be reached when the client needs each week 15 hours of homecare, 4 hours of housekeeping service, 3 hours of personal guidance and goes to a day-care centre 20 hours a week; together costing $€ 5000$ (calculation was made in 2010). Only when the client could stay home 11 months longer, would the system be cost effective (Figure 3).

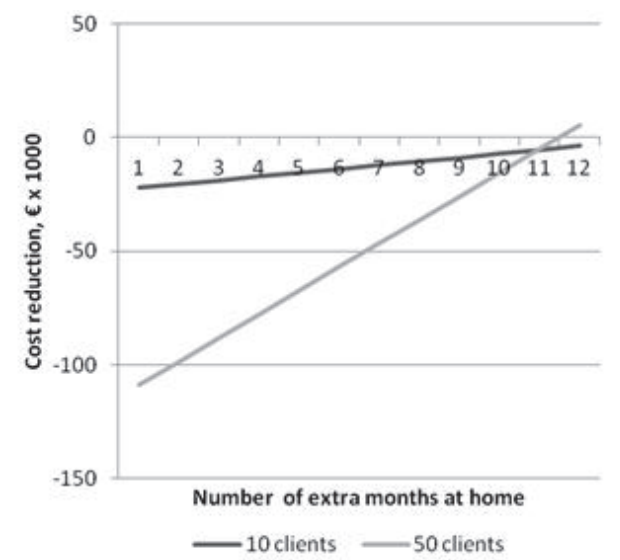

Figure 3 Cost analysis for living at home with a monthly spending on homecare of $€ 5000$ for a roll-out to 10 or 50 clients 
Just like similar systems, the PAL4-dementia system has considerable potential to support persons with dementia $(2,4,5,7-9,19,23-27)$. The system in our pilot study has three out of the four features needed (6): reminding, picture dialling and

\section{Technology generation}

Technology generation and individual prior experience with computers might explain 50 years ago plays an important role in how that person deals with technology nowadays $(28,29)$. Some of our observations correlate with this fact of technology generation. The clients having problems with the usability of PAL4 were of older age, which correlates with the fact that it is harder for this generation to get used to this kind of interface technologies. For family caregivers there was a difference between partners or children, children (younger of age) had less trouble with using PAL4. The professional caregivers using PAL4 differentiated in age, but also here can be seen that the younger a person, the easier he was able to use PAL4.

In terms of usability, the main finding was the system is sometimes difficult to (clients and family caregivers), and was not tested by the target group prior to

\section{System impact}

The greatest positive impact on the client was on self-care by using the agenda to 
For family caregivers the system asked for extra effort and time to learn and use the system. In the long run it could reduce their burden of care.

The cost analysis showed that it is more cost effective for clients with dementia to live at home with the system than to stay in a nursing home. Although - as expectedcost-effectiveness increases if more clients stay at home for more months, we do not know for how long staying at home is an option. However, most people in Europe prefer to stay home for as long as possible (3), but the burden on family caregivers and homecare organizations has a limit. If the different stakeholders, like governments and health insurance companies would take into account cost reductions effected by eHealth technologies, their roll out could be better supported financially.

Going beyond the direct cost reductions, professional caregivers would also save time (and hence costs) by using the system since home visits could be reduced in number without lowering the quality of care.

\section{Limitations}

The above-mentioned criteria are conditions for a new technology to be adopted, but beyond that, having a smooth process for implementing that technology and a good fit between the technology, the users, and the supporting organizations is important. The problems which occurred during this project are the result of a strategy that was technology-driven instead of user centred. A better approach would be to use the holistic framework of Van Gemert et al. (18) where the whole process in a healthcare setting starts with involving the stakeholders in the design process and involving them in redesigning technology for their end-users.

The limitations of this study were first of all the inability to prove quantitatively, that someone could stay home for a longer period of time in comparison with living in a nursing home.

Another limitation concerns the log files of the system. Who is using the system (client or family care giver) is not recorded. The log files also fail to show the amount of time 
spent on the system, but only the number of clicks a person made. The amount of

The role of the client with dementia is minimal in this research; the focus was on impact on family and professional caregivers and direct costs. Caregivers have a Living) and safety issues (24). Clients with dementia report more often on how not know where you are or what year it is. Consequently, there is a marked difference in the needs of people with dementia and the interests of the family members, who provide care or the professional caregivers. In this study, clients were not asked directly about their experiences with the system. Obtaining reliable answers would be a challenge, because of their memory problems.

\section{Finances}

For the cost analysis, we only looked into the cost paid by the Dutch government for taking care of people diagnosed with dementia. We compared the two main options for people diagnosed with dementia. After reaching a certain state of needing care people can either be admitted to a nursing home or receive home care. We only looked to the costs paid by the government, because other costs differ too much among clients. Both sides (nursing home and at home) in this study exclude the mandatory personal financial contribution. And this is where the complex discussion starts. This contribution differs from person to person, as it depends on the amount of care you consume and your income.

We also did not take into account normal living expenses at home like rent, groceries, other shopping, or the qualitative benefits (like higher quality of life, because someone can stay home for a longer period of time). Not included were also extra costs, created by the burden for a family caregiver. If we were able to catch these additional costs, it would make visible that cost reduction is a complex goal. Our figures are only a crude estimation. 
Another issue in the Netherlands nowadays is the way funding for healthcare is organized. The healthcare organizations that invest in new eHealth technologies are usually not the ones that benefit from cost reductions. For example in this specific case study the healthcare organization invests with the aim of let their clients live at their own home for a longer period of time. Financially it might be more profitable to transfer these clients to a nursing home organization. The Dutch Healthcare Authority benefits from letting a person live at their own home for a longer period of time.

\section{Recommendations}

Our pilot study needs to be followed by a large scale endeavour to allow for a quantitative assessment of impact and cost reductions. Such a large scale study could also include clients with other conditions besides dementia. This future research should focus more on client perspectives instead of the perspective of family or professional caregivers and a multitude of research methodologies are needed (18).

Further cost investigation should also consider living expenses, payments by clients, video contacts instead of house visits etc. This could generate more evidence that using technologies in dementia care reduces costs.

Still this pilot showed several possible improvements. This concerns a better education and training of clients and all of their caregivers as to use, structure, aim and working of the system. Systems like PAL4-dementia are most effective when introduced in the early phase of dementia. Efficacy may also be increased by the family caregiver starting to put content into the system before the client starts to use it. When no family caregiver is available, the healthcare organization should find a buddy to do this. The PAL4 Company needs to state more clearly the requirements for the healthcare organization before starting a PAL4 Dementia project. This includes the need for an experienced occupational therapist in the project group, who has enough time available for house visits to train clients and family caregivers. 
In terms of uptake of the system, several suggestions were made by family and

- $\quad$ develop together with the target group and do usability tests.

- $\quad$ develop different interfaces for client and partner (the partner wants other information than the client).

R5

- $\quad$ all buttons should be on the opening page.

$\underline{R 6}$

- install different agenda interfaces, week, full day, or up to $15: 00 \mathrm{H}$, refreshing after that time.

- $\quad$ make games simple, in Dutch, in large print, and without a time limit.

- $\quad$ replace side icons by words.

- make pictures up loadable to the agenda, e.g., a picture of the housekeeping person who is coming.

- $\quad$ make the ringtone unlike that of the clients' phone.

- $\quad$ include a repetition feature for entering appointments by caregivers.

- $\quad$ add the option of spoken messages.

\section{Acknowledgement}

We are thankful to the care organizations ZZG Zorggroep and Bruggerbosch and the 


\section{References}

1. Wimo A, Prince M. World Alzheimer Report. London: Alzheimer's Disease International, 2010.

2. Nijhof N, van Gemert-Pijnen JEWC, Dohmen D, Seydel ER. Dementie en technologie. Een studie naar toepassingen van techniek in de zorg voor mensen met dementie en hun mantelzorgers. Tijdschrift voor Gerontologie en Geriatrie. 2009;40(3):113-32.

3. Tinker A. Housing for elderly people. Reviews in Clinical Gerontology. 1997;7(2):171-6.

4. Alm N, Astell AJ, Ellis MP, Dye R, Gowans G, Campbell J. A cognitive prosthesis and communication support for people with dementia. Neuropsychological Rehabilitation. 2004;14(1-2):117-34.

5. Astell AJ, Ellis MP, Bernardi L, Alm N, Dye R, Gowans G, Campbell J. Using a touch screen computer to support relationships between people with dementia and caregivers. Interacting with Computers 2010;22 (4):267-75.

6. Meiland FJM, Reinersmann A, Bergvall-Kareborn B, Craig D, Moelaert F, Mulvenna M, Nugent C, Scully T, Bengtsson JE, Dröes RM. COGKNOW; Development of an ICT-device to support people with dementia. The Journal on Information Technology in Healthcare 2007;5(5):324-34.

7. Sixsmith A. New technologies to support independent living and quality of life for people with dementia. Alzheimer's Care Quarterly 2006;7(3):194-202.

8. Meiland FJM, Bouman AIE, Sävenstedt S, Bentvelzen S, Davies RJ, Mulvenna MD, Nugent CD, Moelaert F, Hettinga ME, Bengtsson JE, Dröes RM. Usability of a new electronic assisstive device for community-dwelling persons with mild dementia. Aging \& Mental Health. 2012;16(5):584-91.

9. Meiland FJM, de Boer ME, Overmars-Marx T, Verhaeghe S, van Blanken M, StalpersCroeze I, Ebben PWG, Snoeck CM, van der Leeuw J, Karkowski I, Dröes RM. Rosettaondersteunende technologie voor mensen met dementie en hun mantelzorgers. In: van Hoof J, Wouters E, editors. Zorgdomotica. Houten: Bohn Stafleu van Loghum; 2012. p. 151-7.

10. World Health Organization. Medical devices: managing the mismatch: an outcome of the priority medical devices project. Geneva, Switserland: WHO Press,2010.

11. Atienza AA, Hesse BW, Gustafson DH, Croyle RT. E-health research and patient-centered care examining theory, methods, and application American Journal of Preventive Medicine. 2010;38(1):85-8.

12. Black AD, Car J, Pagliari C, Anandan C, Cresswell K, Bokun T, McKinstry B, Procter R, Majeed A, Sheikh A. The impact of eHealth on the quality and safety of health care: a systematic overview. PLoS Med 2011;8(1).

13. Catwell L, Sheikh A. Evaluating eHealth Interventions: The Need for Continuous Systemic Evaluation. PLoS Med. 2009;6(8).

14. Yusof MM, Kuljis J, Papazafeiropoulou A, Stergioulas LK. An evaluation framework for health information systems: human, organization and technology-fit factors (HOT-fit). International Journal of Medical Informatics. 2008;77(6):386-98.

15. Pagliari C. Design and evaluation in eHealth: Challenges and implications for an interdisciplinary field. Journal of Medical Internet Research. 2007;9(2).

16. Kaufman D, Roberts WD, Merrill J, Lai TY, S. B. Applying an evaluation framework for health information system design, development, and implementation. Nurse Researcher. 2006;55(2 Suppl):37-42.

17. Van der Meijden MJ, Tange HJ, J. T, Hasman A. Determinants of success of inpatient clinical information systems: a literature review. Journal of the American Medical Informatics Association. 2003;10(3):235-43. 
18. Van Gemert-Pijnen JEWC, Nijland N, Ossebaard HC, van Limburg AH, Kelders SM, Eysenbach G, Seydel ER. A holistic framework to improve the uptake and impact of eHealth technologies. Journal of Medical Internet Research. 2011;13(4):e111.

19. Cahill S, Begley E, Faulkner JP, Hagen I. "It gives me a sense of independence"Findings from Ireland on the use and usefulness of assistive technology for people with dementia. Technology and Disability. 2007;18(2-3):133-42.

20. Nijhof N. Report project "Staying home longer for people with dementia with technology" June 17. Nijmegen: ZZG Zorggroep,2008.

21. Fokkema E. CMDB Clients PAL4 dementia ZZG Zorggroep. Zeist, 2011 [cited 2011 December 20]; Available from: www.focuscura.nl/cmdb.

22. Folstein MF, Folstein SE, McHugh PR. Mini-mental state. A practical method for grading the cognitive state of patients for the clinician. Journal of psychiatric research. 1975;12 (3):189-98.

23. Lauriks S, Reinersmann A, van der Roest HG, Meiland FJ, Davies RJ, Moelaert F, Mulvenna MD, Nugent CD, Dröes RM. Review of ICT based services for identified unmet needs in people with dementia. Aging Research Reviews. 2007;6(3):223-46.

24. Topo P. Technology studies to meet the needs of people with dementia and their caregivers.A literature review. Journal of Applied Gerontology. 2009;28(5):5-37.

25. Sixsmith A. An evaluation of an intelligent home monitoring system. Journal of Telemedicine and Telecare. 2000;6(2):64-72.

26. Cahill S, Macijauskiene J, Nygård AM, Faulkner JP, Hagen I. Technology in dementia care. Technology and Disability. 2007;19(2-3):55-60.

27. Duff P, Dolphin C. Cost-benefit analysis of assisitive technology to support independence for people with dementia - Part 2: Results from employing the ENABLE cost- benefit model in practice. Technology and Disability. 2007;19(2):79-90.

28. Docampo Rama $\mathrm{M}$, de Ridder $\mathrm{H}$, Bouma $\mathrm{H}$. Technology generation and age is using layered user interfaces. Gerontechnology. 2001;1(1):25-40.

29. Bouma H, Fozard JL, van Bronswijk JEMH. Gerontechnology as a field of endeavour. Gerontechnology. 2009;8(2):68-75. 


\section{Chapter}

Social contact technology residential care:

The use of a technology-based leisure activity to support social behavior of people with dementia

Chapter 6 is based on: Nijhof N, van Hoof J, van Rijn H, van Gemert-Pijnen JEWC. The use of an eHealth based leisure activity to support social behavior for people with dementia. Submitted. 


\section{Abstract}

This paper presents the results of an evaluation of an eHealth-supported leisure game for people with dementia in relation to the stimulation of social behaviour. This used leisure game aims to stimulate social behaviour and interaction among participants with the support of technology (TV, radio, telephone and treasure box). The game was played in a Dutch nursing home with people living in the nursing home or visiting the organization's day-care centre. A mixed-method research design was applied, with observations using the Oshkosh Social Behaviour Coding scale, whereby the statistical method bootstrapping was used because of the small sample size ( $n=10$ participants, multiple rounds of observation), as well as interviews with the activity therapists. Overall, no large differences were observed for social behaviour between the leisure games with or without the use of technology. But the eHealth leisure game does create and stimulate social behaviour. It shows more active behaviour by people with high MMSE scores and by female. eHealth in leisure activities can be supportive for activity therapists organizing the activities, because it helps them to come up with new topics to address in their work. 
Worldwide, there were an estimated 35.6 million people with dementia in 2010. By 2050 an increase to 115.4 million is expected (1). There is a widespread recognition that innovative approaches are required to to meet the overwhelming demands $\underline{\mathrm{R} 5}$ that will be placed upon health and welfare systems in the future (2). These health and welfare systems should not only focus on personal care and domestic tasks of people with dementia, including the differences between male and female dementia patients (3) or the phase of dementia, for example in relation the Mini Mental State Examination (MMSE) (4), but also include opportunities to socialize, engage in activities and to achieve a sense of social integration (5).

Several studies have indicated that people with dementia have a need for company, R13 daytime activities, self-worth, expression of thoughts, social contact and a sense of belonging. Meaningful leisure activities can support people with dementia in these basic needs, which are specifically related to improving physical function, reducing depression and changing behavioural symptoms (6-9). In long-term care people with dementia express happiness and have open eyes more often during recreation times in comparison to other times of the day, so recreation stimulates one's quality of life (10). Leisure should create opportunities to have fun, make a difference, seek freedom, be with, be me, find balance, grow and develop (11). Numerous leisure activities are based on traditional means, such as board games. Innovative approaches, which are required as mentioned before, could also be used for leisure activities.

Various studies have shown that more innovative approaches, such as the use of eHealth, can also be supportive in daily care for people with dementia (12-17). Eysenbach defined eHealth in 2001 as: eHealth is an emerging field in the intersection of medical informatics, public health and business, referring to health services and information delivered or enhanced through the Internet and related technologies. In a broader sense, the term characterizes not only a technical development, but also 
global thinking, to improve health care locally, regionally, and worldwide by using information and communication technology."

This involves that the use of eHealth is not viewed as merely a tool or instrument but that is has to be considered as a way to reinvent the healthcare delivery process. In light of this view, we set up several studies on dementia care exploring the impact of eHealth on care delivery, costs and wellbeing. Especially dementia is important because of the vulnerability of these people and the increase as consequence of aging.

eHealth might also be supportive in leisure activities to improve the abovementioned needs of people with dementia (for example need for social contact), and, through fulfilling these needs, improve the health and well-being of the people with dementia. A small number of studies on the use of eHealth used to stimulate social behaviour showed positive results in relation to a more active role and positive engagement of the persons with dementia $(18,19)$. But, overall, little is known about the use of eHealth in leisure activities.

The ultimate aim of this paper is explore the impact of eHealth supported leisure activities on wellbeing of people with dementia and the work of activity therapists (which are the initiators of leisure activities).

This paper presents the results of the evaluation of an eHealth supported leisure activity called the Chitchatters game (CC) to get an insight into the use of eHealth in leisure activities. The CC aims to stimulate social behaviour and interaction among participants with dementia with the support of eHealth, which triggers people to come up with memories (20). These triggers can be made people-centred, so when needed, also specifically for young people with dementia. This is the first study evaluating the CC. The CC was played in a nursing home with people living in the nursing home or visiting the organization's day-care centre. Research on the use of eHealth in supporting leisure activities for people with dementia is not extensive, but can be effective because of the possibility to create people centred care, make the activity more interactive and be supportive for activity therapists. To partly address the research shortfall, this paper draws upon both qualitative and quantitative 
components to get more insight in the use of eHealth for leisure activities. Because

the purpose of the $\mathrm{CC}$ is to stimulate social behaviour and literature shows that social

The research questions for this study were:

- Which social behaviour occurs during a CC session?

- What are the differences in social behaviour for the CC differentiated by

- What are the differences in social behaviour between leisure games that do or do not use eHealth (Chitchatters versus Questiongame)?

- What are the experiences of therapists with the leisure game $\mathrm{CC}$, related to their daily work?

- Do they experience the CC as easy to use for themselves?

- What are the experiences of therapists with the leisure game $\mathrm{CC}$, related to the social behaviour for people with dementia?

- Do they experience the CC as easy to use to the people with dementia?

For all these research question social behaviour is related to verbal and non verbal

\section{Methods}

In this section, the interventions, study design, study setting, study participants,

\section{Intervention description}

\section{The Chitchatters}

The Chitchatters is a leisure activity developed for people with dementia by two industrial designers from Delft University of Technology, The Netherlands (20). It is intended to stimulate social behaviour and interaction among people with dementia. 
a treasure box (Figure 1), each of which triggers memories in its own specific way using Adobe (Macromedia) director software. The television shows movies, the radio plays music, the telephone tells poems, and the treasure box reveals objects chosen to a source for reminiscence and promote tactile stimulation. These objects were chosen because of their interactive character. The CC requires the participants to play while seated in a circle surrounded by the objects and an activity therapist who's leading the game sits within this circle. The therapist assigns an object with a remote control, and a lamp placed aside the object turns on. The participant with dementia then needs to activate or manipulate this object. These actions include pushing the television button, turning on the radio's volume, answering the phone, and opening the treasure box. After these actions, the object's content is revealed. The designers delivered the content (movies, music, and children's songs) used in this study in collaboration with the therapists. The Regional Archive Eindhoven in The Netherlands provided additional movies related to the region where the CC was used for sessions.

After the participants have watched, listened to or touched the fragments or objects (for example TV fragment and object from the treasure box), they are reminded about something from their own past. This, in turn, should make them come up with a personal story or anecdote related to this fragment or object from the CC. This story or anecdote then activates the other participants carrying out the activity, which is supposed to start a conversation and interaction between the people with dementia themselves and with the activity therapist (who is in the circle with the people playing the game) (20).

The objects of the CC have an old-fashioned look, in order to create a familiar "lookand-feel" for the players. The CC can be made people centred by selecting a specific category in the software to show for example all fragments about ice-skating. After the selection of a specific category or timeframe in the software (made with the remote control by the therapist), the objects (TV, radio, telephone) download the content from that category or timeframe. For instance, the category might be iceskating or the timeframe might be the flower power era. 


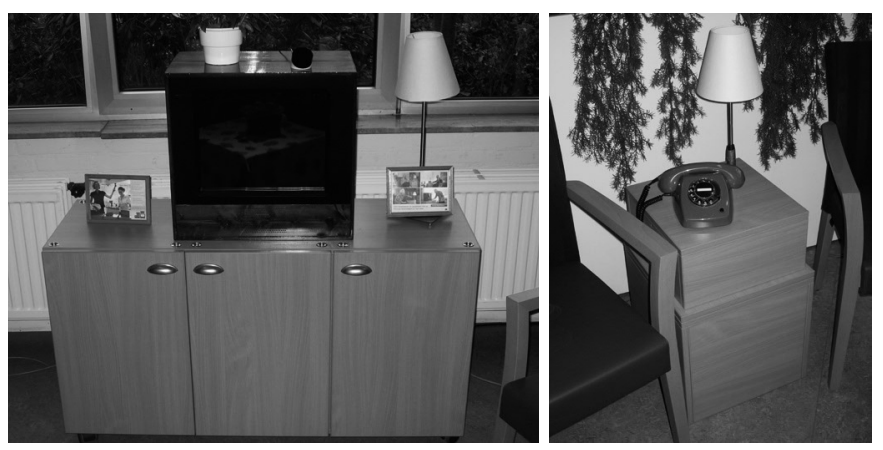

R1

R2

R3

R4

R5

R6

R7

R8
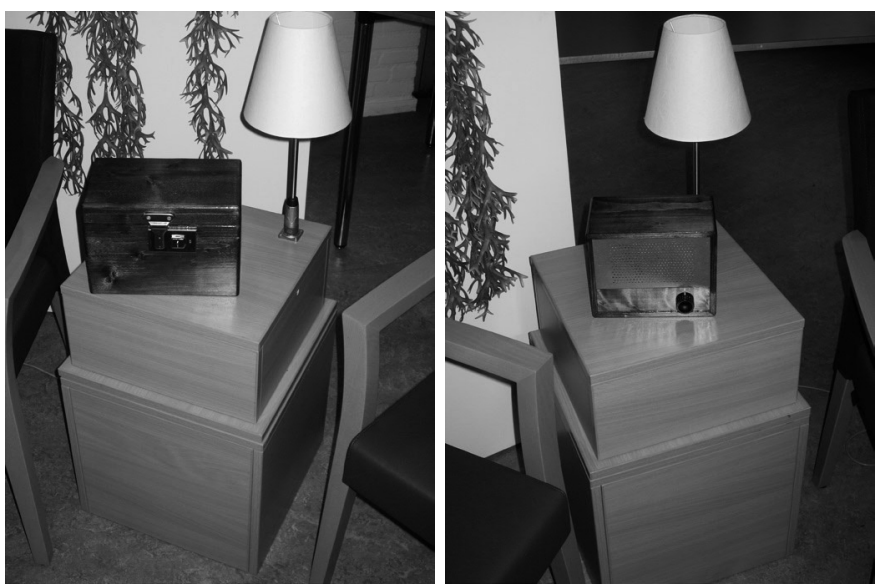

R9

R10

R11

R12

R13

R14

R15

R16

R17

R18

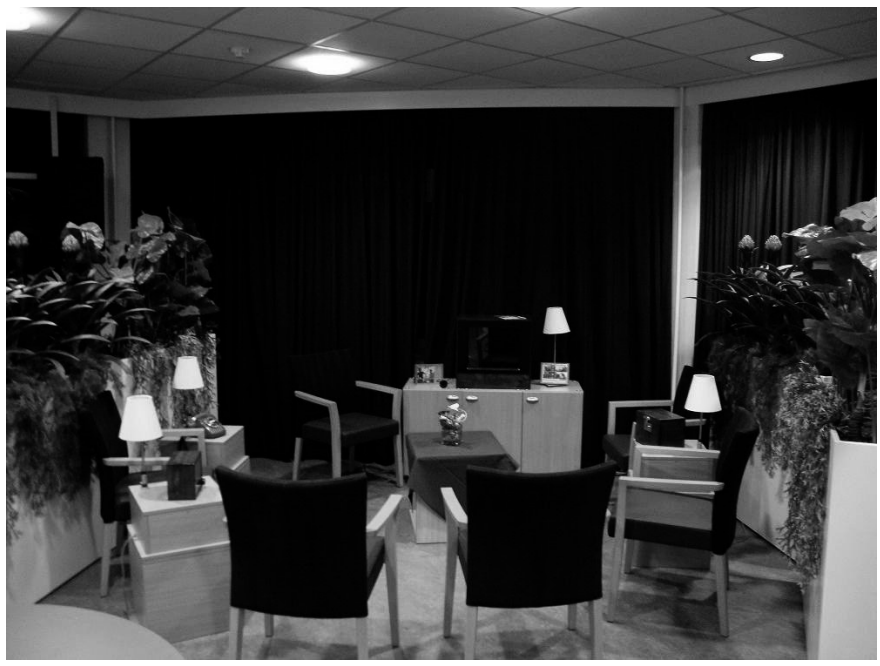

R1s

R2C

R21

R22

R23

$\mathrm{R} 24$

R25

$\mathrm{R} 2 \mathrm{E}$

$\mathrm{R} 27$

R28

R2S

$\underline{\mathrm{R} 3 \mathrm{C}}$

R31

Figure 1 Activity setting of the Chitchatters; television, telephone, treasure box and radio 
The designers introduced the $\mathrm{CC}$ to the therapists, organizing a meeting where explaining the $\mathrm{CC}$ in detail, clarifying the aim of the activity and demonstrating the process. After a few weeks, they also explained to two therapists the possibility of uploading movies and music.

At the start of this study, the nursing home had possessed the CC for three months and respondents had played with it once or twice. The therapists working in the nursing home are responsible for weekly activities for people with dementia living in the participating nursing home or who visit this facility for day-care.

\section{Question Game}

The Question Game (QG) was used as a comparison activity (Figure 2) without the use of eHealth. The QG is created by a company that is specialized in designing products for both younger and older people with disabilities. The QG is a board activity carried out on a table. A player is asked to throw a colour dice. The colour matches with a category on a question card. The different colours relate to different themes, from proverbs, songs, language, nature and an 'all sorts' category. The activity therapist reads the question out loud to the whole group, but the participant who threw the dice, may answer the question first. If the participant does not know the answer, the others are allowed to help. The answers should trigger the thrower's memory and invite other players to start telling stories as well (22).

The purpose of and way of playing with the QG is similar to the CC; it is based on the use of long-term memory, trying to trigger an individual's and group's memories, reminiscence therapy, group activity, sedentary activity in a circle, requiring an initial physical activity (throwing the dice for the QG or turning on the television for the $\mathrm{CC}$ ) and one or two activity therapists are present. QG also differs from the CC: for CC, everybody is free to respond, whereas for the $Q G$, only one participant is supposed to respond. Moreover, the CC can be customized, which is not possible for the QG. The nursing home manager and activity therapists selected the QG after they received an explanation of the CC activity. The principal researcher asked them for an activity with similar aims to the CC's: giving a trigger for social behaviour and interaction. The therapists were familiar with the QG at start of the study. Therefore, this activity did not require any instructions. It was played about once a week. 


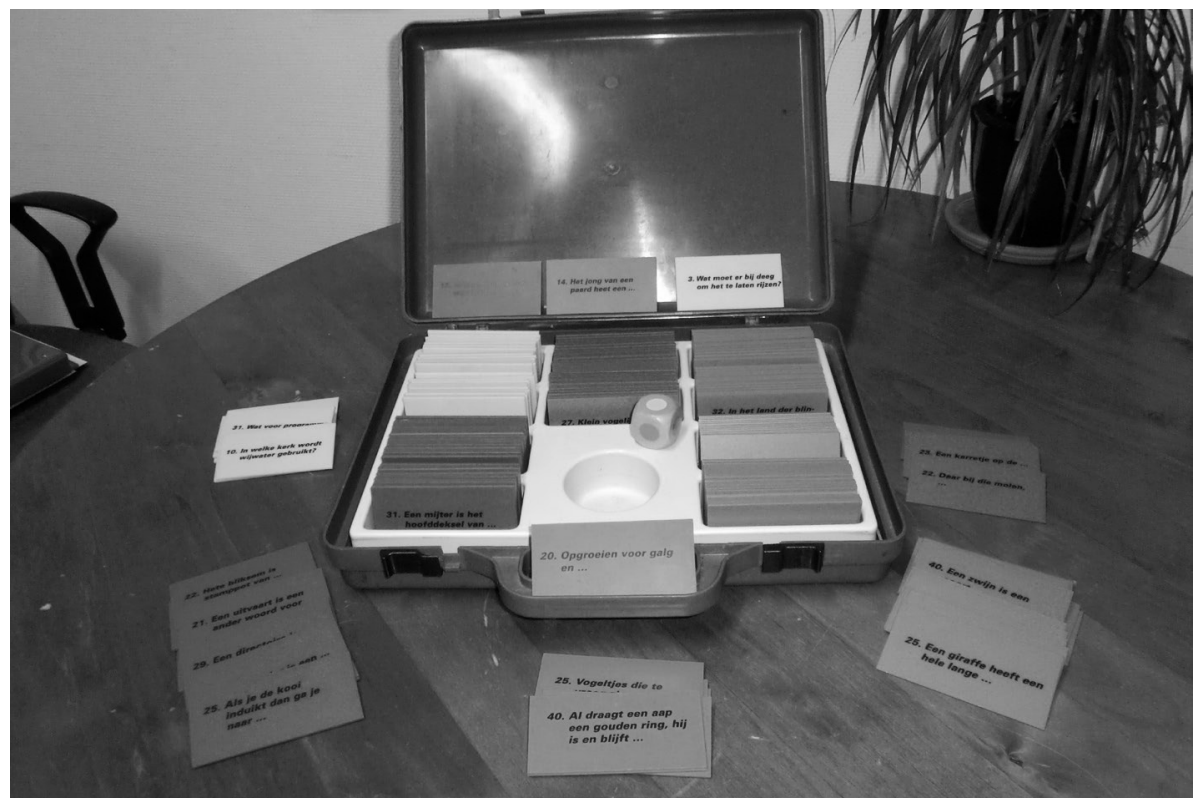

Figure 2 Question Game

\section{Study design}

For the evaluation of an eHealth application in healthcare a mixed-method design, combining qualitative methods with quantitative methods, is proposed to be the best option (23-27). The data from the different sources can be complementary and provide a broader view (27). The mixed method used in this study involved observations during the play of the games by people with dementia by using the Oshkosh Social Behaviour Coding $(O S B C)$ scale $(28,29)$, to answer the research questions related to the occurrence and differences (MMSE, female/male and CC/QG). In addition, semistructured interviews with the activity therapists were undertaken to get insight in the research questions related to supportiveness and ease of use for the therapist and social behaviour and ease of use for the person with dementia.

Participants played the game for two times each, so four play rounds in total for 45 minutes. One participant played the activities three times (she missed one of the QG activity because of a doctor's appointment); one participant played the CC and QG 
Chapter 6

set of data would be 40 (10 participants played the activities four times), because of the missing participants, we collected a set of 37 observations from 45 minutes.

\section{Study setting}

One researcher observed the participants during the activity in an observational study to answer the research questions related to social behaviour and usability. The researcher was seated behind the circle in which the activity was played, so the researcher was not participating in the activity itself. In the morning, the CC and in the afternoon the QG were each tested for 45 minutes. One group of participants with more severe dementia played both of the activities for 25 minutes. The observations were carried out twice in a two month period (October and November 2009), so every person played the CC and the QG for two times. A total of 16 activities were played for four groups in total. Group sizes ranged from three to eight participants assisted by one or two activity therapists. These activity therapists were familiar to the group. In this nursing home certain therapists were linked to specific groups. In some cases two groups were playing together, so there were two therapists steering the group activities.

\section{Study participants}

The study participants comprised people with dementia and activity therapists.

A total of 21 out of 196 persons with dementia living in the nursing home "De Landrijt" or visiting the day-care centre in the city of Eindhoven, The Netherlands, were selected to participate in the activity because of their capability to play both activities (judgement by the head of the activity therapists). A total of ten persons were observed (because of the possibility to observe only three or four persons at a time by the researcher), a responsible relative agreed for the participants to participate in the study. In total, five participants from the day-care group and five participants from the nursing home group played both of the activities.

The participants aged between 52 and 86 , with a mean of 69 . There were six females and four males. Participants' MMSE levels were established by activity therapists trained to do such evaluations. The MMSE of participants differed from 3 to 28 , with 
a mean of 18 , with two missing scores (because it was too confronting for these

participants to do the MMSE test or because they were not able to answer the questions because of an inability to speak). These missing scores were seen as low MMSE scores. Bbased on the judgment of activity therapists, this resulted in six low

The five participating activity therapists were all female, aged from 22 years to 42 years with a mean of 27 years. Their education was mid-level for social workers, specializing in geriatric care. The participating activity therapists were all the

\section{Research instruments}

\section{Observational case study}

The Oshkosh Social Behaviour Coding (OSBC) scale, which measures social behaviour for people with dementia, was used for the research question related to the occurrence and differences in social behaviour. In a comparative analysis between the Greater Cincinnati Chapter Well Being Observation tool (30) and the OSBC, the OSBC appears to be a valid and practical tool. The scale encompasses both verbal and non-verbal, social and non-social behaviour, which are the constructs and are divided in 21 items $(28,29)$. During the observation, the observers scored how often a participant showed a certain type of behaviour, for instance, smiling or gesturing.

If a participant started smiling, asked a question and started smiling again, this was scored as two scores, one for smiling and one for asking a question. The OSBC appears to be a valid and practical tool for measuring social behaviour for people 
The original lists of items of the OSBC scale were translated into Dutch by one of the authors and translated back by another author for reasons of validity before the observations started. The scale was further modified to enable the monitoring of multiple participants:

- A number of items were left out because they did not occur while playing the two activities or they were obsolete given the goals of the study. The scores left out were: greetings, please, thank you, requests, praise, empathy, interruptions, demands, arguing, frowning, physically assisting another, receiving or offering object, touching, fighting, repetitive speech, fidgeting, directed mobility, self-injurious. The omissions do not affect the validity of the scale, or the way the results of this study can be used.

- The item "answering" was split into yes/no answers, sentence answers, and story answer (which could be a personal story or anecdote). This allowed for a more specific scoring of how participants responded.

- The item "singing" was seen as non-social behaviour by the OSBC, but in this specific game "singing" was a social activity, because singing was stimulated by both of the games to do together with the group playing the games.

- The item "complaints" was seen as social behaviour by the OSBC, but in this specific game "complaints" were a non-social activity, because the complaints had a negative overtone.

- The item "smiling" was separated in laughing out loud and smiling (just by moving the mouth), because there is a difference in intensity of laughing, when it is done out loud or just by moving the mouth.

Finally the following constructs and items remained:

- Social verbal: comments, yes/no responses, sentence answers, story answers, questions, joking, singing

- Social non-verbal: laughing, smiling, gesturing

- Non-social verbal: complaints, screaming, talking to self

- Non-social non-verbal: observing/listening, sitting alone/not observing, sleeping, leaving an activity, wandering and handling object 
From the position of the researcher, the researcher scored three or four participants

simultaneously. The researcher was seated opposite their designated participants, so

\section{Interviews with activity therapists}

A total of five activity therapists were interviewed about the CC after the first activity

An interview session had three stages: a start, interview and wrap-up. The start (approximately three minutes) included an explanation about the purpose of the interview. The therapist could then ask any questions that she might have. All therapists signed a consent form so that the sessions could be audio taped. After the orientation, the interview started (which lasted for approximately 25 minutes). A semi-structured interview scheme was used, containing questions related to the supportiveness of the CC in their work (for instance, which advantages do you have from the $\mathrm{CC}$ in your work) and the ease of use of the $\mathrm{CC}$ for the therapists themselves. After these questions we focused the questions for the therapist more on the people with dementia; the social behaviour displayed during the activity by the people with dementia (did participants talk about the CC, and so on) (20) and the ease of use for the people with dementia (was the use of the lamp clear for participants, and so on) $(31,32)$. After the interview, the researcher thanked the therapists verbally for their cooperation and offered to send them a copy of the final report.

\section{Data analysis}

\section{Observational case study with OSBC scale}

The collected observation data of the QG for the two games played by the same

person were used in the same group of data for the analysis. This because the 
was carried out between the first round of game and the second round of game to see if there were any significant differences. There were no significant differences, so the first and the second round of the game (two observations for one group) were used in the same group of data for the analysis. So all the data have been used in one group for analysis.

All the scores were manually added up. SPSS 18.0 had been used for adding up the scores, for the items separately and for the scores of the constructs: answering in total, smiling in total, and so on, and social non-verbal behaviour (so all items for this construct were added up), social verbal behaviour, etc. The main purpose was to study the occurrence of social behaviour, differences in MMSE and gender and the differences between the two activities. The differences in gender and MMSE have been chosen, because of the focus on these differences in the care for people with dementia (5). The $t$-test was first carried out for the differences between the $\mathrm{CC}$ and the QG. After the initial data analysis a distinction between participants with low and high MMSE scores was made. Another distinction was made in the difference between female and male participants.

Because the care for people with dementia is more and more tailored and therefore small scaled, the groups which could play the leisure activities were only small. This has implications for the sample size. To overcome this, bootstrapping has been used to analyze the data. Bootstrap use the data of this observational study as a "surrogate population", for the intention of approximating the sampling distribution of a statistic (33). The randomly selected raw data from the first round are used for replacement by a computer program (33). The observations have to be from an independent and identically distributed population, which is the case for this study. This method of bootstrapping generates samples from the original observed data, whereby the original characteristics of these data are used. Our sample contains 10 people with dementia. We put all the 10 persons in a basket, and then from these 10 persons, we draw 1 person randomly and record the data for that person. After we have recorded it, we put the person back in the basket. Then we make another random draw, this is sampling with replacement. We did this 100 times and it's called 
bootstrap sampling. From a sample we can only get one statistic, for example mean.

The confidence intervals of this mean or distribution of this mean is not known.

In fact it means we used the original data to aggregate form a small sample size to $n=100$ sample size via a formula that translates the data into: means, standard

The bootstrap method has the advantage that it can also be used for uncommon to work with small sample sizes (35). Bootstrapping was developed by Efron in 1979 and has proven to be valid for any kind of data, random and non-random data (36)

For all the data sets, QG and CC, low and high MMSE and male or female the resampling was done for 100 times using Excel 2010 (34), whereby we separately compared QG and the CC, MMSE low and high and female or male. The average mean and SD have been calculated for all the scores separately to answer the research questions related to the occurrence and difference in social behaviour. A set of $t$-tests have been done between the CC and QG, low and high MMSE and female or male, whereby the $p$ value was determined.

\section{Interviews with activity therapists}

A coding scheme to answer the research questions related to the supportiveness of the $\mathrm{CC}$ in the work of the activity therapists, ease of use from CC for therapists and social behaviour (20) and ease of use for people with dementia(31). The therapists were asked a total of 21 questions. The transcripts were read several times in their entirety to capture the experiences of the activity therapists to aid in the coding scheme. 


\section{Results}

In this section the results for the observational study and the interviews with the activity therapists will be described.

\section{Observations}

\section{Occurrence social behaviour CC}

In the observation study, the social behaviour as displayed during a session of the Chitchatters was observed. In Table 1 the occurrence from the different social and non-social behaviours is registered. The mean stands for the mean of the number of times a person for example made any comments.

As shown in Table 1, the means of social behaviour are higher (so higher frequencies of this kind of behaviour) than that of non-social behaviour during a session of the Chitchatters (45 minutes of play). The top 5 of behaviour is comments, yes/no responses, laughing, sentence responses and smiling, which is all social behaviour. Overall people make a lot of comments during the game, which can be seen as positive as they are actively involved in the game. These results show some high standard deviations for the occurrence of "comments" and "talking to self". 
Table 1 Occurrence of social and non social behaviour during the Chitchatters game expressed

in mean and SD

Chitchatters (CC)

( $N=18,100$ bootstrap samples)

Constructs

Social verbal behaviour

Social non-verbal behaviour

Non-social verbal behaviour

Non-social non-verbal behaviour

Items from social verbal behaviour

Comments

Yes/no responses

Sentence responses

Story responses

Asking questions

Joking

Singing

Items from social non-verbal behaviour

Laughing

Smiling

Gesturing

Items from non social non-verbal behaviour

Observing/listening

Sitting alone/not observing

Sleeping

Wandering

Leaving an activity

Handling objects

Items from non social verbal behaviour

Complaints (negative)

Screaming/yelling

Talking to self
Mean

5.09

3.25

0.78

0.61

14.22

7.75

4.13

2.85

1.57

1.72

2.23

4.94

3.75

0.90

0.70

0.39

0.38

0.68

0.25

1.55

0.32

0

2.86

\section{SD}

3.31

1.98

1.41

0.93

14.67

5.63

3.85

3.76

1.72

2.54

1.90

4.02

3.75

1.15

1.25

0.93

0.96

1.74

0.50

1.06

0.74

0

5.88
R2

R3

R4

$\mathrm{R} 5$

R6

R7

$\mathrm{R} 8$

R9

R1

R1

R1

R1

R1

R1

R1

R1

R18

R1S

$\mathrm{R} 2 \mathrm{C}$

$\mathrm{R} 2$

$\mathrm{R} 22$

$\mathrm{R} 2$

$\mathrm{R} 2$

$\mathrm{R} 2$

$\mathrm{R} 2$

$\mathrm{R} 2$

$\mathrm{R} 2$

$\mathrm{R} 2$

$\mathrm{R} 3 \mathrm{C}$

$\underline{\mathrm{R} 31}$

$\mathrm{R} 32$

$\mathrm{R} 3$

R3 


\section{Social behaviour occurrence differentiated for MMSE}

As shown in Table 2 there is only a significant difference between "observing" for people with a low and high MMSE score. People with a high MMSE score tend to observe more often, so watching the television or listening to the song of the radio. Some of the SD's are relatively high, for example also for observing. Overall can be seen that the people with a low MMSE score higher for non-social and non-verbal behaviour.

Table 2 Comparison for the Chitchatters between low and high MMSE score

\begin{tabular}{llll}
\hline $\begin{array}{l}\text { Constructs and } \\
\text { items }\end{array}$ & $\begin{array}{l}\text { MMSE high } \\
\text { (16 or higher) } \\
\text { (N=8; } 100 \\
\text { bootstrapping samples) } \\
\text { Mean (SD) }\end{array}$ & $\begin{array}{l}\text { MMSE low } \\
\text { (15 or lower) } \\
\text { (N=11; } 100 \\
\text { bootstrapping samples) } \\
\text { Mean (SD) }\end{array}$ & $\begin{array}{l}\text { P-value } \\
\text { (average from } 100 \\
\text { bootstrap samples) }\end{array}$ \\
\hline $\begin{array}{l}\text { Social verbal } \\
\text { behaviour }\end{array}$ & $5.19(2.68)$ & $4.90(3.55)$ & 0.48 \\
$\begin{array}{l}\text { Social non-verbal } \\
\text { behaviour }\end{array}$ & $2.88(1.58)$ & $3.39(2.14)$ & 0.45 \\
$\begin{array}{l}\text { Non-social verbal } \\
\text { behaviour }\end{array}$ & $0.17(0.30)$ & $1.21(1.78)$ & 0.15 \\
$\begin{array}{l}\text { Non-social non- } \\
\text { verbal behaviour } \\
\text { Observing }\end{array}$ & $0.31(0.38)$ & $0.78(1.05)$ & 0.29 \\
\hline
\end{tabular}

Note ${ }^{*} p<.05, * * p<.01, * * * p<.001$

\section{Social behaviour occurrence differentiated for gender}

A difference between female and male occurred in relation to the "answers in yes or no", female give more "answers with yes or no" then male, which can be seen in Table 3. Overall can be seen that female score higher on social behaviour then male. 
Table 3 Comparison for the Chitchatters between female and male

\begin{tabular}{llll}
\hline $\begin{array}{l}\text { Constructs and } \\
\text { items }\end{array}$ & $\begin{array}{l}\text { Female } \\
\text { (n=11; } 100 \\
\text { bootstrapping samples) } \\
\text { Mean (SD) }\end{array}$ & $\begin{array}{l}\text { Male } \\
\text { (n=8; } 100 \\
\text { bootstrapping samples) } \\
\text { Mean (SD) }\end{array}$ & $\begin{array}{l}\text { P-value } \\
\text { (average from 100 } \\
\text { beotstrap samples) }\end{array}$ \\
\hline $\begin{array}{l}\text { Social verbal } \\
\text { behaviour }\end{array}$ & $5.68(3.29)$ & $4.26(2.86)$ & 0.38 \\
$\begin{array}{l}\text { Social non-verbal } \\
\text { behaviour }\end{array}$ & $3.86(1.90)$ & $2.33(1.52)$ & 0.17 \\
$\begin{array}{l}\text { Non-social verbal } \\
\text { behaviour }\end{array}$ & $0.18(0.32)$ & $1.53(1.97)$ & 0.14 \\
$\begin{array}{l}\text { Non-social non- } \\
\text { verbal behaviour }\end{array}$ & $0.24(0.33)$ & $0.99(1.11)$ & 0.21 \\
$\begin{array}{l}\text { Answer in yes or no } \\
\text { Mons }\end{array}$ & $10.31(6.06)$ & $4.18(2.90)$ & $0.03^{*}$ \\
\hline
\end{tabular}

Note $* p<.05, * * p<.01, * * * p<.001$

\section{Social behaviour occurrence differentiated for CC and QG}

As shown in Table 4 there is only a difference between the CC and the QG in relation

to "answer in sentences" and "handling objects". For the QG people responded more for the $Q G$ the $S D$ is quite high as well.

Table 4 Comparison of Chitchatters (CC) and Question Game (QG)

\begin{tabular}{llll}
\hline $\begin{array}{l}\text { Constructs and } \\
\text { items-Mean (SD) }\end{array}$ & $\begin{array}{l}\text { Chitchatters (CC) } \\
\text { (N=18, 100 bootstrap } \\
\text { samples) Mean (SD) }\end{array}$ & $\begin{array}{l}\text { Questiongame (QG) } \\
\text { (N=19, 100 bootstrap } \\
\text { samples) Mean (SD) }\end{array}$ & $\begin{array}{l}\text { P-value } \\
\text { (average from } 100 \\
\text { bootstrap samples) }\end{array}$ \\
\hline $\begin{array}{l}\text { Social verbal } \\
\text { behaviour }\end{array}$ & $5.09(3.31)$ & $7.41(4.03)$ & 0.15 \\
$\begin{array}{l}\text { Social non-verbal } \\
\text { behaviour }\end{array}$ & $3.25(1.98)$ & $4.00(2.35)$ & 0.38 \\
$\begin{array}{l}\text { Non-social verbal } \\
\text { behaviour }\end{array}$ & $0.78(1.41)$ & $1.48(2.32)$ & 0.33 \\
$\begin{array}{l}\text { Non-social non- } \\
\text { verbal behaviour }\end{array}$ & $0.61(0.93)$ & $0.32(0.62)$ & 0.33 \\
$\begin{array}{l}\text { Answer in sentences } \\
\text { Handling objects }\end{array}$ & $4.13(3.85)$ & $11.63(7.36)$ & $0.00^{* * *}$ \\
\hline
\end{tabular}




\section{Interviews}

CC in the daily work of activity therapists

All therapists suggested that the CC supports them in their work. It is a very easy way to come up with a topic to discuss with the group members. The younger therapists in particular have difficulties in finding a topic that suits the people they work with, so create patient centred activities is hard for them. It would be even more supportive to have some kind of paper or leaflet with a description of the fragments, so they knew exactly what the song or video sample is about. They also find it nice to play a different kind of activity than the usual, more traditional, activities.

\section{Easy to use by activity therapists}

In general, the therapists find the $\mathrm{CC}$ easy to use, but they were not familiar with $\mathrm{CC}$ at the start of the study and only had access to a paper manual. Some therapists mention that it is practical to turn on the $\mathrm{CC}$ a few minutes before playing the activity, so it starts up immediately when the group is ready to play. Therapists, who lack sufficient experience with computers, find it harder to use the CC.

Therapists mention that it is confusing that they always have to point the remote control towards the television, also when they want to switch the light of the radio, telephone, or treasure box. This is because the receiver of the remote control is placed inside the television stand. This is not intuitive.

\section{Social behaviour for people with dementia}

All five therapists stated that the CC stimulates social behaviour for people with dementia based on their own observations. Participants with dementia see or hear things, which is a trigger for their memory and they come up with stories from their own past. The therapists say the CC gives more triggers than for example the QG. The therapists specifically stressed that the CC makes participants go into a specific topic more deeply than when involved in other activities, because CC triggers memories and people come up with a story. All the therapists mentioned that the objects give a trigger, but that the conversation needs to be initiated by a therapist most of the time, because people do not start talking by themselves. One of the therapists assisting the group of participants with more severe dementia, said that responding to each 
other's stories is still difficult for the participants, because the memory of these more severely demented people is more affected. Of the different objects, the therapists visual tool.

Not all the participants with dementia easily understood how the CC worked. The main complication was how to turn on the different objects. In the view of all the therapists, the lamp that indicates the activated object is not noticed by any of the participants. The therapists think it is also because the light is a white light, which goes unnoticed in a day-lit room. The movies, songs and lyrics are recognized most often by the participants aged 70 years and over. For the younger participants the content is not always recognizable. The telephone was not considered to be sufficiently userfriendly. The participants pick up the phone when it rings and say their name, but the phone instantly starts playing a lyric. This is confusing for most of the participants.

\section{Discussion}

Through observations and semi-structured interviews this evaluation of the CC leisure activity highlighted the occurrence of social behaviour during leisure activities whereby eHealth is used. This eHealth application is used to give triggers to participants for stimulating social behaviour and social interaction. This evaluation study provided insight into the occurrence of social behaviour during the CC game, the differences in social behaviour between low and high MMSE participants, female and male participants, and provided a comparison to a non-technological leisure activity. Moreover, better insight was created through the views of the activity therapists working with the CC. These findings both support and contribute to the current literature in relation to leisure activities for people with dementia and the fact that leisure activities can stimulate social behaviour and with that the well being use of an eHealth application in a leisure activity, this eHealth application made it possible to create a people centred leisure activity and give interactive triggers, 
Previous work has shown the positive results of some sort of eHealth use in the field of dementia care (12-17) and in the field of leisure in particular $(18,19,38)$. A study exploring the use of eHealth to stimulate social contact showed positive outcomes. A multimedia system used in reminiscence therapy, which used photographs, music and video clips, showed a more active role by people with dementia than during the traditional reminiscence therapy (18).

The results of the $\mathrm{CC}$ evaluation indicate that the $\mathrm{CC}$ leads to a higher occurrence of social behaviour (in relation to the frequency of behaviour) instead of non-social behaviour, the highest frequencies are scored for comments, yes/no responses, laughing, sentence response and smiling. This means that the CC stimulates communication and empathy. This social behaviour is an indicator of improved well-being. From the perspective of the observational study, the CC makes people comment a lot on what they see and hear from the objects, which can be seen in the high frequency of comments during the play of the activity. In relation to the behaviour during the $\mathrm{CC}$ sessions, the results for the low and high MMSE scores corresponded with the symptoms of a person in his stage of dementia. So people with a low MMSE score tend to be somewhat less active most of the time and are more frequently observing than people with a high MMSE score, this correlates with the findings.

Looking at gender, the behaviour corresponded with the characteristics of the male and female participants (3). Females more frequently engage in social contact and giving answers than male participants do.

Overall the SD is relatively high in some cases, the explanation for this is that some of the persons playing the game give a lot of comments in comparison with the other players for example, which generates a high SD. So generally said there is a bigger difference in the behaviour of people with dementia, some people are really quiet, while others are talking all the time.

A large difference between leisure activities that either do or do not use eHealth was not seen in this study. The differences, which can be seen for the factors "answer in sentences" and "handling an object", are more outspoken for the QG due to the character of the game. During the QG people have to throw a dice several times so 
the handling an object is more than during the CC. Also people have to answer a

question with the QG, so the answer is most of the time already in a sentence. For

the $\mathrm{CC}$ the purpose is more to create memories and so stories, which happens also more at the CC, but was not a significant difference.

Both leisure activities lead to the occurrence of social behaviour, which could be

The activity therapists think that the CC can be supportive in their work, and they make the content more applicable for younger participants (younger than 65 years), for instance, by changing the music fragments. In addition, the younger activity therapists indicated that additional information about the content would help them in facilitating conversation, because they do not know much about the content themselves. The fragments are older than the therapist themselves, which makes it harder to start up the conversation and keep it going. All the therapists would like to have other types of content, for example, about nature and animals. During the CC sessions it was found that proactive therapists are a necessity to induce social behaviour. With more relevant and recognizable content, people may not need full support and might start talking more on their own.

While the findings of this study support much of what is already written in literature, this study is also unique in its focus on leisure with the help of eHealth. Furthermore, this study shows the enhanced occurrence of social behaviour during this specific leisure activity. The findings of this study have implications for both practice and further research. Looking at the practical implications it can be concluded that the CC

The limitations of this study were that a comparison of the CC to another more traditional activity is difficult to achieve. There are some relevant differences between how the various activities are played and between the various features. In this study, a selection was made of both activities because of their dependence on memory and 
Chapter 6

The OSBC scale allows only for the detailed study of the occurrence of social and non-social behaviour. It could be worth investigating if the CC stimulates social interaction as well, because this could be different for leisure activities where there is a possibility to create people centred activities and more interactive triggers. More specifically can be looked to the amount of time and the way of communicating between participants, such as whether a person talks to another person and for what amount of time, and to investigate if they respond to each other's questions.

The final limitation is the fact that the statistical method bootstrapping gives a first impression of the effects of using eHealth in leisure activities, but future research remains necessary. It is hard to observe large groups of people with dementia, because the care for these people is nowadays more and more small scaled. In this study we used bootstrapping with 100 samples, because the number of included patients in this study was too small to get reliable conclusions. Bootstrap is used more in healthcare research in the last few years, for instance for constructing confidence intervals for treatment differences, cost-effectiveness analysis in RCTs, assess provider performance for providers with small numbers of observed events (39-43). The value of bootstrapping in healthcare research is growing and also the fact that it can be supplementary to the conventional statistical thinking (44). The simplicity of the method allows its application more and more, like in this study for a small group of respondents. But still with less than 20 participants where you use this bootstrapping method, like in this study the outcomes may be less reliable. So this research was exploratory to see if there were any differences between the two games or within MMSE score and gender, but also to see the influence from eHealth in leisure games for people with dementia. Further research will be necessary with larger samples of clients.

Overall, no large differences were observed for social behaviour factors between the CC and the QG, but the CC does create and stimulate social behaviour. The CC shows more active behaviour by people with high MMSE scores and by female. eHealth in leisure activities can be supportive for activity therapists organizing the activities, because it helps them to come up with new topics to address in their work. 


\section{Acknowledgements}

The authors would like to thank the care organization SVVE Archipel, the Landrijt,

Eindhoven, The Netherlands, dr. L.S. van Velsen and dr. M.E. Zonderland for the support in conducting this evaluation. 


\section{References}

1. Wimo A, Prince M. World Alzheimer Report 2010. London: Alzheimer's Disease International, 2010.

2. Bharucha AJ, Anand V, Forlizzi J, Dew MA, Reynoalds CF, Stevens S, Wactlar H. Intelligent Assistive Technology Applications to Dementia Care: Current Capabilities, Limitations and Future Challenges. American Journal of Geriatric Psychiatry. 2009;17(2):88-104.

3. Ott BR, Tate CA, Gordon NM, Heindel WC. Gender differences in the behavioral manifestations of Alzheimer's disease. Journal of the American Geriatrics Society. 1996;44(5):583-7.

4. Folstein MF, Folstein SE, McHugh PR. Mini-mental state. A practical method for grading the cognitive state of patients for the clinician. Journal of psychiatric research. $1975 ; 12$ (3):189-98.

5. Bamford C, Bruce E. Defining the outcomes of community care: the perspectives of older people with dementia and their carers. Ageing and Society. 2000;20(5):543-70.

6. van der Roest HG, Meiland FJ, Comijs HC, Derksen E, Jansen AP, van Hout HP, Jonker $C$, Droës RM. What do community-dwelling people with dementia need? A survey of those who are known to care and welfare services. International Psychogeriatrics. 2009;21(5):949-65.

7. Sterns HL, Camp CJ. Applied gerontology. Applied Psychology. 1998;47(2):175-98.

8. Buettner LL, Ferrario J. Therapeutic recreation-nursing team: A therapeutic intervention for nursing home residents with dementia. Therapeutic recreation news; 1997/1998 [cited 2012 June 6]; Available from: http://www.recreationtherapy.com/re-dem.htm.

9. Koger SM, Chapin K, Brotons M. Is music therapy an effective intervention for dementia? A meta-analytic review of literature. Journal of Music Therapy. 1999;36(1):2-15.

10. Schreiner A, Yamamoto E, Shiotani H. Positive affect among nursing home residents with Alzheimer's dementia: the effect of recreational activity. Aging and Mental Health. 2005;9(2):129-34.

11. Dupuis SL, Whyte C, Carson J, Sadler L, Meschino L. Liberating leisure from therapy. Leisure Studies Association annual conference; Leeds, England.2010.

12. Lauriks S, Reinersmann A, van der Roest HG, Meiland FJ, Davies RJ, Moelaert F, Mulvenna MD, Nugent CD, Dröes RM. Review of ICT based services for identified unmet needs in people with dementia. Aging Research Reviews. 2007;6(3):223-46.

13. Cahill S, Begley E, Faulkner JP, Hagen I. "It gives me a sense of independence"Findings from Ireland on the use and usefulness of assistive technology for people with dementia. Technology and Disability. 2007;19(2-3):133-42.

14. Cahill S, Macijauskiene J, Nygård AM, Faulkner JP, Hagen I. Technology in dementia care. Technology and Disability. 2007;19(2-3):55-60.

15. Nijhof N, van Gemert-Pijnen JEWC, Dohmen D, Seydel ER. Dementie en technologie. Een studie naar toepassingen van techniek in de zorg voor mensen met dementie en hun mantelzorgers. Tijdschrift voor Gerontologie en Geriatrie. 2009;40(3):113-32.

16. Duff P, Dolphin C. Cost-benefit analysis of assisitive technology to support independence for people with dementia - Part 2: Results from employing the ENABLE cost- benefit model in practice. Technology and Disability. 2007;19(2-3):79-90.

17. Topo P. Technology studies to meet the needs of people with dementia and their caregivers.A literature review. Journal of Applied Gerontology. 2009;28(1):5-37.

18. Astell AJ, Ellis M, Alm N, Dye J, Campbell J, Gowans G. Facilitating communication in dementia with multimedia technology. Brain and language. 2004;33(1):304-6. 
19. Theng YL, Bin Dahlan A, Akmal ML, Myint TZ. An exploratory study on senior citizens' perceptions of the Nintendo Wii: The case of Singapore. Icreat; April 22-26; Singapore: ACM; 2009.

20. van Rijn H, van Hoof J, Stappers PJ. Designing leisure products for people with dementia: devloping "the Chitchatters" game. American Journal of Alzheimer's Disease \& Other Dementias. 2010;25(1):74-89.

21. Genoe R, Dupuis SL. The role of leisure within dementia context. Dementia. 2012.

22. Koene M. Vragenderwijs Blauw deel 2. Grou, The Netherlands [cited 2012 June 6]; Available from: http://www.michelkoene.nl/produkt/41590000/Vragenderwijs_ Blauw_deel_2.htm.

23. Catwell L, Sheikh A. Evaluating eHealth Interventions: The Need for Continuous Systemic Evaluation. PLoS Med. 2009;6(8).

24. Yusof MM, Kuljis J, Papazafeiropoulou A, Stergioulas LK. An evaluation framework for health information systems: human, organization and technology-fit factors (HOT-fit). International Journal of Medical Informatics. 2008;77(6):386-98.

25. Pagliari C. Design and evaluation in eHealth: Challenges and implications for an interdisciplinary field. Journal of Medical Internet Research. 2007;9(2).

26. Kaufman D, Roberts WD, Merrill J, Lai TY, S. B. Applying an evaluation framework for health information system design, development, and implementation. Nurse Researcher. 2006;55(1).

27. Van der Meijden MJ, Tange HJ, J. T, Hasman A. Determinants of success of inpatient clinical information systems: a literature review. Journal of the American Medical Informatics Association. 2003;10(3):235-43.

28. Lunsman M, McFadden SH, Andel R, editors. Comparative analysis and interrater reliability of the Oshkosh Social Behaviors Scale for dementia patients. Gerontological Society of America; 2007; San Francisco, California.

29. McFadden SH, Lunsman M. Continuity in the midst of change: Behaviors of residents relocated from a nursing home environment to small households. American Journal of Alzheimer's Disease and Other Dementias. 2010;25(1):51-7.

30. Kinney JM, Rentz CA. Observed well-being among individuals with dementia: Memories in the Making, an art program, versus other structures activity. Journal of Alzheimer Disease and Other Dementias. 2005;20(4):220-7.

31. Nielsen J. Usability engineering. San Francisco: Morgen Kaufmann; 1993.

32. Kushniruk AW, Patel VL. Cognitive and usability engineering methods for the evaluation of clinical information systems. Journal of Biomedical Informatics. 2004;37(1):56-76.

33. Akins RB, Tolson H, Cole BR. Stability of response characteristics of a Delphi panel: application of bootstrap data expansion. BMC Medical Research Methodology. 2005;5(37).

34. Teknomo K. Bootstrap Sampling Numerical Example. 2006 [cited 2012 June 20]; Available from: http://people.revoledu.com/kardi/tutorial/Bootstrap/examples.htm.

35. Linden A, Adams JL, Roberts N. Evaluating disease management program effectiveness: an introduction to the bootstrap technique. Disease management \& health outcomes. 2005;13(3):159-67.

36. Edgington ES. Randomization tests. New York: Dekker; 1996.

37. Good P. Permutation tests: a practical guide for resampling methods for testing hypotheses New York: Springer-Verlag; 2000.

38. Orpwood R, Gibbs C, Adlam T, Faulkner R, Meegahawatte D. The design of smart homes for people with dementia-user interface aspects. Universal Access in the Information Society. 2005;4(2):156-64. 
Chapter 6

39. Maetzel A, Strand V, Tugwell P, Wells G, Bombardier C. Economic comparison of Leflunomide and Methotrexate in patients with rheumatoid arthritis. Pharmacoeconomics 2002;20(1):61-70.

40. Peris F, Martinez E, Badia X, Brosa M. latrogenic cost factors incorporating mild and moderate adverse events in the economic comparison of Aceclofenac and other NSAIDs. Pharmacoeconomics. 2001;19(7):779-90.

41. Neymark N, Adriaenssen I, Gorlia T, Caleo S, Bolla M, Brochon D. Cost-effectiveness of the addition of early hormonal therapy in locally advanced prostate cancer: results decisively determined by the cut-off time point chosen for the analysis. European Journal of Cancer 2001;37(14):1768-74.

42. Chen M, Kianifard F. A nonparametric procedure associated with a clinically meaningful efficacy measure. Biostatistics. 2000;1(3):293-8.

43. Bredell H, Crookes RL, Heynes dPA, Schoub BD, Morris L. Molecular investigation of two possible cases of accidental HIV-1 transmission in South Africa. AIDS Research Human Retroviruses. 2003;19(7):613-7.

44. Henderson AR. The bootstrap: a technique for data-driven statistics. Using computer intensive analyses to explore experimental data. Clinica Chimica Acta. 2005;359 (1-2):1-26. 


\section{Chapter 7}

Conclusions and discussion

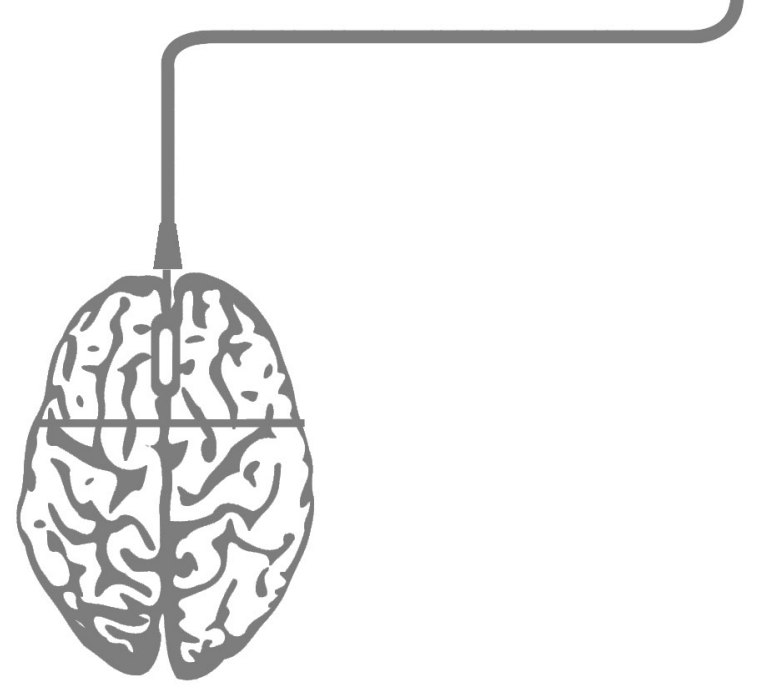


Chapter 7

$\mathrm{R} 1$

$\mathrm{R} 2$

$\mathrm{R} 3$

R4

$\mathrm{R} 5$

\begin{tabular}{l}
$\mathrm{R} 6$ \\
$\mathrm{R} 7$ \\
\hline
\end{tabular}

$\mathrm{R} 8$

$\mathrm{R} 9$

$\mathrm{R} 10$

R11

$\mathrm{R} 12$

$\mathrm{R} 13$

R14

$\mathrm{R} 15$

R16

$\underline{\mathrm{R} 17}$

$\underline{118}$

R19

$\mathrm{R} 20$

R21

R22

2

$\underline{R 24}$

$\underline{225}$

R26

227

$\mathrm{R} 2 \varepsilon$

R2S

$\mathrm{R3}$

R31

R32

$\mathrm{R} 33$

R34 
The goal of this dissertation is to present the implications of developing and implementing eHealth for people with dementia in home-based and residential care with a focus on technology used to monitor patients and improve their social contact. The research questions of this dissertation focus on the use of eHealth technologies in dementia care, the implementation of eHealth in practice, its uptake and impact, as well as the implications of developing eHealth and implementing it for patients

The introduction of this dissertation illustrated the growing number and cost of people there is a changing healthcare structure, with fewer people working in the healthcare sector, but more people to care for. eHealth might be one of the approaches which are required to meet the demands upon formal and informal care systems in the future. There is a lack of scientific evidence in the field of eHealth for people with dementia and many eHealth technologies in general are not doing well in providing sustainable innovations in healthcare practices.

In this dissertation our focus was on the operationalization and summative evaluation of the use of eHealth technologies for people with dementia, in people's own homes and in residential care. We followed the CeHRes roadmap to guide the evaluation process (1). We used a literature review and four case studies to answer our research questions. For the operationalization phase we looked into the implementation of the eHealth technology used. For the summative evaluation we looked into uptake:

In this section of the Conclusions and Discussion we will comment on the findings with 
the discussion we will comment on the methods used, and on the strengths and limitations of this research. The research we have done in this dissertation creates new research questions for the future, which will be described at the end of this chapter as well.

\section{Conclusions}

In this dissertation we investigated the type of technologies that were generally used in dementia care. From the literature review in chapter 2, it appeared that the impact of the technologies used has not been studied extensively. The technologies can be divided into signalling, monitoring and social contact technologies (Research question 1). The scientific evidence of technology related to social contact and monitoring is especially rare. There are more practical descriptions for these kinds of technologies, than scientific studies. But still the preliminary results out of the literature review for these two categories of technologies look promising in relation to patients' quality of life and patients' behaviour. This is also the reason why this dissertation focused on monitoring and social contact technology.

The findings of this dissertation can be applied to monitoring and social contact technologies used for people with dementia. However, the findings, implications and recommendations might even be useful for the use of signalling technologies for people with dementia or the use of eHealth more generally for groups other than those consisting of people with dementia. The monitoring technologies might also be useful for people with other cognitive impairments and the social contact technologies might be useful for people with other (not) congenital cognitive impairments or for elderly and vulnerable people. The monitoring technologies create a feeling of safety and the social contact technologies create structure during the day or alternatively could be used to reduce loneliness. 
In three studies (chapters 3, 4 and 5) the activities that were carried out for the implementation of eHealth were also evaluated. In all of these studies improvements

The problems as seen in the studies were related to changes in the project groups, a lack of internal communication about the project within the organization, a lack of

No difference in home-based/residential care or monitoring/social contact technology was observed.

\section{Literature}

Mair et al. (2) carried out a literature review of sixty-six review papers related to barriers against, and facilitators of, the implementation of eHealth. The key barriers included inadequate information management, inadequate inter-agency cooperation, intrusive technology/rigidity of the system, cost, and the absence of any of testing systems. The key facilitators for eHealth included positive inter-agency co-operation, flexibility, ease of use, organizational willingness and ability to order information. In other studies the following suggestions are given for the implementation of eHealth: see the patient as a person, the product as a service, and ensure that the service is validated by the person (3). But also create staff involvement and commitment, with little attention paid, or interest given, to the impact of new eHealth technologies on the workload, inter-professional relationships, and the communication between caregivers and patients (5). Broens et al. named five categories which influence the implementation of an eHealth technology: technology, acceptance, financing, 
These afore mentioned results in the studies related to implementation show similarities with the results of our research. Even though all of these studies relate to eHealth, and not specifically to use by people with dementia, the implementation of eHealth has the same issues as it does for people with dementia. Examples include the development together with the end-users or embedding eHealth in the daily care practice routine.

\section{Implications}

Implementation plays a major role in determining the success of an eHealth technology. Implementation influences the uptake and impact of an eHealth technology. As mentioned in our introduction as well, there is a proven relationship between the sustainability of an eHealth technology in a healthcare setting and its implementation (5) (chapter 1). A well-organized implementation process was missing in the studies included in this dissertation, which will be the reason for lower uptake and less impact.

First of all, it is important to have an active project group with all of the stakeholders involved from the outset, that is: from the family/professional caregiver to the people with dementia, to the policymakers themselves. These project groups should be involved right from the start, receive time to spend on the project, and should be communicating regularly with the rest of the healthcare organization (chapter 3, 4 and 5).

Secondly, there is no need to embed eHealth in the daily care routine right from the start of the project, because users have to be given enough time to get used to the technology as well. However, there should eventually be a focus on the changes that eHealth will bring to the daily care routine. If the technology is more frequently used, a detailed analysis should be carried out of how these daily care processes should be changed (chapters 3-6).

Consequently, for the implementation phase it is important to let people get used to the technology (give them the time and proper training for this as well), let the 
innovation diffuse itself within the organization (7). After that, create changes in the

daily care routine and with that look for a business model which might be interesting.

This business model could focus on different factors such as: more efficiency in the night care with fewer people working, video contact instead of house visits,

Another and final subject which is not always taken into account with eHealth have more insight into their relative's data, although the professional caregivers did say that this was linked to the privacy of the patient (chapter 3 ). It is wise to think about these issues early on in the implementation phase and not when a specific situation might occur (8).

\section{Uptake}

\section{Empirical research}

Monitoring technologies (chapters 3 and 4) prescribe a certain usage, active or passive, depending on the user. The person with dementia is a passive user, only having the technology in their home or around their wrist in our studies. The professional caregiver has to analyze the data of the monitoring technology. This analysis of the data was carried out differently in the two studies, every day and twice a week. For the 'technology used on a daily basis' an intended usage was given,

Social contact technologies (chapters 5 and 6 ) require active usage by the people 
Chapter 7

Apart from the difference between individuals for the actual usage, the not given intended usage also creates differences in actual usage.

In relation to the usability of the eHealth technology, all of the technologies received several suggestions and comments about user-friendliness (chapters 3-6). The userfriendliness could be improved because the technologies used were not tailored from the mindset of people with dementia (cognitively impaired) or their caregivers (not used to working with technologies) and should be more tailor-made to the individual (because every person with dementia is different). The technology was also still prone to too many glitches (Research question 3).

\section{Literature research}

In the existing literature, no research was found about the actual usage of eHealth technology by people with dementia, although there is some literature in the field of actual usage of eHealth for other patients, which is in turn mostly related to internet technologies. For internet technologies in the healthcare sector, it can be seen that the actual usage is much lower than the intended usage. They offer two solutions for this: create an attitude towards unintended use in relation to further valuable adoption and support the use of the service, instead of only the e-service (9). For a web-based, disease management programme for supporting the self-care of diabetes patients the technology was hampered by low enrolment and non-usage attrition. The main barriers were poor user-friendliness, absence of push factors (prompts), and selection of the 'wrong' users. The solutions given in this study were as follows: avoid selective enrolment, make use of participatory design, and develop persuasive technology (10).

These internet technologies are not totally comparable to the technologies used in our study. In our study we used devices instead of internet technologies, but nonuser-friendliness was mentioned by the people with dementia themselves as well as by the caregivers. Push factors were not specifically mentioned in our projects, but for people with dementia you have to create specific reminders, because of their cognitive abilities. The caregivers received instructions for one project about how 
often to use the technology, which were followed. For people with dementia no real instructions were given and if this was the case (such as: put on PAL4 every morning) this did not always work for this specific group of people because of their cognitive abilities. Reminders should be given several times and in an easy and clear way.

The differences we found in our study between the actual usage in relation to gender, MMSE and personality were not found in other studies for people with dementia and the use of eHealth technologies.

As mentioned above, in our studies the technologies used are not always userfriendly, but in Lauriks' et al. review the technologies seem to be easy to use (11). A possible reason for this is that most of the technologies in Lauriks' et al. study were not commercially available technologies, but rather research technologies, whereby the phase of contextual inquiry - and so the development of the technology - was done together with the end-users, because these technologies were developed during the research period.

On the other hand, comparable with other commercially available technologies, our studies showed positive results in relation to the usability, for example the measurement and improvement of the sleep and wake patterns of a person with dementia. In our study (chapter 4), we showed positive results, but in another study in which they used motion sensors, bed mat and bed sensors it was much more difficult to measure, because people with dementia get in and out of their bed. Even if people were in their bed it was hard to ensure that a person was asleep (12). The IST Vivago watch is definitely an improvement in contrast with these sensor technologies, although not all people with dementia prefer to have something to wear like a watch.

The possibility of creating heuristics to choose from for an eHealth technology for people with dementia is also mentioned by Kinney et al. (13), in which the caregivers 
As mentioned in our studies as well, most technologies do have glitches, which is common in other studies as well: in a project in a residential care setting the technical staff had to work 12 to 16 hours each week to solve bottlenecks with the technology (14).

\section{Implications}

The uptake related to usage can be increased by describing the intended usage, users and context of usage (home/residential) of the monitoring and social contact technologies. The uptake related to usability can be created to match the technology with the users' needs, which creates more user-friendly eHealth technologies. This should all be done in the contextual inquiry and implementation phase (operationalization) of an eHealth technology (see CeHRes roadmap).

In all of the four studies (chapters 3-6) there was no match between the needs of the people using the technologies. These needs were not recognized during the development of the technologies, for example: the watch which was used did not work well with the fragile arms of an older person.

First of all, because the needs are so different from those for 'usual seniors' it is hard for a healthy person to imagine how a person with dementia sees the world.

Secondly, it is also hard from the perspective of validity to ask people with dementia directly (especially in the more severe stage of dementia) what they feel and think about general things and the fact that all people with dementia have different wishes and needs. But even though it is hard to get a clear and real life view of the lives of people with dementia, it is important to attempt to do so in order to strive for the eHealth technologies to be worthwhile. This could be done by observations or through interviews with the family caregivers if people are in a more severe stage of dementia. If people are in the initial phase of dementia it is possible to ask them about their needs themselves most of the time.

The needs of Roest et al. (15) might be of assistance, but we have to think about how to integrate these needs in technology (chapter 1 ). These needs, which are related to 
the domains of memory, information, company, psychological distress and daytime activities, need to be analyzed more. So for the need 'company', what exactly do the people with dementia want in relation to company? Do they want a real life visit or is the possibility of talking to someone (even if it is through a video contact) enough? Or do they want both of them? If so, in what frequencies? All these details need to be explored in more detail through interviews with people with dementia themselves or R6 their family caregivers, before the technology can play any sort of meaningful role.

Furthermore, the wishes and needs of people with dementia differ from individual to individual and because it is commercially-wise not possible to create an individual eHealth technology for every person separately, it would be wise to create heuristics to choose from, in short: a people-centred and flexible eHealth technology. For PAL4, for example, in the newest version the possibility to choose three different sorts of agendas was included: a daily agenda till $3 \mathrm{pm}$ (after that it refreshes itself for the appointments after $3 \mathrm{pm}$ ), a daily agenda in total, and a week agenda (chapter 5).

Next to this more in-depth analysis of the needs of the end-users, it is also important to let people know the possibilities of today's cutting edge technology. Elderly people with dementia today are unaware of all these possibilities. The danger is that if a person with dementia is asked whether he or she would like to use technology for some of their needs, they do not have the slightest clue of the possibilities. Therefore, scenarios and possibilities should be explained and showed to the person with dementia to give him or her a good overview (chapter 3 and 5).

Family caregivers who are closely related to people with dementia have to be included in this contextual inquiry as well. For example, for the ADLife system all of them said that the monitoring system should be expanded to monitoring and signalling situations (in other words, the system should also generate an alarm when someone falls down), which would make them feel more safe.

People with dementia and family caregivers are not the only users of the technology; the professional caregivers also use it. These professional caregivers are familiar with all the ins and outs of caring for people, but not about working with technology or 
even more specifically eHealth technologies. Data as shown on a webpage of ADLife might be easy for a technician to understand, but not necessarily for the professional caregiver (chapter 3).

Overall, it is important, right from the start, to involve the end-users in the choice or design of a specific eHealth technology. After that has been accomplished, the intended usage for every technology should be thought about carefully, together with the users and the context of its use, because this is very different for every technology; there are no straight-forward rules for this.

\section{Impact related to well-being}

\section{Empirical research}

In this dissertation we use a broad definition of the well-being of people with dementia; it could be all sorts of good or satisfactory conditions of existence (16) because the eHealth technologies have different purposes in relation to wellbeing, ranging from feelings of safety and security, social contact, and sleeping, to supportiveness in their daily life.

Firstly, focus on the well-being of the people with dementia themselves. For monitoring technology (chapters 3 and 4), improvements for well-being are in relation to the health status of people with dementia or to creating a feeling of safety and security. But this feeling is only for the people with dementia who are aware of the monitoring technology in their home, for example if people with dementia still know after a few days or weeks that there were sensors in their house registering their patterns. After the installation, most people forgot that these sensors were in their homes.

For social contact technology (chapters 5 and 6) improvements are observed in relation to social behaviour, a feeling of safety, and pleasure for the people with dementia. For example, by playing the memory games on PAL4, using the agenda, or making video contact with family caregivers. 
Although not quantitatively proven nevertheless, according to the caregivers (qualitatively proven), the technologies used in home care also make it possible for

Secondly, we looked at the well-being of family caregivers. In residential care, decrease the burden for them: they still had to do the laundry, grocery shopping or take care of the financial administration for their sick relative, which takes up a lot of effort and time (Research question 4).

\section{Literature research}

For the impact related to well-being, the positive results in our study correlate with the findings of other studies $(11,17)$ and with our own literature review results (18) in which social contact technologies were liked by people with dementia and were supportive for caregivers. For the monitoring technologies, we found that they increased the sense of safety and reduced feelings of fear and anxiety for people with dementia and their family caregivers.

In our studies there was supportiveness for the family caregiver, but no reduced burden. In a study where family caregivers of dementia patients could use a technology-based psycho-educational intervention, a significant decrease in this burden was observed (19). In another study, no significant differences were found for burden, depression, coping, quality of life, knowledge and satisfaction after the use of a screen-phone to support and educate caregivers (20). These studies and 
As also mentioned in this study, it is quite hard to quantitatively prove that someone can live at home for a longer period of time through the use of eHealth. In a study with a monitoring and signalling eHealth technology, six out of the 18 people experienced a delay or prevention in being taken into residential care by the system that was used, for five persons a delay was not possible, and for the other persons there were different reasons for their institutionalization (21).

\section{Implications}

The positive impact of well-being for people with dementia and their family caregivers was observed in the use of eHealth technologies, but could be expanded further.

One of the possibilities to expand this impact is a match between the technology and the needs of the users and a well-organized implementation process, as described earlier. The last possibility to expand this impact on well-being is by focusing on the phase of value specification from the CeHRes roadmap.

In this dissertation we saw that, for most of the time, the reason for being taken into residential care is because the patient becomes too much of a burden for the caregiver (chapter 3). Unfortunately, the technologies used in this dissertation did not reduce the burden on these family caregivers. The overall goal of eHealth is to generate a higher quality of care, but with that it must also be cost-effective and this can be created to enable people to continue living in their own homes for as long as possible, so less burden should also be created instead of only supportiveness and a feeling of safety as proved in this dissertation. These values should be specified together with the stakeholders before designing and implementing the technology.

The stakeholders could be the person with dementia himself, the family and professional caregiver, the policymaker, the specialist in elderly care, etc. The values of the stakeholders should be taken into account and given priority. In general, it was stated in all the studies we did, which were pilot projects, that the healthcare organization wanted to create cost savings and a better quality of life for the person with dementia, so this has a high value and should also be included in the eHealth technology used (value specification). 
The monitoring technologies (chapters 3 and 4) generate the possibility to create interventions as seen in our studies. It gives the professional caregivers an extra sensory organ. For the social contact technologies (chapters 5 and 6), the healthcare

For the residential care (chapters 4 and 6), the impact on healthcare delivery is in relation to night shifts or efficiency in the work (with the support of eHealth). In the homecare (chapters 3 and 5) the impact on healthcare delivery is more in relation to creating more independence for the person with dementia, more support for the family caregiver, and some efficiency possibilities in the work of professional caregivers (for example, making video contact instead of a house visit).

The eHealth technologies that were used could all have their impact on healthcare delivery in the participating healthcare organization. Not all of the participating healthcare organizations have embedded the technologies totally in the organization of their daily care routine, so the impact differs for every organization, not only in terms of the degree of the impact, but also on how the impact is experienced (Research question 4).

\section{Literature research}

The results in this dissertation relating to healthcare delivery correlate with findings in other studies $(11,18)$ where interventions, where started by monitoring technologies and social contact technologies to create support in the work of professional caregivers. The fact that eHealth is not embedded in the routine practice of daily care, is also indirectly seen in a study where they used motion sensors in a nursing home. The professional caregivers mentioned that the workload and stress increased, because there was a lot more to deal with during working hours (22). If the eHealth technology that was used had been embedded into the routine practice of daily care this would not have been the case. In this sense, eHealth should create some support 
no negative effect on the workload of the caregiver (23). In this dissertation small changes could be seen, some house visits were done by video contact for example. So this study shows that changes in the healthcare delivery are possible, but again embedding in daily care practice is necessary to expand this impact.

\section{Implications}

eHealth technologies create possibilities for efficiency in healthcare delivery. But the possibility to create just-in-time care instead of just-in-case care is still not fully used, which is also a consequence of the fact that the professional caregivers are not used to working with these kinds of technologies and do not know how to interpret the data or let the technology support them in their work and make care decisions from the things they see at a patients' room or home, together with the technology (chapters 3-6). The possible solution for this lies in the points described for the development and implementation for embedding the eHealth technology in the routine daily practice of care.

\section{Impact related to cost savings}

\section{Empirical research}

The costs savings investigated in this dissertation are created by letting someone live at home for as long as possible instead of having them taken into residential care.

Compared to staying in residential care, for 10 clients living at home with ADLife for duration of two months, the savings were $€ 23,665$, while for 50 clients the savings were $€ 124,122$ (chapter 3). For 10 clients living at home with PAL4 for one month longer, instead of in residential care, the savings were $€ 8237$, while for 50 clients this was $€ 43,187$ of savings (chapter 5 ). Therefore, cost savings can be created by postponing the moment of intake into a nursing home through the use of supportive eHealth technologies. The breakeven point is for both of the technologies around the $€ 5000$ for home care and next to that the use of the technology. So if a person is getting more severe dementia and also has to receive higher levels of care, it will finally turn out to be more cost-effective to let someone go into residential care (chapters 3 and 5). 
Not in this dissertation, and in no other single scientific study carried out so far, it

has been quantitatively proven that someone is definitely able to live at home for a

\section{Literature research}

Other studies related to cost savings show different kinds of results; in one study, admitting a person into residential care was cheaper than providing home-based care, which often involved frequent and costly visits to the person's home (13). Another people in the intervention group for 21 months), because admission into residential care, a hospice or hospital could be delayed (25). But there will be a breakeven point, when living in residential care might be more cost-effective, in a study where they used a signalling and monitoring technology, people with dementia were able to stay at home, but the caregivers had to come by eight or nine times a day, which is very expensive (21).

\section{Implications}

Cost savings can be generated by using eHealth for people with dementia. In relation to the cost savings, which is a major point for the Dutch Healthcare Authority and with that the Healthcare insurances, the cost savings as shown in this dissertation have already been used by 'Zorgverzekeraars Nederland' (the Dutch association of health insurers) for a more in-depth study about these costs in relation to the cost components they have concerning dementia-related health care. In the study, the aim was to provide third party payers (the party besides the patient and the health care provider that is concerned with the payment of healthcare) with a methodology to conduct economic analyses (EAs) facilitated by an economic model (EM) for the 
different groups of people with dementia were formulated: diagnosis, domestic support, domestic care and nursing home care. Scenarios were also formulated such as 'Implementation in Domestic Support phase, Maximum Delay, Best Case Scenario' (with 'delay' was meant no intake in a nursing home and with 'best case' that the technology life span was 5 years, data could be read by 30 people and with a complete cost reduction in hospital care, extramural care and intramural care). A model was built and, for the ADLife case study which was used, the model showed positive results again. This model was different to our model, because we used specific clients details about the costs of homecare and in this model national numbers were used for the costs of dementia care. Also in this study depreciation and different scenarios were tested, which was not the case in our study. ADLife had the ability to improve the efficiency in the delivery of care at home, with maximum possible savings of up to $€ 118,606$ (for the period the person receives care) when the technology was implemented in the Domestic Support phase and €89,694 when the technology was implemented in the Domestic Care phase. The worst case scenarios showed that when ADLife was implemented in the Domestic Support phase, cost savings of $9 \%$ made the implementation of ADLife break even with the costs of current care. When ADLife was implemented in the Domestic Care phase these costs savings needed to be $7 \%$. This means that if the current care is $€ 242$, the care with technology is $€ 266$, there will need to be a saving of $€ 25$ in the care to allow the technology to be more cost-efficient. In percentages this is $(266-242) / 242=0.09(26)$.

In our study we did not directly use the groups of diagnosis, domestic support, etc. as Vermeulen et al. did (26). We did, however, use the MMSE score in three out of the four studies (chapters 3, 5 and 6), but this score will not exactly correlate with these groups, a person with a low MMSE score, so more severe dementia, might still be in the domestic support phase, because of a lot of help from a partner. The studies which we have done in residential care correlate with the nursing home or domestic care (people coming to the day-care centre of the healthcare organization, but still living at home). The studies we have done in the homecare correlate with domestic support (for social contact technology) and domestic care (for monitoring technology). As seen in this dissertation, the use of the technology has a lot to do 
with the personality, gender and MMSE of the person with dementia (chapters 5 and

6), so combining these details with these groups will be useful for further research

Overall, the Dutch healthcare system does not have an adequate finance structure nowadays to create a more structural way of funding for eHealth technologies for people with dementia. The financial aids are well-organized in the Netherlands in comparison with other countries, but the structural finance is more harsh. The healthcare organization that is making the investment does not always get a return on this investment. Homecare in the Netherlands is financed by the so-called AWBZ (Exceptional Medical Expenses Act), but an intake into residential care is paid by the Dutch Health Insurances, so if an intake into a residential care home is delayed this will benefit the Healthcare Insurance. But nowadays the investment for the eHealth technologies comes from the homecare organizations and thus the AWBZ. This might change in the future, but this dissertation describes the situation nowadays.

Overall, more in-depth research into the possible cost savings is necessary, whereby the model of Vermeulen et al. (2012) could be useful in new studies (26).

\section{Discussion}

\section{Methods}

The methods used in this dissertation were always a mixed method design, so a combination of qualitative and quantitative methods; one of the best methods to evaluate eHealth technologies (27-31). Interviews, observations, focus groups and diaries were the qualitative methods and the analysis of the monitoring data, log files and cost analysis were the quantitative methods. These methods were also linked with each other, so if the interviews about using the IST Vivago watch showed us that the professional caregivers changed a specific medication, the monitoring data from the watch could be used to see the impact of this on the sleep of that specific 
In some cases, such as the monitoring data of the Watch, the collected data were still pretty small (chapter 4 ) and for the ADLife data we did not look in detail into the red, yellow and green alarms and taken actions (chapter 3). And for PAL4, the log files were not as detailed as we had initially wanted. Consequently, we could only see the number of clicks people made and not, for example, the time they spent on a specific button (chapter 5). For the Chitchatters, we used the Oshkosh behaviour scale, but we did change this scale for our specific study, which might have produced a bias and we used bootstrapping because of the small sample size (chapter 6). Overall, the quantitative analysis still gave enough insight into the uptake and impact of the eHealth technology.

For the interviews, we always talked to the professional and family caregivers and not to the patients with dementia themselves. Although the thoughts and needs will be different for these groups (caregiver or patient) $(15,32-35)$. For the interviews with family caregivers from the participants of PAL4 and ADLife (chapters 3 and 5), some clients themselves were there when the interview took place, so the comments they made were included in the transcripts of the interviews. It would have been preferable to include interviews with people with dementia as well, but new methods should be developed on how to do this in an efficient and reliable way. At the outset of this dissertation we did interviews with people with dementia themselves about their expectations of the technology, however, they did not answer the questions, but instead started talking about the grocery shopping, for example. This is probably due to the symptoms of dementia, but also because of the totally new use of a technology; one which this generation of people with dementia is not used to. For the recruitment of clients for the different projects, we did not randomly choose the clients. The clients were recruited by the professional caregivers who knew the clients. If the professional caregivers thought that the client would be capable of using the technology, or for the monitoring technology would have profited from the technology, and they and their family caregivers wanted to join the project, then they were included. We did this because the projects were all small and in small districts or residential cares, so we did not have the possibility to randomly choose the clients. 
With that we did not have a control and intervention group as well, because of the

small size of the sample, but also because of the difficulty to make a comparison

\section{Strengths and Limitations}

Firstly, when examining the strengths of this dissertation, one of its main qualities is the empirical aspect. In this dissertation, commercially available systems have been used in order to evaluate them; the main advantage is that other healthcare organizations around the world could easily use the same eHealth technologies and learn a lot from the main findings of the current research.

Moreover, the research carried out in the field of eHealth for people with dementia is minimal, so the research done for this dissertation helps to fill this research gap. Alongside the practical and scientific added value, the topic of this dissertation fits in with current developments within today's healthcare system. There are an ever increasing number of elderly and chronically ill people, but fewer people to care for them, so there is a need for change and eHealth could play a supportive role in this.

The healthcare organizations are looking for recommendations to implement eHealth for people with dementia and this dissertation provides such recommendations.

On the other hand, when we look at the limitations; it was sometimes harder to change some small aspects in the technology (29). If the technologies used were research technologies, then this would have been easier.

This dissertation gives a first impression of the use of eHealth for people with 
larger groups of people, is necessary. Unfortunately for this dissertation, the eHealth technologies used are still quite expensive, so they are less easy to apply for hundreds of people with dementia.

Furthermore, the cost analysis carried out in this research provides the first design of a possible business model for people with dementia (chapters 3 and 5). However, more detailed figures are necessary and, for example, the implementation costs which play a major role in the cost analysis were not used in the cost analysis because they differ too much for every organization separately and, next to that, these implementation costs are one-time-only costs.

\section{Future research}

A number of suggestions can be given for future research. The main track for future research would be to create larger sample sizes for the research, so that the conclusions can be made more quantitative and to create control and intervention groups even in the future. If larger groups of respondents were created this would make it possible to generate more statistics about someone who lives at home and thereby increase the possibility of letting someone live at home for a longer period of time by creating quantitative evidence for this.

As mentioned earlier, it might also be interesting to include the views and opinions of people with dementia themselves, although specific research techniques should be used to create reliable results because of the cognitive impairment of people with dementia.

By collecting these opinions and views of people with dementia themselves, it might be possible to create characteristics in type of dementia, age, gender, MMSE, personality and groups like domestic care, domestic support, etc.(26) and determine which individuals would respond well to a specific technology and which individuals would not. 
In this dissertation we did not make a direct link between the needs of people with

dementia as mentioned in the introduction of this dissertation and the technology itself. It would be interesting to focus on a specific need; for example, creating daytime activities and trying to find a technology which could be a solution for this and see whether the technology is really helpful or not.

In addition, more insight is necessary in the cost analysis. The cost analysis done in this research was preliminary, however more sophisticated details are necessary $\underline{\mathrm{R} 8}$ about the costs that someone incurs at home for grocery shopping, rent, etc. Details about the costs of the general practitioner would also be necessary, along with the amount paid for the personal contribution for the care, etc. Vermeulen et al. made the next first analysis with our data, but this is just the initial model; the real projects should be included to test this model and possibly to complete this model further (26).

In this study we only looked at the impact of the technologies used for people with dementia, yet the technologies could also be useful for people with other cognitive impairments. Research into these groups, for example CVA patients, will also be useful.

Not only might different groups be useful, but also the use of different technologies, we focused on four technologies, but there are more new technologies these days, also on different kind of hardware, for example mobile phones or tablets. The usefulness of these technologies for people with dementia is interesting.

Finally, we did not carry out any research in this dissertation that was specifically related to the ethics of the use of technology for people with dementia. However, this is an important issue for further research. This topic is named by the CeHRes roadmap in the phase of value specification, whereby stakeholders are needed to know the conditions, technical and ethical for employment of technologies for the most vulnerable people. 


\section{References}

1. Van Gemert-Pijnen JEWC, Nijland N, Ossebaard HC, van Limburg AH, Kelders SM, Eysenbach G, seydel ER. A holistic framework to improve the uptake and impact of eHealth technologies. Journal of Medical Internet Research. 2011;13(4):e111.

2. Mair FS, May C, Finch T, Murray E, Anderson G, Sullivan F, O'Donnell C, Wallace P, Epstein $\mathrm{O}$. Understanding the implementation and integration of e-health services. Journal of Telemedicine and Telecare. 2007;13 (1):36-7.

3. Vitacca M, Mazzu M, Scalvini S. Socio-technical and organizational challenges to wider e-Health implementation. Chronic Respiratory Disease. 2009;6(2):91-7.

4. Greenhalgh T, Robert G, Bate P, Kyriakidou O, Macfarlane F, Peacock R. How to Spread Good Ideas. A systematic review of the literature on diffusion, dissemination and sustainability of innovations in health service delivery and organisation. London: NHS, 2004.

5. Mair FS, May C, Murray E, Finch T, Anderson G, O'Donnell C, Wallace P, Sullivan F. Understanding the implementation and integration of e-Health Services. London, 2009.

6. Broens THF, Huis in 't Veld RMHA, Vollenbroek-Hutten MMR, Hermens HJ, van Halteren AT, Nieuwenhuis LJM. Determinants of successful telemedicine implementations: a literature study. Journal of Telemedicine and Telecare. 2007;13(6):303-9.

7. Cain M, Mittman R. Diffusion of Innovation in Health Care. Oakland: California Health Foundation, 2002.

8. Zwijsen SA, Niemeijer AR, Hertogh CMPM. Ethics of using assistive technology in the care for community-dwelling elderly people: an overview of the literature. Aging and Mental Health. 2011;15(4):419-27.

9. Westelius A, Edenius M. Gaps between intended and actual use- turning problems into opportunities in health informatics. International Journal of Public Information Systems. 2006;2(2):33-53.

10. Nijland N, van Gemert-Pijnen JEWC, Kelders SM, Brandenburg BJ, Seydel ER. Factors Influencing the Use of a Web-Based Application for Supporting the Self-Care of Patients with Type 2 Diabetes: A Longitudinal Study. Journal of Medical Internet Research. 2011;13(3)

11. Lauriks S, Reinersmann A, van der Roest HG, Meiland FJ, Davies RJ, Moelaert F, Mulvenna MD, Nugent CD, Dröes RM. Review of ICT based services for identified unmet needs in people with dementia. Aging Research Reviews. 2007;6(3):223-46.

12. Vilans. Alzheimerwatcher. Vilans; 2006 [cited 2008 June 5]; Available from: http:// www.domoticawonenzorg.nl/smartsite.dws?id=103539.

13. Kinney JM, Kart CS, Murdoch LD, Ziemba TF. Challenges in caregiving and creative solutions: using technology to facilitate caring for a relative with dementia. Ageing International. 2003;28(3):295-314.

14. Nouws H, Sanders L, Heuvelink J. Domotica voor dementerenden. De eerste ervaringen in het Leo Polakhuis te Amsterdam en het Molenkwartier te Maassluis. Amersfoort: De Vijfde Dimensie; 2006.

15. van der Roest HG, Meiland FJ, Comijs HC, Derksen E, Jansen AP, van Hout HP, Jonker C, Dröes RM. What do community-dwelling people with dementia need? A survey of those who are known to care and welfare services. International Psychogeriatrics. 2009;21(21):949-65.

16. Crisp R. Well being. Stanford: MetaPhysics Research Lab, Stanford University; 2008 [cited 2012 August 30]; Available from: http://plato.stanford.edu/entries/well-being/. 
17. Sixsmith A. New technologies to support independent living and quality of life for people with dementia. Alzheimer's Care Quarterly 2006;7(3):194-202.

18. Nijhof N, van Gemert-Pijnen JEWC, Dohmen D, Seydel ER. Dementie en technologie. Een studie naar toepassingen van techniek in de zorg voor mensen met dementie en hun mantelzorgers. Tijdschrift voor Gerontologie en Geriatrie. 2009;40(3):113-32.

19. Finkel S, Czaja SJ, Schulz R, Martinovich Z, Harris C, Pezzuto D. E-Care: A Telecommunications technology intervention for family caregivers of dementia patients. American Journal of Geriatric Psychiatry 2007;15(5):443-8.

20. Dang S, Remon N, Harris J, Malphurs J, Sandals L, Carbrera AL, Nedd N. Care coordination assisites by technology for multiethnic caregivers of persons with dementia: a pilot clinical demonstration project on caregiver burden and depression. Journal of Telemedicine and Telecare. 2008;14(8):443-7.

21. Van Hoof J, Kort HSM, Rutten PGS, Duijnstee MSH. Ageing-in-place with the use of ambient intelligence technology: Perspectives of older users. International Journal of Medical Informatics. 2011;80(5):310-31.

22. Engstrom $M$, Ljunggren $B$, Lindqvist $R$, Carlsson $M$. Staff perceptions of job satisfaction and life situation before and 6 and 12 months after increased information technology support in dementia care. Journal of Telemedicine and Telecare. 2005;11(6):304-9.

23. Lauriks S, Osté JP, Hertogh CMPM, Dröes RM. Effectenonderzoek naar de toepassing van domotica in kleinschalige groepswoningen voor mensen met dementie. Amsterdam: GGD, 2008.

24. Tinker A. Housing for elderly people. Reviews in Clinical Gerontology. 1997;7(2):171-6.

25. Woolham J. The effectiveness of assistive technology in supporting the independence of people with dementia. London: Hawker publications; 2006.

26. Vermeulen A, de Vries S, Nijhof N, van Gemert-Pijnen JEWC, Redekop K. A Methodology for Reimbursing Health Technology through Economic Modelling: Derived from a Case Study Regarding Telehealth and Dementia. Rotterdam: Erasmus University; 2012.

27. Catwell L, Sheikh A. Evaluating eHealth Interventions: The Need for Continuous Systemic Evaluation. PLoS Med. 2009;6(8).

28. Yusof MM, Kuljis J, Papazafeiropoulou A, Stergioulas LK. An evaluation framework for health information systems: human, organization and technology-fit factors (HOT-fit). International Journal of Medical Informatics. 2008;77(6):386-98.

29. Pagliari C. Design and evaluation in eHealth: Challenges and implications for an interdisciplinary field. Journal of Medical Internet Research. 2007;9(2).

30. Kaufman D, Roberts WD, Merrill J, Lai TY, Bakken S. Applying an evaluation framework for health information system design, development, and implementation. Nursing Research. 2006;55(2 Suppl):37-42.

31. Van der Meijden MJ, Tange HJ, J. T, Hasman A. Determinants of success of inpatient clinical information systems: a literature review. Journal of the American Medical Informatics Association. 2003;10(3):235-43.

32. Kirsi T, Hervonen A, Jylha M. Always One Step Behind: Husbands' Narratives about Taking Care of their Demented Wives. Health (London). 2004;8(2):159-81.

33. Pollitt PA, Andersont I, D.W. OC. For better or for worse: The experience of caring for an elderly dementing spouse. Ageing and Society. 1991;11(4):443-69.

34. Bank AL, Arguelles S, Rubert M, Eisdorfer C, Czaja SJ. The value of telephone support groups among ethnically diverse caregivers of persons with dementia. The Gerontologist. 2006;46(1):134-8.

35. Nolan $\mathrm{M}$, Ingram $\mathrm{P}$, Watson R. Working with family carers of people with dementia. Dementia. 2002;1(1):75-93.

36. Atienza AA, Hesse BW, Gustafson DH, Croyle RT. E-health research and patient-centered care examining theory, methods, and application American Journal of Preventive Medicine. 2010;38(1):85-8. 


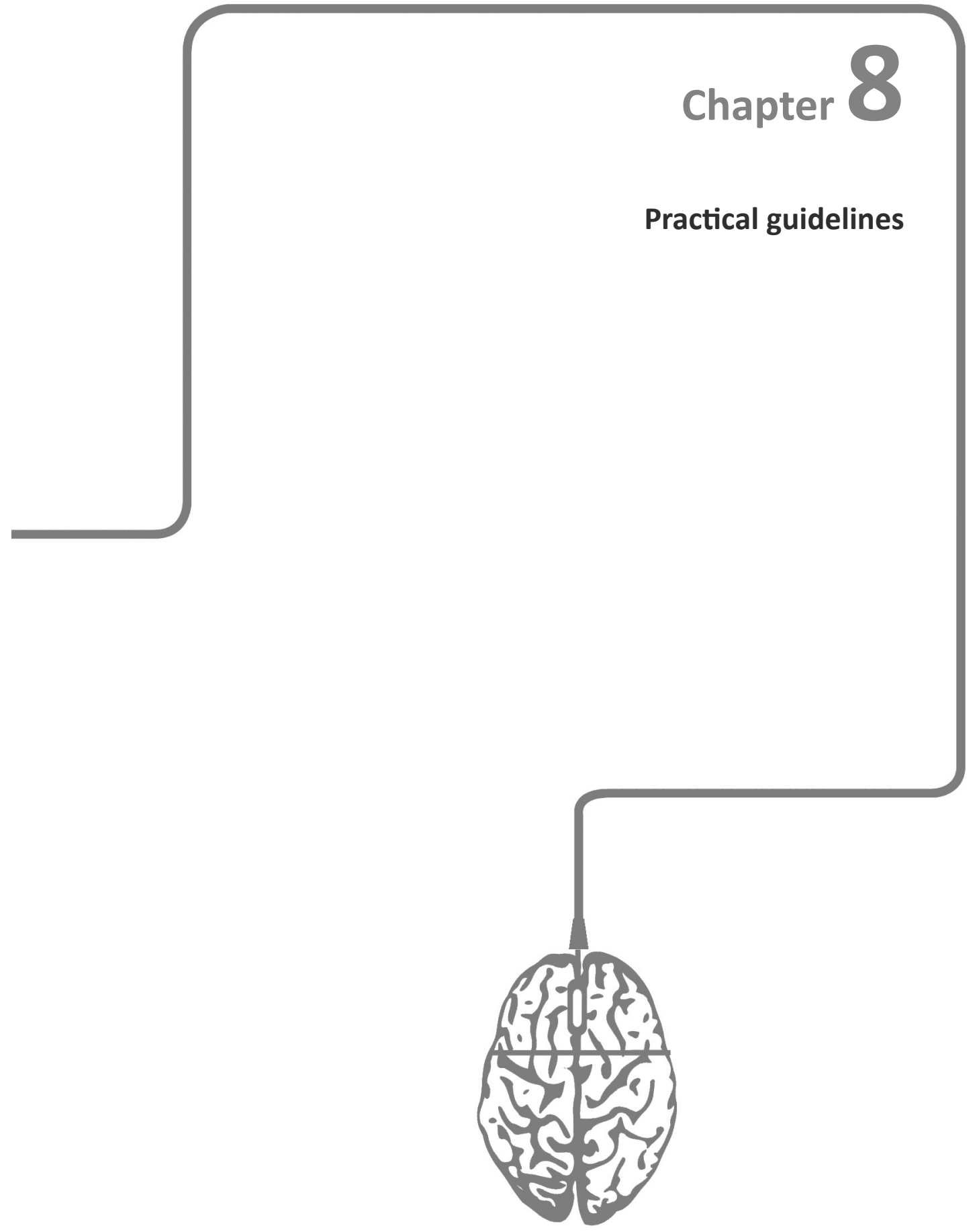


Chapter 8

$\mathrm{R} 1$

$\mathrm{R} 2$

$\mathrm{R} 3$

R4

$\mathrm{R} 5$

\begin{tabular}{l}
$\mathrm{R} 6$ \\
$\mathrm{R} 7$ \\
\hline
\end{tabular}

$\mathrm{R} 8$

$\mathrm{R} 9$

$\mathrm{R} 10$

R11

$\mathrm{R} 12$

$\mathrm{R} 13$

R14

$\mathrm{R} 15$

R16

$\underline{\mathrm{R} 17}$

$\underline{118}$

R19

$\mathrm{R} 20$

R21

R22

2

$\underline{R 24}$

$\underline{225}$

R26

227

$\mathrm{R} 2 \varepsilon$

R2S

$\mathrm{R3}$

R31

R32

$\mathrm{R} 33$

R34

206 
This chapter is meant to give practical recommendations for the use of eHealth in dementia care. The recommendations are presented in order to increase the uptake to the results and conclusions from this thesis (chapters 2-7) within the structure of

\section{Contextual Inquiry}

The project manager starts by identifying the stakeholders and then creates a project

\section{Checklist}

- Define group of stakeholders

For example: People with dementia, family caregivers, professional caregivers, policymakers, researcher, technician, project manager.

- Analyze the healthcare problem

For example: A residential care setting has a long waiting list for people with dementia

- Analyze the needs of users in relation to a possible eHealth application

$\checkmark$ Observations

For example: People with dementia want to feel safe in their own home. People with are not used to working with new technologies.

- Create a list for the healthcare organization outlining all the necessities:

$\checkmark$ Project team members should have enough time to spend on the 
Involved occupational therapist is required if the people with dementia have to learn to use the technology themselves (chapter 5).

$\checkmark$ Make timely contact with caregivers from within the family so that they too can participate (chapter 5).

- Make a decision about the different responsibilities of the project team members

For example: the policymaker should only be at the project team meetings at the beginning and end of the project, the other people should be present at the project team meetings all the time.

\section{Value specification}

The stakeholders should make decisions and priorities regarding their values and discuss the contribution of the technology.

\section{Checklist}

- Decide the main values of the demands/solution and how eHealth technology can support this.

For example: Create a feeling of safety for the person with dementia and their caregiver from the family by making it possible for them to detect dangerous situations that call for immediate action and create just-in-time care to prevent or postpone intake into residential care and with that create cost savings.

- Discuss with stakeholders the potential contribution of the technology related to the values to be achieved.

For example: Monitoring technology could detect situations requiring urgent intervention and might be a possibility for the above-mentioned values.

- Discuss together with the users possibilities of support by technology

$\checkmark$ Use scenarios

$\checkmark$ Use demonstration models of possible technologies

For example: Show a person with dementia several technologies and ask them if this helps them in their needs as determined at the contextual inquiry phase.

- Describe requirements for the technology 
For example: The technology should be plug-and-play, because of the possibility of

a quick decrease in the situation of the person with dementia, and with that the

\section{Design}

From the requirements a technology that is already available can be chosen or a

\section{Checklist}

- Choose or design a matching technology; possibilities: signalling technology (chapter 1), monitoring technology (chapters 3 and 4) and social contact technology (chapters 5 and 6) or a combination of these technologies.

For example: Monitoring technology is a suitable technology to prevent urgent situations; in this context we used ADLife technology.

- Involve all stakeholders in the design process of the selected technology. Start with prototypes for the design of technology

- In the case of technology that is already available, before deciding to use it, first carry out some research to see whether the technology is suitable in relation to the needs of the users (chapter 3 )

For example: Let the professional caregivers use the website to read out the data and

- For technology for people with dementia themselves as end- users, create the possibility of individual heuristics to choose from (chapters 5 and 7).

For example: With an electronic agenda it might be wise to let the people choose for a day-to-day agenda or weekly agenda.

\section{Operationalization}

In this phase the implementation plan will be made which will include actions for the dissemination, adoption and incorporation, or internalization of the technology. practice of care. 


\section{Checklist}

- Start with specific, basic functionalities of the technology and expand to the different functionalities later, so people first get the opportunity to get used to the technology (chapter 5).

For example: For PAL4, first start using the agenda and after a few weeks start making video contact.

- Create manuals in the language of the end-users and other groups that might become involved (chapter 3 ).

For example: For ADLife a manual in the local language should be made for the people with dementia as well. Even though they are not the end-users of the technology, they still have the technology in their house and can get confused about flickering lights, for example.

- $\quad$ Start to create input for a business model

$\checkmark \quad$ Decide upon and focus on a business model (canvas model)

For example: Letting someone live at home for a longer period of time, change house visits to video contact moments or create efficiency in residential care by having fewer professional caregivers on duty during the night shifts.

$\checkmark$ Start collecting the figures that are required from the start of the project (chapters 3 and 5).

For example: required figures for letting someone live at home for a longer period of time:

Living at home:

- Homecare costs

- Purchase and installation of eHealth technology

- Subscription use of eHealth technology

- Service of eHealth technology

- Costs for professional caregivers using technology

Possibilities of extra costs by living at home:

- Implementation costs of the technology

- Grocery shopping

- Gas, water and electricity

- Health insurance and other insurances 
- Personal contribution homecare

- Monthly costs for internet, telephone and TV

- Town taxes

- Rent or mortgage

Nursing home:

- Monthly fee for living in a nursing home (in the Netherland

this is known as a ZZP)

Possibilities of extra costs in the nursing home:

- Health insurance or other insurances

R9

- Extra costs for living in nursing home

R1

A difference should be made between couples and people with dementia who live alone, because if one person from a couple going into a nursing home, the rent, for example, will still have to be paid.

$\checkmark$ Use the model of Vermeulen et al. (2012)(6) whereby general figures for taking care of a person with dementia are used, but the exact costs of technology still have to be filled in (chapter 7).

- Create a possibility for the end-users to try out the technology in a demo room

For example: For ADLife people should be able to come to a special room inside the healthcare organization to see what the sensors look like and how they are attached to the walls. Otherwise enable the professional caregiver who recruits the people with dementia to take the sensors with them to show them in the houses of the people with dementia.

- Create embedding of the eHealth application in the daily care practice

$\checkmark$ Let people start to use the technology for a while to get used to this (chapter 4).

$\checkmark$ Train professional caregivers to use and apply the technology in daily practice (chapter 3 ).

$\checkmark$ After a few weeks decide, together with the professional caregivers, how the eHealth technology could be implemented in the day-to- 
For example: for PAL4 people use it first for a while, then the professional caregivers receive training in how to make good video contact and after a few weeks house visits could be replaced by video contact.

- Decide about ethical situations

$\checkmark \quad$ Let the person with dementia always know about the technology used.

$\checkmark$ Decide about the role of the family caregivers in relation with the privacy of the client.

$\checkmark \quad$ If necessary let the ethical committee of the healthcare organization decide about the technology.

For example: for the ADLife system the person with dementia should give their permission for showing the data to the family caregiver once a month. If the person does not give this permission the data will not be shared with family caregivers.

- Make inclusion criteria for people who are able to use the technology

$\checkmark$ Look at their personality, especially their willingness to learn something new and no fear for technology

$\checkmark$ Look at age

$\checkmark$ Look at gender

$\checkmark \quad$ Look at MMSE or other scores related to the phase of dementia

$\checkmark$ Look at the phase of receiving care; diagnosis, domestic support, domestic care or nursing home (chapter 7)

$\checkmark \quad$ Need to involve a family caregiver and the availability of such a person (chapter 3 )

$\checkmark$ If the technology is used at home and the technology is expensive, decide how many months a person should have been forecasted as likely to be able to stay at home (chapter 3 and 5).

For example: For ADLife people should be diagnosed with dementia, have an MMSE score lower then 25, should not be anxious about the sensors in their house, should be in the domestic care phase and should not be likely to be admitted to a nursing home for the coming 4 months (because of the long waiting list).

- Give suggestions about the intended usage 
For example: For reading out the data from ADLife, checking email alerts daily and

- Test the technology beforehand to prevent possible interruptions

For example: For ADLife use the sensors in the demo room installed to see if they work

- Plan the roll-out of the technology

\section{Summative evaluation}

\section{Uptake}

- Evaluate the use, usage and motivation or capability of the person using the technology

$\checkmark \quad$ Log files (data about how much and/or how often a person uses the technology)

$\checkmark$ Survey

$\checkmark$ Interviews

R1:

$\checkmark$ Etc.

For example: Evaluate the reasons of less or non- usage and evaluate for people with

\section{Impact}

- Evaluate the main purpose they had for starting with the technology

- Fill in your business model and start talking about the results with policymakers

- Try to involve people who actually have dementia in the evaluation process

$\checkmark \quad$ Use photos instead of words

$\checkmark$ Make observations

- Effects of eHealth

$\checkmark$ Assess performance and process (chapter 2-7) 
Samenvatting

(Summary in Dutch) 
Samenvatting

$\mathrm{R} 1$

$\mathrm{R} 2$

$\mathrm{R} 3$

$\mathrm{R} 4$

$\mathrm{R} 5$

$\mathrm{R} 6$

$\mathrm{R7}$

$\mathrm{R} 9$

$\underline{\mathrm{R} 10}$

R11

R12

R13

R14

$\mathrm{R} 15$

R16

$\underline{\mathrm{R} 17}$

$\underline{\mathrm{R} 18}$

R19

$\mathrm{R} 20$

R21

R22

$\mathrm{R} 23$

$\underline{R 24}$

R25

R26

$\mathrm{R} 27$

R2

R2S

$\mathrm{R} 30$

R31

R32

$\mathrm{R} 33$

R34 


\section{Samenvatting}

(summary in Dutch)

Dementie is een overkoepelende term voor verschillende ziektes, waarbij sprake is van geheugenverlies. Dit geheugenverlies is geen onderdeel van het natuurlijke verloop van het verouderinsproces. Dementie heeft invloed op het geheugen, denken, gedrag en het omgaan met dagelijkse activiteiten. Alzheimer is de meest voorkomende vorm van dementie. Andere vormen zijn bijvoorbeeld frontotemporale dementie, vasculaire dementie en Lewy body dementie. Er zijn in totaliteit meer dan 50 verschillende vormen van dementie (Alzheimer Nederland, 2013).

In 2010 waren er wereldwijd naar schatting 35,6 miljoen mensen met dementie, op dat moment 0,5\% van de gehele wereldpopulatie. In 2050 is de verwachting dat er wereldwijd 115,4 miljoen mensen met dementie zijn. Volgens Alzheimer Nederland zijn er in Nederland momenteel 250.000 mensen met dementie. In 2050 dit zal dit aantal, samenhangend met de vergrijzing, rond de 500.000 liggen. Ook mensen onder de 65 jaar worden gediagnosticeerd met dementie, dit zijn momenteel rond de 12.000 personen.

De kans dat iemand dementie krijgt in zijn leven, is $20 \%$. Voor vrouwen is dit percentage hoger (rond de 30\%), omdat vrouwen gemiddeld genomen ouder worden. Hou ouder men wordt, hoe groter de kans op het krijgen van dementie. Bij mensen ouder dan 90 jaar heeft $40 \%$ dementie.

Kijkend naar deze sterk groeiende aantallen van mensen met dementie wereldwijd en in Nederland, is er behoefte aan hulp om mensen met dementie te kunnen verzorgen. De verwachting is dat met de teruglopende beroepsbevolking in Nederland niet aan de zorgbehoefte van dementerenden kan worden voldaan. Daarnaast wordt veel zorg verleend door mantelzorgers (veelal familieleden). Echter, 82\% van de mantelzorgers is overbelast.

Het 'Wereld Alzheimer Rapport' uit 2010 concludeert dat er investeringen in onderzoek en kosteneffectieve methoden nodig zijn om goede zorg te kunnen blijven bieden aan deze sterk groeiende groep van mensen met dementie. eHealth kan hierbij ondersteunend zijn. eHealth staat voor de innovatieve toepassing van 
informatie communicatie technologie (ICT) in de zorg, waarbij het volgens de definitie van eHealth door Eysenbach (2001) niet alleen gaat om de techniek, maar ook om de gedachtegang, houding etc. om gezondheidszorg te verbeteren met behulp van ICT. Ook Alzheimer Nederland beschrijft het nut van het gebruik van eHealth in hun 'Zorgstandaard dementie' van 2012.

Hoewel eHealth nog niet veel toegepast is bij dementie zijn er wel positieve resultaten te noemen: minder belasting van de mantelzorger, bevordering van zelf management van mensen met dementie, meer efficiency in de zorg, hogere kwaliteit van leven voor mensen met dementie, minder valincidenten en de mogelijkheid voor bijvoorbeeld bewoners van verpleeghuizen om vrij rond te kunnen lopen (Nijhof et al., 2009).

Het doel van dit proefschrift is het geven van inzicht en advies voor de ontwikkeling en implementatie van eHealth in dementiezorg. In dit proefschrift is literatuuronderzoek verricht naar al bestaande onderzoeken op het gebied van dementie en eHealth. Tevens is aan de hand van de CeHRes roadmap empirisch onderzoek verricht. Deze CeHRes roadmap kan gebruikt worden voor zowel de ontwikkeling als de evaluatie van eHealth om de adoptie en impact van eHealth technologie te vergroten (van GemertPijnen et al., 2011). De empirische onderzoeken in dit proefschrift zijn gericht op monitoring en sociaal contact technologiën voor mensen met dementie. In totaliteit zijn 4 verschillende eHealth technologieën beschreven in dit proefschrift, al deze 4 technologieën zijn commercieel verkrijgbaar. Het betreft een monitoring (IST Vivago watch) en sociaal contact technologie (Klessebessers) in een verpleeghuissitiatie (intramuraal), en een monitoring (ADLife) en sociaal contact technologie (PAL4) in de thuissituatie (extramuraal). In deze empirische onderzoeken stond centraal hoe eHealth gebruikt wordt, of het gebruiksvriendelijk is, maar eveneens wat de impact is op het welzijn van de persoon met dementie, de mantelzorger en de professioneel zorgverlener. Tevens is gekeken naar de impact op de manier van zorgverlening en of er kostenbesparingen zijn te realiseren door het gebruik van eHealth door mensen met dementie langer zelfstandig thuis te laten wonen.

In hoofdstuk 2 wordt het literatuur onderzoek beschreven en in de opvolgende hoofdstukken worden de empirische onderzoeken beschreven. Tot slot worden in hoofdstuk 7 en 8 de conclusies beschreven en praktische aanbevelingen gedaan voor het gebruik van eHealth in dementiezorg. 
In dit hoofdstuk is een quickscan beschreven naar publicaties over eHealth in als nationaal. In totaliteit zijn 18 internationale en 8 nationale studies beschreven. In deze quickscan is onderscheid gemaakt in technologie, welke mensen met dementie en hun mantelzorgers helpt bij het omgaan met de symptomen van dementie (bijvoorbeeld een foto telefoon, waarbij men alleen de foto hoeft aan te klikken om een persoon te bellen); technologiën, welke de behoefte van mensen met dementie op het gebied van sociaal contact ondersteunt (zoals een multimedia systeem waar foto's op bekeken kunnen worden, muziek luisteren etc.) en als laatste technologiën, welke de gezondheid en veiligheid van mensen met dementie monitort (bijvoorbeeld sensorentechnologie, die registreert of iemand in zijn bed slaapt).

De eerste resultaten uit de verschillende studies, zoals beschreven in deze quickscan, zijn positief. Er zijn significante verbeteringen aangetoond op het gebied van de kwaliteit van leven van de persoon met dementie en het effect welke de technologie had op het gedrag van de persoon met dementie (zoals minder vallen). Ook mantelzorgers bespaarden tijd met de technologie en hadden minder depressieve gevoelens. De mantelzorgers en mensen met dementie zelf zijn tevreden over de gebruiksvriendelijkheid van de technologie. Daarentegen zijn de aanschafprijs en beheerskosten van de eHealth technologieën nog vaak te hoog.

Al lijken deze eerste resultaten positief, gedegen wetenschappelijk onderzoek ontbreekt tot op heden naar het gebruik van eHealth in dementiezorg. Deze quickscan toont ook aan in welke richting vervolgonderzoek nodig is, namelijk op het gebied van gedegen opgezet onderzoek bij de inzet van techniek bij mensen met dementie, hun mantelzorgers en zorgverleners. Hierbij rekening houdend met de fase van dementie, de manier hoe zorgverleners met de techniek omgaan en de mogelijkheid tot besparingen in de dagelijkse zorg.

\section{Hoofdstuk 3: Monitoring technologie extramuraal}

Dit hoofdstuk beschrijft het gebruik van het zogenaamde ADLife systeem voor mensen met dementie. Dit is een preventief sensorensysteem, dat dagelijkse patronen 
situaties te voorkomen. Er is gebruik gemaakt van een personenalarmering, deur sensoren, elektrisch verbruik sensoren, bedmat, stoelmat en bewegingssensoren. In dit hoofdstuk worden de resultaten gepresenteerd van de evaluatie van het gebruik van het ADLife systeem voor 9 maanden bij 14 mensen met dementie in de thuissituatie.

Het onderzoek is zowel kwantitatief als kwalitatief: interviews met mantelzorgers en professionele zorgverleners, observaties van de projectgroepbijeenkomsten, analyse van dagboeken van de professionele zorgverleners en een kostenanalyse, waarbij gekeken is naar het verschil tussen thuiswonen met thuiszorg en technologie of opname in een intramurale setting.

Mensen met dementie en de mantelzorgers ervaarden een toename in het gevoel van veiligheid door het gebruik van ADLife. ADLife ondersteunt de mantelzorger en heeft de potentie om mensen met dementie langer thuis te laten wonen. In dit onderzoek zijn twee 'gevaarlijke' situaties geconstateerd, een persoon die geen avondeten meer at en een persoon die niet meer in zijn bed sliep. Tevens zijn er besparingen aangetoond door het moment van opname in een verpleeghuis uit te kunnen stellen. Indien 10 cliënten 2 maanden langer thuis kunnen wonen met behulp van ADLife bespaart dit $€ 23.665$ en voor 50 cliënten is dit bedrag $€ 124.122$. Indien een persoon met dementie echter meer thuiszorg nodig heeft, ligt het omslagpunt dat opname uiteindelijk toch goedkoper is, bij $€ 5000$ thuiszorg per maand. Dit staat gelijk aan bijvoorbeeld wekelijks $15 \mathrm{u}$ thuiszorg, $4 \mathrm{u}$ huishoudelijke verzorging, $3 \mathrm{u}$ persoonlijke begeleiding en 20u dagopvang.

Een procesevaluatie toont verschillende aanbevelingen voor het gebruik van ADLife in de toekomst: meer gedegen implementatie van ADLife in de zorgorganisatie, de weergave van data kan verbeterd worden en meer ondersteuning voor de professionele zorgverleners om te leren werken met ADLife in de dagelijkse zorgverlening.

\section{Hoofdstuk 4: Monitoring technologie intramuraal}

In dit hoofdstuk wordt een horloge dat het slaap- en waakritme meet van mensen met dementie beschreven, aangezien mensen met dementie vaak een verstoord slaap- en waakritme hebben. Het doel van deze studie is inzicht creëren in de 
effecten van het horloge op het slaap/waak ritme van mensen met dementie en het

proces van zorgverlening. Het horloge is bij 7 personen met een verstoord slaap/

waakritme gebruikt in een intramurale instelling.

Ook bij dit onderzoek zijn zowel kwalitatieve als kwantitatieve onderzoeksmethoden

gehanteerd, variërend van interviews met de professionele zorgverleners, analyse

tot aan analyse van de data van het horloge over de slaaptijd, slaapperiodes en de verhouding tussen dag en nacht activiteit. Deze onderzoeksmethoden werden met elkaar gecombineerd, indien het logboek een interventie toonde, welke door de zorgverleners was uitgevoerd, werd de data van het horloge gebruikt om het effect van de interventie op te zoeken op het slaap- en waakritme.

Er kan worden geconcludeerd dat het horloge de potentie heeft om het slaap- en waak ritme van mensen met dementie te verbeteren. Het is niet zozeer het horloge zelf dat deze verbeteringen mogelijk maakt, maar de interventies welke plaatsvinden aan de hand van de data, die het horloge genereert. Zo toonde het horloge bij een van de respondenten aan dat de inslaap medicatie om 21 uur gegeven werd en de doorslaap medicatie om 0.00 uur, waarna deze persoon langere tijd wakker lag (door het wakker maken voor de medicatie). Dit is aangepast nadat men dit door het horloge inzag, waardoor de nachtrust van deze persoon verbeterde. Tevens kan het horloge bijdragen aan een meer efficiënte zorgverlening. Een concreet voorbeeld hierbij is dat er gedurende de nacht geen meerdere nachtrondes gelopen hoeven te worden, echter alleen indien een persoon wakker blijkt te zijn hoeft de zorgverlener er naartoe. De gebruiksvriendelijkheid van het horloge werd minder positief beoordeeld, het horloge was erg groot en te log voor de vaak dunnere polsen van oudere mensen.

Voor het opschalen van de bovengemoemde positieve effecten is het wel noodzakelijk dat er een infrastructuur aanwezig is, welke faciliterend is, er adequate communicatie kanalen en de juiste condities voor implementatie aanwezig zijn.

\section{Hoofdstuk 5: Sociaal contact technologie extramuraal}

Dit hoofdstuk beschrijft de evaluatie van het zogenaamde PAL4 dementie systeem, een ondersteunend programma voor mensen met dementie, werkend op een 
touchscreen. Dit programma bevat de volgende functies: agenda, levensalbum, dagboek en een knop met informatie over dementie, de wijk, waarin men woonachtig is, geheugenspelletjes etc. Tevens kon er met PAL4 videocontact gemaakt worden met mantelzorgers en/of professionele zorgverleners. De evaluatie heeft plaatsgevonden gedurende 9 maanden bij 16 cliënten bij twee zorgorganisaties in Nederland. Er is gebruik gemaakt van kwalitatieve en kwantitative onderzoeksmethoden zoals interviews met mantelzorgers en professionele zorgverleners, een focusgroep met professionele zorgverleners, observaties van gebruik van PAL4, analyse van log files en er is een kosten analyse uitgevoerd. De kostenanalyse is gericht op de effecten van thuiswonen met thuiszorg en PAL4 ten opzichte van opname in een verpleeghuis. Mensen met dementie en de mantelzorgers rapporteerden ondersteuning in het dagelijks leven door PAL4. Men gaf aan dat het systeem zou kunnen bijdragen aan het langer zelfstandig thuis wonen van de persoon met dementie. De kostenanalyse laat een maandelijkse besparing zien van thuis wonen met PAL4 ten opzichte van opname in een verpleeghuis van €820 per maand per cliënt bij 10 cliënten en €860 per maand per cliënt bij 50 cliënten. Indien iemand met dementie echter meer thuiszorg nodig heeft (rond de $€ 5000$ aan thuiszorg) dan zal iemand 11 maanden langer thuis moeten kunnen blijven wonen, voordat PAL4 kosten effectief zal zijn. Ondanks deze positieve resultaten werden er ook verschillende problemen gedetecteerd: technische storingen, onvoldoende kennis van de professionele zorgverleners over hoe PAL4 werkte, onvoldoende betrokkenheid van mantelzorgers en een onvoldoende gebruiksvriendelijke lay-out van PAL4.

\section{Hoofdstuk 6: Sociaal contact technologie intramuraal}

In dit laatste empirische hoofdstuk wordt een onderzoek beschreven naar het spel de Klessebessers. Dagactiviteiten zijn van groot belang voor mensen met dementie, eHealth wordt hier echter nog weinig toegepast. Bij dit spel werd gebruik gemaakt van technologie als een tv, radio, telefoon en een schatkistje, waar de fragmenten die door een activiteiten begeleider werden geselecteerd de interactie en het sociale gedrag tussen de personen met dementie die het spel speelde, diende te bevorderen. Het spel werd in een verpleeghuissituatie gespeeld, waar mensen woonachtig waren of de dagopvang bezochten. Dit onderzoek betreft een observatie studie met een 
bestaande gedragsobservatieschaal en interviews met de activiteitenbegeleiders. In

deze studie is het spel de Klessebessers vergeleken met een ander soortgelijk spel, Vragenderwijs, waar echter geen gebruik werd gemaakt van eHealth. Tevens is er onderscheid gemaakt in de mate van dementie door gebruik te maken van MMSE scores en is er gekeken naar het verschil tussen man en vrouw. In verband met het $\underline{\mathrm{R} 5}$ kleine aantal respondenten is de statistische methode van bootstrapping gebruikt.

Er kon in deze studie geen groot verschil aangetoond worden tussen deze activiteit waarbij eHealth gebruikt werd en een activiteit, waarin dit niet gebruik werd. Maar het eHealth spel de Klessebessers creëerde en stimuleerde wel sociaal gedrag, specifiek op het gebied van communicatie en empathie. Mensen met een hoge MMSE score (minder ver gevorderd in proces van dementie) en vrouwen waren meer actief tijdens het spel. Daarnaast bleek dat het gebruik van eHealth in activiteiten ondersteunend kon zijn voor activiteiten begeleiders, omdat het onderwerpen genereerde waar men over kon praten met de mensen met dementie. De inhoud van de Klessebessers kan wel nog meer aangepast worden op jonge mensen met dementie.

\section{Hoofdstuk 7 en 8: Conclusies, discussie en aanbevelingen}

De resultaten uit de verschillende studies in dit proefschrift zijn gericht op het gebruik van monitoring en sociaal contact technologie bij mensen met dementie. Echter, de resultaten kunnen ook van belang zijn voor mensen met andere cognitieve beperkingen of voor het gebruik van signalerende technologie. De resultaten zijn dus breder inzetbaar.

De studies zoals beschreven in dit proefschrift laten positieve resultaten zien voor het gebruik van eHealth in dementiezorg. eHealth kan het welzijn van mensen met dementie en hun mantelzorgers bevorderen, kan het proces van zorgverlening ondersteunen en zorgt eveneens voor kostenbesparingen op het moment dat uitstel van opname gerealiseerd kan worden.

Uit de verschillende studies komt naar voren dat implementatie een belangrijke rol speelt bij het succes van eHealth. Deze implementatie kan op velerei gebieden verbeterd worden bij het gebruik van eHealth in dementiezorg. Een belangrijker 
van de verkenning van wensen en behoeften, waarden specificatie naar design, naar de daadwerkelijke operationalisatie en tot slot evaluatie. Speerpunten, die genoemd kunnen worden bij een succesvolle implementatie zijn: een actieve projectgroep, eHealth langzaam een structurele plek geven in de dagelijkse zorgpraktijk en daar een passend business model bij genereren en als laatste vooraf nadenken over ethische kwesties.

Eveneens kan het gebruik en de gebruiksvriendelijkheid van eHealth verder bevorderd worden. Dit gebruik kan bevorderd worden door een richtlijn geven voor het gebruik en eventuele herinneringen aan het gebruik. Dit is zeker bij mensen met dementie essentieel. De gebruiksvriendelijkheid kan bevorderd worden door de behoeften van de gebruikers af te stemmen op de techniek, waarbij specifiek rekening moet worden gehouden met mensen met dementie. Zij hebben andere behoeftes dan de normale senioren. In de verschillende studies in dit onderzoek zijn de behoeften en achtergrond van de gebruikers niet afgestemd op de technologie. Zo was het horloge zoals gebruikt om het slaap - en waakritme te meten erg groot en ongemakkelijk voor de vaak dunne polsen van oudere mensen of was de data van ADLife voor zorgverleners lastig uit te lezen.

Het welzijn van mensen met dementie en hun mantelzorgers wordt ondersteund door de gebruikte technologieën in deze studie. Voorbeelden hiervan zijn een groter gevoel van veiligheid en structuur voor de persoon met dementie. Echter heeft eHealth in de studies in dit proefschrift bij mantelzorgers niet explicitiet gezorgd voor een verminderde belasting. De belasting van zorg wordt vaak veroorzaakt door het doen van boodschappen, financiële administratie etc., hierin hebben de eHealth technologieën in dit proefschrift niet ondersteund. De welzijnseffecten zouden vergroot kunnen worden door eveneens te kijken, welke type personen, gelinieerd aan MMSE scores, geslacht, leeftijd en persoonlijkheid geschikt zijn voor het gebruik van welke soort technologie. Hier dient uiteraard rekening gehouden te worden met de individuele verschillen tussen mensen met dementie. Hiernaast dient technologie vanaf het begin gekoppeld te worden aan de doelen die men wil bereiken met de technologie. Indien ontlasting van de mantelzorger gewenst is, dient er eerst gekeken te worden naar welke aspecten deze belasting teweeg brengen en hoe deze belasting dus kan worden verminderd met behulp van technologie. 
eHealth kan ervoor zorg dragen dat de zorg "just-in-time" wordt in plaats van "just-

in-case", dit wordt tot op heden echter niet volledig benut. Dit heeft er ook mee te

maken dat een professionele zorgverlener in zijn werk gewend is om te 'zorgen',

maar niet om met technologie om te gaan en tevens niet om op basis van data uit

deze technologie zorgbeslissingen te kunnen maken. Hier dient veel meer aandacht

$\underline{\mathrm{R} 5}$ aan te worden besteed tijdens de implementatie.

Zoals beschreven in hoofdstuk 4 en 6 kan eHealth kostenbesparingen realiseren in de zorg voor mensen met dementie, door het moment van opname in een intramurale $\underline{\mathrm{R} 8}$ setting uit te stellen. De analyse, zoals heeft plaatsgevonden in dit proefschrift, laat hier de eerste positieve resultaten van zien. Vervolgonderzoek is echter noodzakelijk, waarbij ook meer inzicht moet worden gecreëerd in de kosten van bijvoorbeeld iemand die thuis woont en boodschappen doet, de zorgverzekering betaald, een eigen bijdrage betaalt voor zijn thuiszorg etc. Deze kosten voor bijvoorbeeld het boodschappen doen, zijn er namelijk niet nadat iemand opgenomen is in een verpleeghuis. Deze kosten zijn in de huidige kostenanalyse nog achterwege gelaten, samenhangend met het feit dat deze kosten zeer lastig inzichtelijk zijn te krijgen.

Naar aanleiding van dit proefschrift is vervolgonderzoek wenselijk in de richting van grotere aantallen respondenten, zodat meer kwantitatief onderzoek zou kunnen plaatsvinden. Daarnaast is het wenselijk om meer expliciet de mening te vragen van mensen met dementie zelf en dit niet via de mantelzorger of professionele zorgverlener te vragen. Onderzoek bij andere doelgroepen met cognitieve beperkingen en tevens andere technologieën, waaronder mobiele technologie (smartphone, tablet) is als laatste ook van toegevoegde waarde. 


\section{Dankwoord}


Dankwoord

$\mathrm{R} 1$

$\mathrm{R} 2$

$\mathrm{R} 3$

$\mathrm{R} 4$

$\mathrm{R} 5$

$\mathrm{R} 6$

$\mathrm{R7}$

$\mathrm{R} 9$

$\mathrm{R} 10$

R11

$\mathrm{R} 12$

R13

R14

$\mathrm{R} 15$

R16

$\underline{\mathrm{R} 17}$

$\underline{118}$

R19

$\mathrm{R} 20$

R21

R22

23

$\underline{R 24}$

R25

R26

227

$\mathrm{R} 2 \varepsilon$

R2S

$\mathrm{R3}$

R31

R32

$\mathrm{R} 33$

R34 
Een geweldige ervaring, dat zijn de afgelopen 4,5 jaar voor mij geweest, door het kunnen combineren van praktijkwerk bij Focus Cura en het doen van onderzoek op de UT. Mooie projecten begeleiden en dan eveneens kunnen onderzoeken wat de effecten zijn van datgene wat je inzet. Tuurlijk heb ik ook zeker mijn "dipmomenten" R5 gehad, maar al met al ben ik ontzettend blij nu dat ik nu zo'n resultaat als mijn R6 proefschrift voor mij heb liggen. Uiteraard was dit niet gelukt zonder alle mensen waar ik de afgelopen jaren mee heb samengewerkt of die voor de nodige ontspanning $\mathrm{R} 8$ zorgde. Enkele mensen wil ik hierbij in het bijzonder bedanken.

$\underline{\mathrm{R} 9}$

Ten eerste wil ik Lisette van Gemert, mijn dagelijks begeleidster, bedanken voor de begeleiding de afgelopen jaren. We hebben de nodige discussies gevoerd, maar nu achteraf zie ik in, dat alle stukken die nu hier in mijn proefschrift staan beter geworden zijn door jouw aanvullingen, opmerkingen en overwegingen. Ik wil je bedanken voor alle vrijheid die je mij altijd gegeven hebt gedurende mijn onderzoek. I vond het ontzettend prettig om op die manier echt mijn eigen onderzoek vorm te geven. Daarnaast sta je echt altijd klaar voor je aio's, op elk moment van de week, heb je een ongekende energie en enthousiasme! Dank je wel voor dit alles. Onze directe samenwerking zal stoppen na mijn promotie, maar ik hoop dat we elkaar nog vaak zullen tegenkomen in "zorgland."

Erwin, mijn promotor, wil ik ook bedanken voor zijn begeleiding de afgelopen noodzakelijk was, kon ik wel altijd even bij je aankloppen. Het is geweldig hoe jij mensen kan motiveren en inspireren. Dank daarvoor.

Uiteraard wil ik ook graag de leden van mijn promotiecommissie bedanken voor de tijd en moeite voor het lezen van mijn proefschrift en het aanwezig zijn tijdens mijn verdediging. Prof. dr. Andrew Sixsmith, thank you for taking part in my graduation committee and for the wonderful time I had in Vancouver, Canada in 2011, when I 
dr. ir. Hermie Hermens, dr. ir. Joost van Hoof en prof. dr. Marcel Olde Rikkert, we zijn elkaar de afgelopen jaren meerdere malen tegengekomen in het werkveld van dementie en eHealth en ik vind het dan ook een eer dat jullie deel uitmaken van mijn commissie. Prof. dr. ir. T. de Vries, vooral in het begin van mijn promotie ben ik met regelmaat in Leiden bij je op bezoek geweest om over mijn proefschrift te praten en daarna gezellig samen met te eten, hartelijk dank hiervoor.

Tijdens de gehele looptijd van mijn proefschrift ben ik bij Focus Cura werkzaam geweest en dat is altijd een geweldige baan geweest, mede dankzij de leuke collega's en de vrijheid die mij geboden werd. Daan, dank je wel voor al je support de afgelopen jaren en het gebruik mogen maken van je enorme netwerk. Speciale dank voor mijn collega's en oud collega's, Anneloes, Eelko, Huub, Jorin, Jeroen van der Heijden, Michel, Martie, Leendert-Jaap, Pia, Roel, Ruud, Stijn, Sabine en Yvonne. Dank voor de fijne samenwerking en ontzettend veel gezelligheid. Milan, jij als oud collega, ook bedankt voor het geweldige ontwerp van de kaft van mijn proefschrift. Ook al ga ik Focus Cura verlaten, ik zal jullie allen oprecht missen!

Naast mijn groep collega's bij Focus Cura had ik ook een leuke groep collega's bij de UT. Ik was hier dan wel minder vaak aanwezig, maar wil jullie wel ontzettend bedanken voor de fijne samenwerking de afgelopen jaren. De eHealth club is een gemotiveerde en gezellige club, dank aan jullie allen: Hans, Jobke, Lex, Lisette, Maarten, Marjon, Nicol, Nienke, Saskia, Maarten, Olga en Joyce. In het speciaal wil ik mijn kamergenoten Nicol en Lex bedanken voor het oppeppen als het nodig was en de hulp bij de verschillende vragen die ik jullie als "al gepromoveerde" stelde. Excuus, voor mijn belabberde zangkunsten die ik jullie wel eens ten gehore bracht!

Tevens dank voor alle organisaties waar ik in mijn onderzoek mee heb samengewerkt, Limez, SVVE Archipel en Zuwe (Erik Loeffen). Met speciale dank voor de projectgroep bij ZZG Zorggroep; Esther, Bas, Ria, Ria en Hans en de projectgroep bij Bruggerbosch; Henk Bijleveld, Marianne, Henk de Marie, Murk, Renate, Chantal en vooral Diana en Trudy. Joost en Helma, jullie bedankt voor de leuke en vooral soms ook lachwekkende uurtjes tijdens het "Klessebessen". 
Tijdens mijn onderzoek heb ik hulp gehad van verschillende afstudeerders, zij hebben een essentiële bijdrage geleverd aan mijn onderzoek. Els, Harmen, Marieke, Pia, ontzettend bedankt voor jullie gedrevenheid en enthousiasme! Niet al jullie onderzoeken heb ik volledig gebruikt in dit proefschrift, maar jullie onderzoeken hebben allen waardevolle resultaten opgeleverd.

Ja... en dan wil ik ook nog al mijn geweldige lieve vriendinnen bedanken. Lieve meiden van thuis, Hely, Lotte en Simone, we kennen elkaar al zo onwijs lang en ik hoop dat onze vriendschap nog tot ons 100 e zal duren. Lieve meiden van Chiaro Divina, Anne, Amke, Carolien, Karlijn, Pien en Valérie, dank voor alle super gezellige etentjes, borrels, weekenden etc. in de afgelopen jaren, dat er nog vele mogen volgen. Lieve meiden van Spooky, Anne Marie, Annalies, Bianca, Juul, Maaike en Maartje, ook jullie bedankt voor alle etentjes, borrels en leuke momenten. Lieve meiden van de Mina, Hanneke, Judith en Yvonne, we zien elkaar niet meer zoveel als vroeger, toen we elkaar elke dag bijna wel zagen, maar het is nog altijd even gezellig als we elkaar zien, dank jullie wel! Annemarijn, jou heb ik leren kennen via Focus Cura, maar inmiddels hebben we het al over zoveel andere dingen gehad dan werk, dank je daarvoor! Ik ben erg blij met zoveel lieve vriendinnen en ben ze allemaal dankbaar voor de gezelligheid, steun en lieve woorden in de afgelopen jaren!

Twee van mijn vriendinnen zijn eveneens mijn paranimfen, Maartje, dank je wel voor alle momenten die we de afgelopen jaren ook samen hebben gehad op de UT. Het was fijn iemand dichtbij mij te hebben die ook werk deed in de praktijk in combinatie met onderzoek. Anne, wat ben jij toch een schat, altijd even bellen hoe het gaat, ondanks je enorm drukke schema en altijd de Brabantse gezelligheid zelve :-)!

Eveneens dank voor mijn lieve schoonfamilie die altijd oprechte interesse hebben getoond in mijn proefschrift en voor alle gezellige momenten. Dank je wel, Jan, Sieneke, Erik, Willeke en natuurlijk Annemijn en Evelien! 
Dankwoord

Lieve Elke, dank je wel voor het zijn van mijn lieve zusje en nu je ouder wordt steeds meer sparringpartner over van alles en nog wat. Joris, mijn (bijna) zwager $(-)$, wat ben jij altijd enorm oprecht geïnteresseerd in wat ik deed en wat ben je lief voor mijn zusje, dank je wel daarvoor!

Pap en mam, jullie zijn er echt altijd voor mij en ik ben jullie daar enorm dankbaar voor. Pap, dank voor het doorlezen van mijn gehele proefschrift en mam, dank voor het altijd klaarstaan voor mij, Siev en Ties. Het is ook zo mooi om te zien hoe gek jullie zijn met Ties!

En dan als laatste, maar wel meest belangrijke, mijn twee mannen (:) Lieve Sievert Jan (laat ik hier maar netjes je gehele naam een keer schrijven...), ik kende jou net, toen ik begon aan dit proefschrift en je hebt alle fases met mij doorlopen en jij hebt er mede voor gezorgd dat ik nu dit eindresultaat kan afleveren. Je bent er altijd voor mij en ik kan mij oprecht geen betere vriend wensen. Dank je wel daarvoor! Daarnaast ben ik je natuurlijk eeuwig dankbaar voor onze zoon Ties!

Lieve Ties, dank je wel dat je er bent! Je bent de liefste, mooiste en alles voor mij! 